Portland State University

PDXScholar

Spring 6-5-2019

\title{
Analytical and Numerical Modeling of Long Term \\ Changes to Tides, Storm Surge, and Total Water \\ Level Due to Bathymetric Changes and Surge \\ Characteristics
}

Ramin Familkhalili

Portland State University

Follow this and additional works at: https://pdxscholar.library.pdx.edu/open_access_etds

Part of the Civil and Environmental Engineering Commons

Let us know how access to this document benefits you.

\section{Recommended Citation}

Familkhalili, Ramin, "Analytical and Numerical Modeling of Long Term Changes to Tides, Storm Surge, and Total Water Level Due to Bathymetric Changes and Surge Characteristics" (2019). Dissertations and Theses. Paper 5014.

https://doi.org/10.15760/etd. 6890

This Dissertation is brought to you for free and open access. It has been accepted for inclusion in Dissertations and Theses by an authorized administrator of PDXScholar. Please contact us if we can make this document more accessible: pdxscholar@pdx.edu. 
Analytical and Numerical Modeling of Long Term Changes to Tides, Storm Surge, and Total Water Level Due to Bathymetric Changes and Surge Characteristics

\author{
by \\ Ramin Familkhalili
}

\begin{abstract}
A dissertation submitted in partial fulfillment of the requirements for the degree of
\end{abstract}

\author{
Doctor of Philosophy \\ in \\ Civil and Environmental Engineering
}

Dissertation Committee:

Stefan A. Talke, Chair

David A. Jay

Edward D. Zaron

Paul C. Loikith

Portland State University

2019 
(C) 2019 Ramin Familkhalili 


\begin{abstract}
Natural and local anthropogenic changes in estuaries (e.g., sea-level rise, navigation channel construction and loss of wetlands) interact with each other and produce nonlinear effects. There is also a growing recognition that tides in estuaries are not stationary. These factors together are changing the estuarine water level regime, however the implications for extreme water levels remain largely unknown. Changes over the past century in many estuaries, such as channel deepening and streamlining for navigation have significantly altered the hydrodynamics of long waves, often resulting in amplified tides (a $~ 85 \%$ increase in Wilmington, NC since 1900) and storm surge in estuaries. This research focuses on establishing analytical and numerical models that simulate a wide range of systems and flow conditions that combine multiple flood sources: astronomical tide, storm surge, and high river flow. To investigate the effects of estuarine bathymetry conditions (e.g., channel depth, convergence length), hurricane conditions (e.g., pressure and wind field), river discharge, and surge characteristics (e.g., time scale and amplitude and relative phase) on tide and storm surge propagation, I develop an idealized analytical model and two numerical models using Delft-3D. The Cape Fear River Estuary, NC (CFRE), and St Johns River Estuary, FL (SJRE) are used as case studies to investigate flood dynamics. The analytical approach has been compared and verified with idealized numerical models.
\end{abstract}

I use data recovery, data analysis, and idealized numerical modeling of the CFRE to investigate the effects of bathymetric changes (e.g., dredging and channel 
modification) on tidal and storm surge characteristics over the past 130 years. Data analysis and modeling results suggest that long-term changes in tides can be used along with the tidal analysis tools to investigate changes in storm surge. Analysis indicate that tidal range in Wilmington, $\mathrm{NC}(\mathrm{Rkm} 47)$ has doubled to $1.55 \mathrm{~m}$ since the $1880 \mathrm{~s}$, while a much smaller increase of $0.07 \mathrm{~m}$ observed close to the ocean in Southport (Rkm 6) since the 1920s. Further, model results suggest that the majority of long term changes in tides of this system have been caused by deepening the system from $7 \mathrm{~m}$ to $15.5 \mathrm{~m}$ due to dredging, rather than by changes in the coastal tides. Numerical modeling using idealized, parametric tropical cyclones suggests that the amplitude of the worst-case, CAT-5 storm surge has increased by $40-60 \%$ since the nineteenth century.

Storm surges are meteorologically forced shallow water waves with time scales that overlap those of the tidal bands. Using data, I show that the surge wave can be decomposed into two sinusoidal waves. Therefore, I analytically model surge via a 3constituent analytical tide model, where the third constituent is the dominant semi-diurnal tide and friction is linearized via Chebyshev polynomials. A constant discharge is considered to approximate fluvial effects The analytical model is used to study how surge amplitude, surge time scale, and surge-tide relative phase affect the spatial pattern of amplitude growth and decay, and how depth changes caused by channel deepening influence the magnitude of a storm surge. I use non-dimensional numbers to investigate how channel depth, surge time scale and amplitude, surge asymmetry, and relative timing of surge to tides alter the damping or amplification of surge along the estuary. The nondimensional numbers suggest that increasing depth has similar effects as decreasing the 
drag coefficient. Similarly, larger time scale has an equivalent effect on tide and surge as increasing depth due to channel deepening. Analytical model results show that the extent of the surge amplification is dependent on the geometry of the estuary (e.g., depth and convergence length) and characteristics of the surge wave. Both models show that much of the alterations of water levels in estuaries is due to channel deepening for navigation purposes and that the largest temporal change occur for surges with a high surge to $D_{2}$ amplitude ratio and a short time scale. Model results farther indicate that surge amplitude decays more slowly (larger e-folding) in a deeper channel for all surge time scales (12hr72hr). Another main finding is that, due to nonlinear friction, the location of maximum change in surge wave moves landward as the channel is deepened. Thus, changes in flood risk due to channel deepening are likely spatially variable even within a single estuary.

Next, I use the verified analytical model and numerical models to investigate the effects of river flow on surge wave propagation, and spatial and temporal variability of compound flooding along an estuary. To model the historic SJRE, I digitize nautical charts of SJRE to develop a numerical model. Both the numerical and analytical models are used to investigate the contribution of tide, surge, and river flow to the peak water level for historic and modern system configurations. Numerical modeling results for hurricane Irma (2017) show that maximum flood water levels have shifted landward over time and changed the relative importance of the various contributing factors in the SJRE. Deepening the shipping channel from $5.5 \mathrm{~m}$ to $15 \mathrm{~m}$ has reduced the impacts of river flow on peak water level, but increased the effects of tide and surge. Sensitivity studies also show that peak water level decreases landward for all river flow scenarios as channel 
depth increases. Model results show that the timing of peak river flow relative to the time of maximum surge causes very large changes in the amplitude of total water level, and in river flow effects at upstream locations for modern configuration than for the historic model. Changes in surge amplitudes can be interpreted by the non-dimensional friction number $\left(\psi=\frac{c_{d}^{\xi} \xi \omega^{2} L_{e}^{3}}{g h^{3}}\right)$, which shows that depth $(h)$, surge time scale $\left(T=\frac{1}{\omega}\right)$, and convergence length-scale $\left(L_{e}\right)$ affect the damping/amplification of both tides and surge waves.

Overall, this study demonstrates that a system scale alteration in local storm surge dynamics over the past century is likely to have occurred in many systems and should be considered for system management. The results of this research give the scientists and engineer a better understanding of tide, river flow, and surge interactions, and thereby contribute to an understanding of how to predict storm surges and help mitigate their destructive impacts. Future system design studies also need to consider long-term and changes of construction and development activities on storm surge risk in a broader context than has historically been the case. 


\section{Dedication}

To everlasting love of my life, Maryam 


\section{Acknowledgments}

I would like to express my sincere gratitude and appreciation to my advisor, Dr. Stefan Talke, who made the journey possible and provided me with invaluable guidance, unfailing encouragement, and endless support. He has encouraged me to try and learn new stuff and expand my knowledge. Without his guidance and persistent help this dissertation would not have been possible. Dear Stefan, thanks for always being there for me and believing in me. My gratitude also extends to Dr. David Jay, who has the attitude and the substance of a genius, for his help and valuable comments and discussions throughout this research study.

I would like to thank my Graduate Committee members, Dr. Edward Zaron and Dr. Paul Loikith, for their willingness to serve on my committee, their help, advice, and intellectual support.

I am also thankful of the kind staff of the Department of Civil and Environmental Engineering, specifically Helen Frey, Megan Falcone, and Kiley Melicker who were always supportive, great resources and helped me navigate my work in the department.

I am grateful to my wonderful friends and colleagues (too many to name) across

all the departments I have come into contact, for always being there for me during my graduate studies.

My heartfelt thanks to my parents for supporting me throughout my life. Last but foremost, my loving thanks to my wife, Maryam, for her unconditional love, understanding, patience, and unwavering support. This thesis would not have been 
possible without encouragement and endless love from her. To my wonderful wife and my parents, I love you and I dedicate this achievement to you. 


\section{Table of Contents}

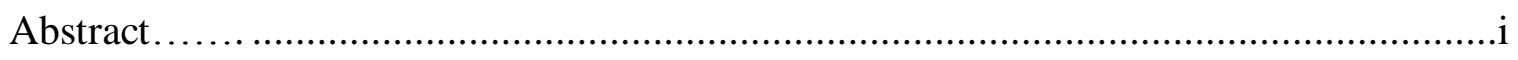

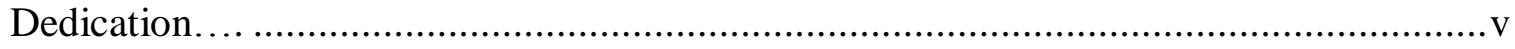

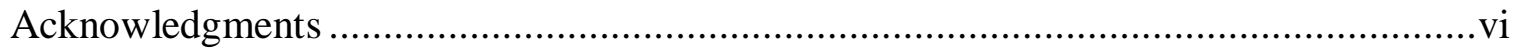

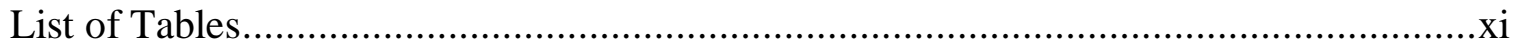

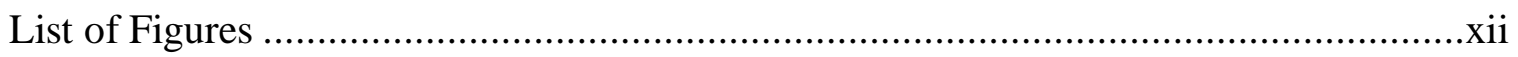

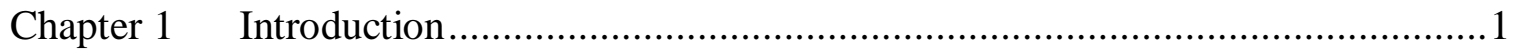

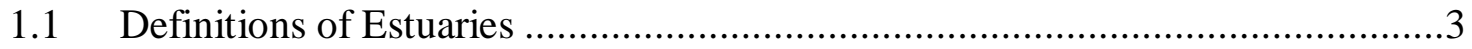

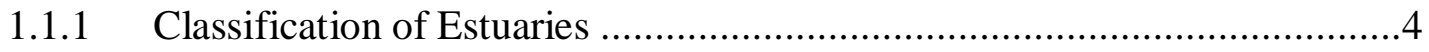

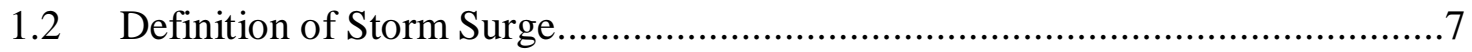

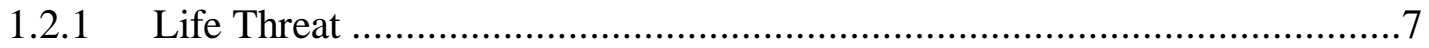

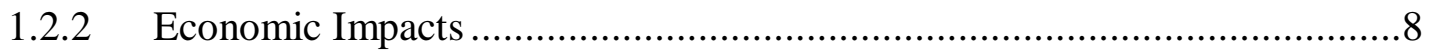

1.2.3 Ecological and Water Quality Impacts of Storm Surge …………..............

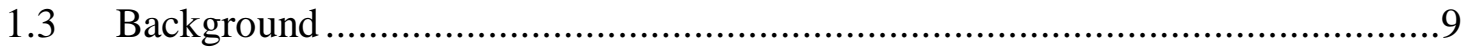

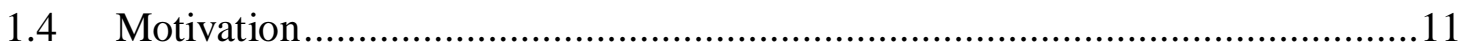

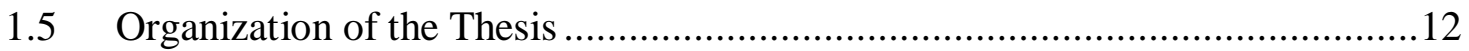

Chapter 2 Idealized Modeling of Storm Surge ………............................................... 16

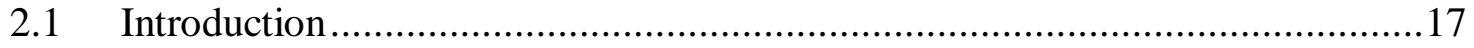

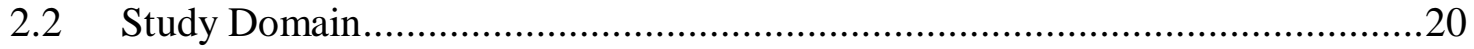

2.2.1 Hydraulics Evolution of the Cape Fear River Estuary ……........................22

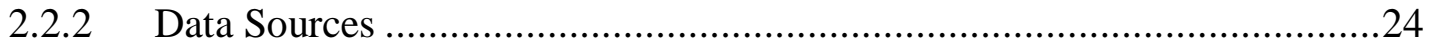

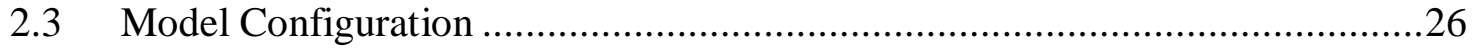

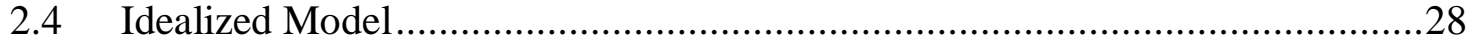

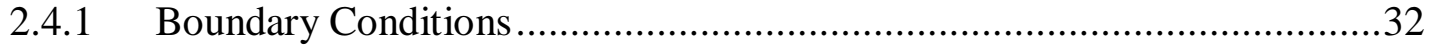

2.4.2 Meteorological Forcing ..................................................................

2.4.3 Wind Drag ..................................................................................

2.5 Model Calibration and Validation ...................................................................

2.6 Sensitivity Analysis .................................................................................

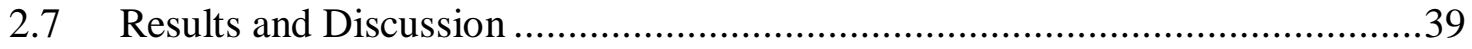

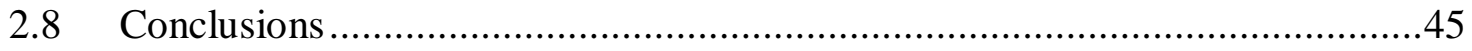

Chapter 3 Analytical Modeling of Storm Surge ……….......................................47 


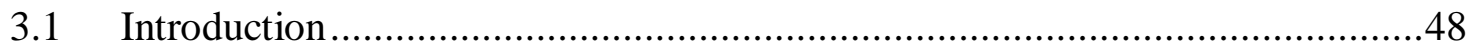

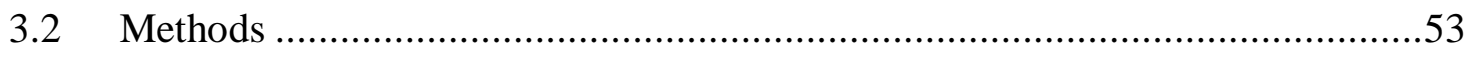

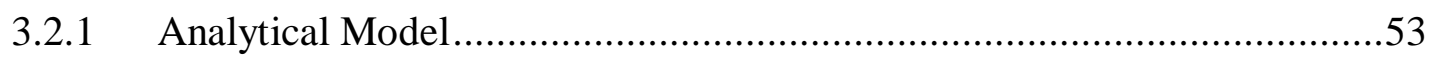

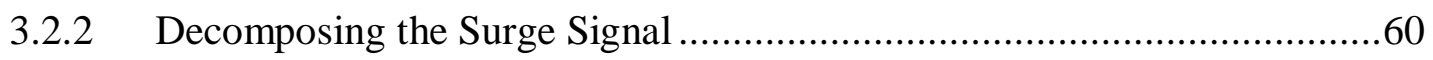

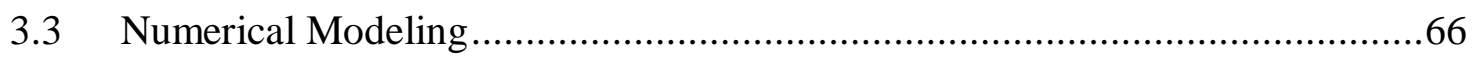

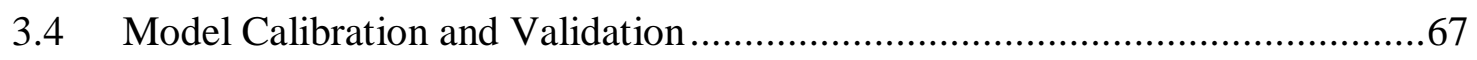

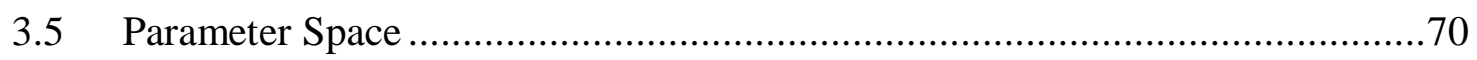

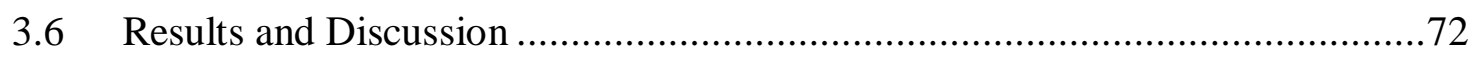

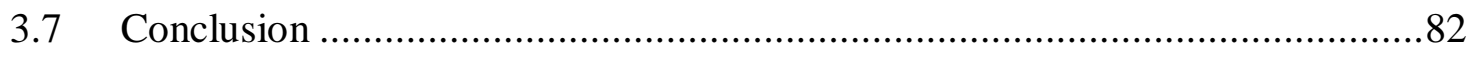

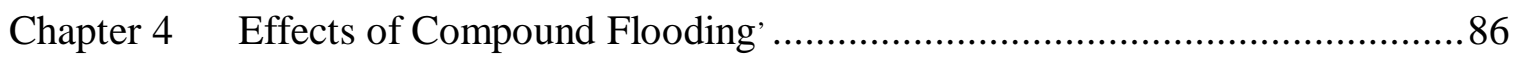

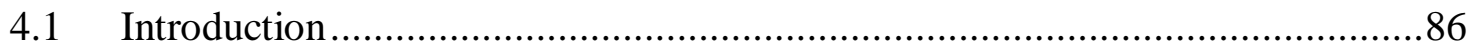

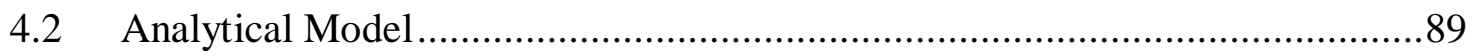

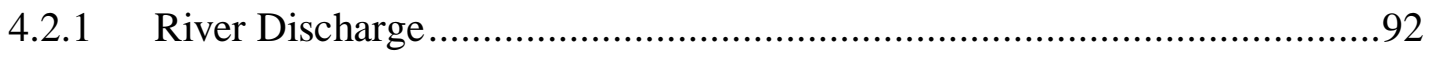

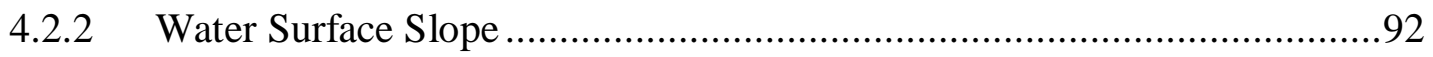

4.2.3 Dimensional and Non-Dimensional Parameter Space ……........................94

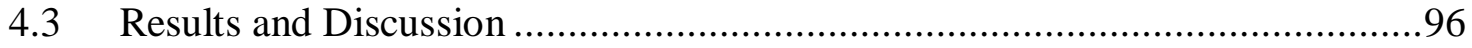

4.3.1 Effects of River Discharge on Water Level ............................................96

4.3.2 Frictional Effects of River Discharge on Surge Amplitude ........................98

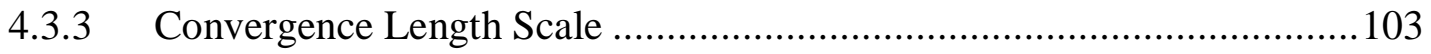

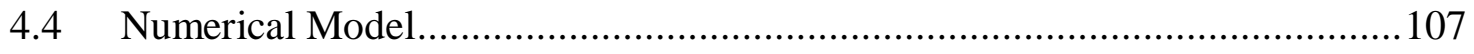

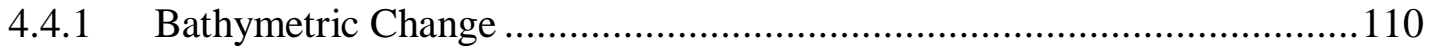

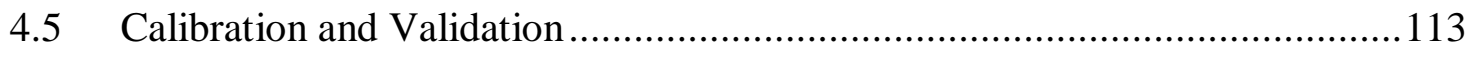

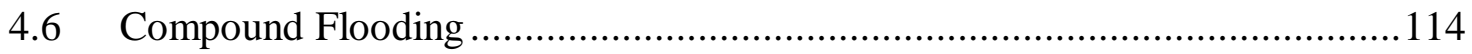

4.6.1 Analysis of 2017 Flood Event............................................................114

4.7 Sensitivity to Timing and Amplitude of Peak Flow .........................................119

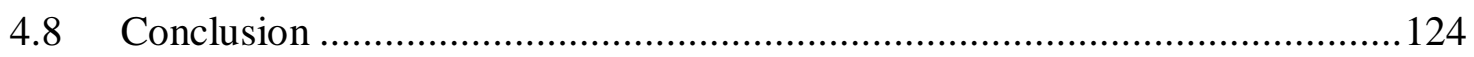

Chapter 5 Concluding Remarks and Future Directions............................................ 126

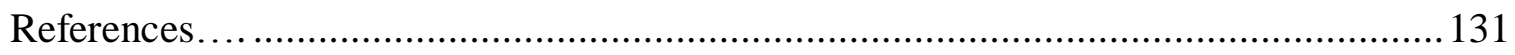

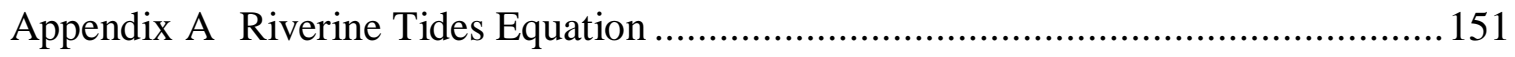

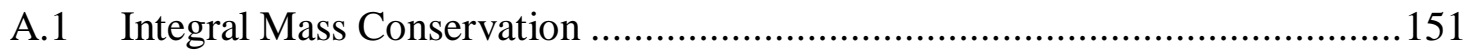

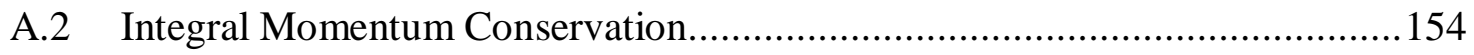

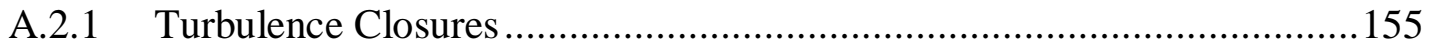




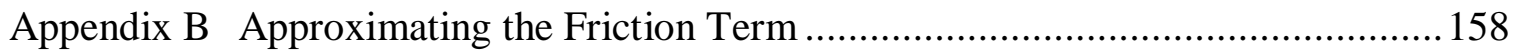

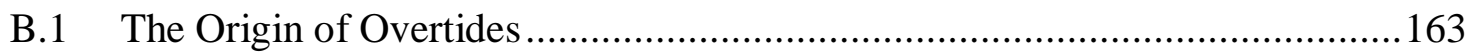

B.2 Verification and Comparison of Results....................................................... 165

Appendix C Analytical Solution to the Tidal Propagation Equations ........................... 167

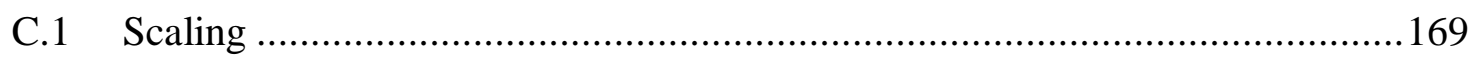




\section{List of Tables}

Table 2-1: Chronology of navigational developments in the CFRE [Welch and Parker, 1979]

Table 2-2: Definition of the typical sustained wind speed and minimum surface pressure for different categories of tropical cyclones. The typical range is given in parentheses [National Oceanic and Atmospheric Administration, National Hurricane Center]. .........34

Table 3-1: Parameter space used in modeling........................................................... 71

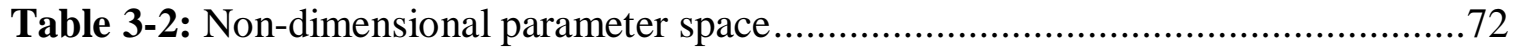

Table 4-1: Parameter space used in analytical model...........................................95 


\section{List of Figures}

Figure 1-1: Conceptual model of flood water components in an idealized tidal estuary. 11

Figure 1-2: An overview of the structure of this dissertation. .15

Figure 2-1: Cape Fear River Estuary, [USGS, The National Map, http://www.nationalatlas.gov] and tide gauge locations at Wilmington (NOAA Station ID: 8658120) and Southport (NOAA Station ID: 8659084).....

Figure 2-2: Yearly averaged GDR at (a) Southport and (b) Wilmington. Data recovered and digitized from archival sources plotted in cyan and data obtained from NOAA plotted in blue.

Figure 2-3: (a) Idealized model bathymetry (b) the plan view of TC tracks on the continental shelf, which move from right to left (c) Idealized channel cross-section at the mouth, and (d) the plan view of the first $60 \mathrm{~km}$ of estuary grid.

Figure 2-4: 1888 topographical map of the Cape Fear River, channel, and location of cross-sectional profiles (T1-T6) that are in $1.5-6 \mathrm{~km}$ increments with an average of $3.5 \mathrm{~km}$. It is assumed that cross-sections are perpendicular to the channel direction (part one)...29 Figure 2-5: 1888 topographical map of the Cape Fear River and location of crosssectional profiles (T6-T23) that are in $1.7-3.5 \mathrm{~km}$ increments with an average of $1.7 \mathrm{~km}$. It is assumed that cross-sections are perpendicular to the channel direction (part two).......30

Figure 2-6: Observed and modeled (a) width and (b) cross sectional area along the channel. Zero is at the river entrance and positive direction is landward to the left of the graph.

Figure 3-1: The conceptual plan view and cross-section area of the model..................54

Figure 3-2: Example of an approximation to $u|u|$ by Chebyshev polynomials for the case of three sinusoidal constituents $(6,12$, and 24 hour period $)$, i.e., $u_{(x, t)}=u^{\prime}=0.3 \cos (\omega t)$ $+0.5 \cos (2 \omega t)+0.2 \cos (4 \omega t), U_{(x)}=1$. The green line represents the velocity flow $\mathrm{u}$ $[\mathrm{m} / \mathrm{s}]$, while the blue line represents the square of the velocity, $u|u|\left[(\mathrm{m} / \mathrm{s})^{2}\right]$. The Chebyshev approximation (red-line) well represents $u|u|$.

Figure 3-3: Decomposing surge into different sinusoidal waves, red circles represent surge and calculated by subtracting predicted tide from measured water level and blue line is the one sine-wave fit, green is two sine-wave fit that is the sum of $S u_{P r i}$ and $S u_{S e c}$. Black dashed line shows the $0.3 \mathrm{~m}$ threshold. Periods of $S u_{P r i}, S u_{S e c}$, are $22.6 \mathrm{hr}$, and $10.9 \mathrm{hr}$, respectively.

Figure 3-4: Probability distribution of multi waves fit. The hourly tide data is obtained from the National Oceanographic and Atmospheric Administration (NOAA) for Lewes, DE (Station ID 8557380: 1936-2018). 
Figure 3-5: Probability distribution of ratio of surge-primary to surge-secondary (a) amplitude, (b) time scale, (c) relative phase and (d) ratio of $S u_{P r i}$ period to $M_{2}$

Figure 3-6: Evolution of dominant tidal constituent $\left(M_{2}\right)$ in a $5 \mathrm{~m}$ deep convergent estuary for (a) single tide and (b) three tides model with no river flow. The ocean/estuary boundary is at Rkm 0, SS means single-segment, and MS refers to multi-segment model.

Figure 3-7: Importance of $S u_{P r i}$ amplitude for four different amplitudes relative to $D_{2}$ tide at the ocean boundary, $\gamma=A m p$. Su $u_{\text {Pri }} / A m p . D_{2}=1,2,4$ and 6, (a) surge amplitude, (b) normalized amplitude $\delta=A m p$. Su $u_{\text {Pri }} /$ Max. surge Amp. , and (c) surge amplitudes relative to $D_{2} . L_{*}=x / L_{e}$ is normalized length. I assume that $D_{2}$ has period of $12 \mathrm{hr}(\Omega=1)$ for simplicity of parameter space used in modeling.

Figure 3-8: The influence of surge period on surge-tide propagation along an idealized estuary for four different periods $\Omega=$ Period $S u_{\text {Pri }} /$ Period $D_{2}=1,2$, 4, and 6. (a) normalized amplitude and (b) relative amplitude to $D_{2} . L_{*}=x / L_{e}$ is normalized length, relative to the length-scale of convergence.

Figure 3-9: The influence of surge time scale and channel depth on surge-tide propagation along an idealized estuary. The color scaling represents the normalized amplitude $\delta$ and equals one at the ocean boundary, $L_{*}=0$. Each plot represents a different time scale for the primary surge component, from 12 to $72 \mathrm{hr}$. For a configuration with no reflection effects, $\delta$ decreases into the estuary (left direction). The black, dashed-line represents location of maximum change relative to the $5 \mathrm{~m}$ depth condition and the black dotted-line represents the location of the e-folding scale of normalized amplitude. Note that the friction number $\psi$ associated with each depth is plotted on the right hand side of each plot.....

Figure 3-10: Location of maximum change of surge waves $\left(L_{* \max }\right.$, that occurs for depths of 7 to $20 \mathrm{~m}$ relative to an original depth of $h=5 \mathrm{~m}$ ) for symmetric surge (relative phase of $S u_{P r i}$ and $S u_{S e c}$ is set to zero) at (a) high water, (b) mid-tide, and (c) low water as a function of channel depth and $\left(\Omega=\right.$ Period $S u_{\text {Pri }} /$ Period $\left.D_{2}\right)$

Figure 3-11: The effects of surge asymmetry for (a) fast-rise and (b) slow-rise surge on the location of maximum change of surge $\left(L_{* \max }\right)$ for different channel depths and $\left(\Omega=\right.$ Period. Su $u_{\text {Pri }} /$ Period. $\left.D_{2}\right)$ with $\gamma=A m p . S u_{\text {Pri }} / A p . D_{2}=1$ and Su$u_{S e c} A m p .=$ $0.25 \mathrm{~m}$.

Figure 4-1: Idealized bathymetry and plan view of the conceptual model...................90 Figure 4-2: Definition of the water surface slope. Along channel direction $x$ is upstream with $x=0$ at the ocean.

Figure 4-3: (a) The importance of channel depth for $1 \mathrm{~km}^{3} / \mathrm{s}$ flow and (b) the importance of river flow for $5 \mathrm{~m}$ depth in an idealized estuary. Vertical axis is $Z$ that is tidally 
averaged water level and horizontal axis represents dimensionless coordinate system of $L_{*}=x / L_{e}$

Figure 4-4: The effects of river flow $\left(\theta=u_{R} / u_{M_{2}}\right)$ and surge periods $(\Omega=$ Period $\mathrm{Su}_{\text {Pri }} /$ Period $\mathrm{D}_{2}$ ) along an idealized weakly convergent estuary for channel depth of (a) $5 \mathrm{~m}$, (b) $7 \mathrm{~m}$, (c) $10 \mathrm{~m}$, and (d) $15 \mathrm{~m}$. 100

Figure 4-5: Comparison of contribution of tide, surge, and river flow to compound flooding between $5 \mathrm{~m}$ and $10 \mathrm{~m}$ depth channel and $S u_{P r i}=24 \mathrm{hr}$. The convergence length scale is $80 \mathrm{~km}$ and $x$-axis represents dimensionless coordinate system of $L_{*}=x / L_{e}$ and $y$ axis shows non-dimensional river flow $\left(\theta=u_{R} / u_{M_{2}}\right)$

Figure 4-6: The influence of surge period and channel depth on primary surge amplitude ( $A_{*}$ is normalized amplitude to the surge amplitude at ocean boundary $L_{*}=0$ ) along a strongly convergent estuary $\left(L_{e}=20 \mathrm{~km}\right)$. 104

Figure 4-7: The effects of convergence length scale on primary surge amplitude $\left(A_{*}\right.$ is normalized amplitude) along an estuary $\left(L_{e}=20-80 \mathrm{~km}\right)$. 107

Figure 4-8: Map of St Johns River Estuary, FL with locations of gauges, MP =NOAA gauge at Mayport (Station ID: 8720218), DP =NOAA gauge at Dames Point (Station ID: 8720219), LB= NOAA gauge at Longbranch (Station ID: 8720242), JX = NOAA gauge at Jacksonville (Station ID: 8720226), and AB = USGS gauge at Acosta Bridge. 109

Figure 4-9: (a) historic (1898), and (b) modern (2014) bathymetry of St Johns River Estuary, FL with locations of gauges at Mayport (MP), Dames Point (DP), Longbranch (LB), Jacksonville (JX), and USGS gauge (AB).

Figure 4-10: Changes in shipping channel between 1898 and 2014.

Figure 4-11: Spatial changes of measured and modeled $M_{2}$ tidal amplitude for historic and modern model.

Figure 4-12: Comparison of spatial pattern of (a) TWL, (b) tide, (c) surge, and (d) river flow during hurricane Irma 2017 under modern (red) and historic (blue) configurations.

Figure 4-13: Modeled contribution of tide, surge, and river flow into peak TWL at Mayport (MP) and Jacksonville (JX) for historic and modern configuration.

Figure 4-14: St. Johns hourly river discharge at Acosta Bridge $(A B)$, negative value is toward upstream and positive is toward the ocean.

Figure 4-15: Flow at Jacksonville (red dots) and Gaussian estimate (blue line) after removing tidal flow from total measured flow, day hour of 2017/9/11.

Figure 4-16: The effects of timing of river flow max peak $\left(10 \mathrm{~km}^{3} / \mathrm{s}\right)$ on TWL components along the channel for modern (red) and historic (blue) configuration. The fill areas represent the range of results obtained from changing the timing of peak river flow $+/-12 \mathrm{hr}$ relative to the time of maximum surge. 
Figure 4-17: The effects of river flow magnitude $\left(2 \mathrm{~km}^{3} / \mathrm{s}-10 \mathrm{~km}^{3} / \mathrm{s}\right)$ on TWL components along the channel for modern (red) and historic (blue) configuration. 123 


\section{Chapter 1 Introduction}

Coastal areas are vulnerable to flooding caused by global environmental changes, including sea level rise [e.g., Intergovernmental Panel on Climate Change, 2007; Church and White, 2011] and possibly the increasing strength and frequencies of cyclones [e.g., Holland and Webster, 2007; Grinsted et al., 2012]. Locally, human development such as channel deepening, streamlining, and wetland land cover reduction are also impacting estuarine geomorphology, with possible impacts on tides, storm surge, and circulation patterns [e.g., Talke et al., 2014; de Jonge et al., 2014; Orton et al., 2015; Familkhalili and Talke, 2016].

Though many factors (such as increased depth to accommodate shipping) have been implicated in tidal change, the relative contribution of different anthropogenic factors remains an area of active research. Therefore, this study is motivated by a general need to enhance knowledge of the effects of estuary geometry, surge characteristics, and river flow effects on tide-surge propagation along estuaries. This study helps to increase understanding of the factors that determine the distribution of water flood along a tidal estuary on secular time scales.

Numerous factors affect storm surge heights and flood risk, including storm properties (pressure, track, radius, and wind speed) [Peng et al., 2004; Xia et al., 2008; Rego and Li, 2010], tides and other currents, and local factors (such as: topography, 
hydraulic roughness, and wetland plants) [Shen et al., 2006; Familkhalili and Talke, 2016; Orton et al., 2015]. Further, as sea level increases due to climate change and other factors, the same storm surge can produce larger extreme water levels and worsen the flood hazard [e.g., Kemp and Horton, 2013; Arns et al., 2017]. In addition, there is a developing concern that climate change can increase the frequency and intensity of storms and/or the magnitude of storm surge independently of sea-level rise [e.g., Holland and Webster, 2007; Grinsted et al., 2012; Lin et al., 2012; Tebaldi et al., 2012; Neumann et al., 2015], though gaps in the historical record and short records complicate interpretation of secular trends [e.g., Landsea et al., 2010].

Considering these factors, I ask the following questions in this thesis:

- Is storm surge, like a tide wave, affected by channel deepening, width alteration, and streamlining?

- Why are some estuaries more sensitive to human activities and engineering alterations than others?

- What are the effects of surge characteristics (e.g., amplitude, time scale, asymmetry, and relative phase to tide) on surge propagation?

- How have the contributions of tides, surge, and river flow to flood water level changed over time?

I investigate these questions using a combination of data recovery, data analysis, analytical and numerical model experiments (see Figure 1-2 for a graphical presentation of the subjects covered and their relationships). I next summarize the objectives of this 
study, after first reviewing the characteristics of estuaries, tidal dynamics, and storm surge to provide needed context.

\subsection{Definitions of Estuaries}

A tidal river is a region between the head of the tide and the point where the lowest water levels are lower on neap tides than on spring tides [e.g., Jay et al., 2014]. Seaward of a tidal river is an estuary, where may include both tidal fresh and brackish reaches [Hoitink and Jay, 2016]. According to Cameron and Pritchard [1963], "an estuary is a semi-enclosed coastal water body where sea water is measurably diluted by fresh water from river flow". In a larger sense, an estuary extends from the landward limit of tidal effects to the seaward limit of coastal effects, with regimes that shift from fluvially dominated (upstream) to tidally dominated (near coast) [e.g., Godin, 1985; Jay et al., 2015; Moldwin, 2016]. The lower portion of an estuary is the 'marine section' and is highly impacted by tides, while the upper section, the tidal river, is strongly influenced by river flow and has a tidal region that responds to river flow. In an intermediate section, both river flow and tides are of importance.

Estuaries are often formed within low-relief coastal plains (e.g., U.S. East Coast and Northwest Europe). Coastal plain estuaries in the North Atlantic are frictionally dominated and are mainly forced by semidiurnal tides. The natural width and cross section area of the estuary channel usually reduces landward, resulting in a funnel shape system [e.g., Savenije, 2005; Prandle, 2009], though coastal sand bars may limit the 
width of the estuary enterance. Because many cities and harbors are located within estuaries, many systems have been modified to accommodate navigation.

\subsubsection{Classification of Estuaries}

Classification of estuaries based upon their characteristics defines representative types of systems. Estuarine classification systems can be defined based on I) geomorphology, II) water balance, III) vertical structures of salinity, IV) non-dimensional numbers related to hydrodynamics of estuaries. These classifications are discussed below.

I) Pritchard [1952] classified estuaries as coastal plain, fjord, bar-built, and tectonics according to their geomorphology. Coastal plain estuaries are defined as the seaward portion of a drowned river valley. These were formed during flooding over millennia as result of the Pleistocene increase in sea level. Typically, they are wide and shallow (e.g., Chesapeake Bay and Delaware Bay), but may have a narrow entrance. Fjords are formed by the submergence of a glaciated valley and usually are deep, narrow, and located at high latitudes where glaciers are prominent. Bar-built estuaries are the result of littoral drift of sand bars which separate a part of the coast water from the ocean. Earthquakes and tectonic movements can create fault-block estuaries as semi-enclosed body of water adjacent to the ocean (e.g., San Francisco Bay).

II) The supply of fresh water into the estuary from upstream and its interaction with salt water from the ocean causes longitudinal density gradients that result in surface outflow and net inflow near the bed. Estuaries maybe classified as positive, inverse and 
low inflow estuaries. An estuary is positive if the incoming fresh water (from river discharge or rain) is larger than fresh water losses (due to evaporation, freezing, and infiltration), while in a low inflow estuary the water losses outweigh the fresh water inflow. The inverse estuary is a low-in-flow estuary in which evaporation and/or cooling are so strong that the water density of the estuary is higher than the ocean, causing surface inflow and near-bed outflow, as in the Mediterranean Sea [Valle-Levinson, 2010].

III) Estuaries can be classified as salt wedge, strongly stratified, weakly stratified, and vertically mixed based upon vertical salinity structures(stratification), a classification approach that considers the balance of buoyancy forcing from river discharge and mixing from tidal forcing [Pritchard, 1955; Cameron and Pritchard, 1963]. A simple classification is made by defining stratification number $(G / J)$ which represents ratio of energy dissipation to rate of potential energy gained from moving water over a defined channel length [Ippen and Harlemann, 1961; Prandle, 1986]. A drawback of $G / J$ classification is that it needs at least another parameter to have a direct relation to actual estuaries [Jay et al., 1999], therefore, two parameter classification approaches [e.g., Hansen and Rattray, 1966] are used to classify estuaries by capturing different aspects of estuarine circulation and stratification. Another form of classification considers different combinations of strong and weak river discharge and tidal forcing, and therefore classifies estuaries as strongly stratified estuaries (moderate to large river discharge with weak to moderate tidal forcing), weakly stratified or partially mixed estuaries (moderate to strong tidal forcing accompanied by weak to moderate river discharge), salt wedge 
estuaries (large river discharge and weak tidal forcing), and vertically mixed estuaries (strong tidal forcing and weak river discharge). In this type of classification many systems (e.g., the Hudson River and the Columbia River) change classification as the tidal and river discharge vary over time.

IV) Hansen and Rattray [1966] proposed a more widely accepted classification by using two non-dimensional parameters which are based on hydrodynamic characteristics of estuaries; circulation $\left(u_{s} / U_{f}\right)$ and stratification $\left(\Delta S / S_{0}\right)$ where $\Delta S, S_{0}, u_{s}$, and $U_{f}$ represent the vertical salinity difference, cross-sectionally averaged salinity, near-surface velocity, and cross-sectionally averaged velocity, respectively. According to this, estuaries can be classified to four groups; a) estuaries with no vertical structure in net flow, b) estuaries in which net flows reverse at depth, c) estuaries with well established gravitational circulation, d) and salt wedge estuaries (weak vertical structure and highly stratified). Recent studies show the importance of momentum input of tides and wind on mixing in estuaries that challenges the gravitational circulation [e.g., Geyer and MacCready 2014]. Jay and Smith [1990] categorized estuaries into highly stratified, partially mixed, and weakly stratified by dominant mixing process.

Understanding both physical and ecological processes are important to clarify coastal, tidal, and fluvial dominant sections of tidal rivers [Jay et al., 2015]. Since the importance of tides and river flow vary along the channel, my interests lie in investigating the tides, surge, and river flow interactions in coastal plain tidal rivers 
where all the factors are important and can have a great impact on the amplitude of flood water.

\subsection{Definition of Storm Surge}

A storm surge is a meteorologically forced long-wave generated by tropical and extratropical cyclones which produce a super-elevation of water level above the level caused by astronomical tides. The strength of a storm surge and its impact depend on the intensity and the path of the storm, and the geometric properties of the estuary [e.g., Peng et al., 2004; Xia et al., 2008; Rego and Li, 2010; Familkhalili and Talke, 2016; Talke et al, 2014]. Historically, storm surges have been the deadliest phenomenon associated with hurricanes in coastal regions [Ludlam, 1963], and the severe devastation often caused by storm surges is an important reason for investigating them.

\subsubsection{Life Threat}

About half the world's population lives within $100 \mathrm{~km}$ of the coast [World Resources 1996-97; Pugh and Woodworth, 2014]. Many of these densely populated coastal areas are vulnerable to flooding from storm surge [e.g., see CCSP, 2008], therefore, any local changes that impact the magnitudes of tidal, surge, and river water levels has important implications for flood risk [Merkens et al., 2016].

Severe storm surges historically have been responsible for many of the natural

disaster deaths in coastal regions worldwide [e.g., Doocy et al., 2013]. Over the past 15 years, catastrophic storm surges in Bangladesh (2007; 5100 deaths), in Myanmar (2008; 
138000 deaths), in Philippines (2013; 6000 deaths) and in the U.S. (Hurricane Katrina, 2005; 1800 deaths; Hurricane Sandy, 2012; 170 deaths) killed many people [Shibayama, 2015].

\subsubsection{Economic Impacts}

Many large cities are found within 100km of the ocean, and $~ 90 \%$ of global trade is carried by sea [e.g., Hulme, 2009]. As a result, coastal floods can be harmful to the local economy, particularly areas where major roads, railroads, and airports have been constructed on low-lying lands. More than half of the U.S. economic productivity is located in coastal areas [NOAA, 2014], within the reach of strong storm surge events. Therefore, storm surge may result in significant economic losses for coastal communities. There are numerous studies on the economic impacts of storm surges caused by hurricanes [e.g., CCSP 2008, Impacts of Climate Change and Variability on Transportation Systems and Infrastructure]. For example Hurricane Katrina (2005) caused \$125 billion damage to the New Orleans area and along the Mississippi. Other catastrophic hurricanes are Hurricane Rita (2005; $\$ 18.5$ billion), Hurricane Ike (2008; $\$ 30$ billion), and Hurricane Sandy (2012, \$65 billion), Hurricane Matthew (2016; \$10 billion), Hurricane Harvey (2017; $\$ 125$ billion), and Hurricane Irma (2017; $\$ 50$ billion). [United States National Hurricane Center, 2018; Graumann et al., 2006]. 


\subsubsection{Ecological and Water Quality Impacts of Storm Surge}

Storm surges have effects on water quality of coastal waters and estuaries. Temporary salinity and sedimentation patterns change due to hurricanes storm surge and can alter transport pattern of nutrients in the river channel [e.g., Lowery 1992; Van Dolah and Anderson 1991]. For example, inputs of swamp runoff into the Cape Fear River system results in massive fish kill due to post-hurricane flooding which cause severe water quality problems and reduced levels of dissolved oxygen in the system [Mallin et al., 1999]. Mortality and displacement of birds, sea turtle, fish, and oyster are directly or indirectly caused by hurricanes, storm surge, and intense rainfall [Mallin et al., 1999].

\subsection{Background}

The influence of geometrical variations of estuaries (e.g., depth, cross-sectional area, and convergence) on tidal propagation have long been studied analytically [e.g., Dronkers, 1964; Prandle and Rahman, 1980; Jay, 1991; Friedrichs and Aubrey, 1994; Lanzoni and Seminara, 1998; Godin, 1999; Kukulka and Jay, 2003a, b], using linearized solutions. Analytical models generally assume that the cross section area is constant or varies exponentially along-channel. Furthermore, they assume that the tidal range is very small compared to depth and neglect the Coriolis force. Overall, studies of tidal dynamics with idealized models show that for a given tidal frequency, tidal amplitudes decrease upriver when frictional effects dominate over the funneling effect caused by decreasing width; by contrast, strong convergence can produce increasing amplitude when friction is 
relatively weak. Therefore, changing the balance between bed friction, convergence, and river flow, will specify if the tidal amplitudes decrease, increase, or remain constant along a convergent estuary [e.g., Jay, 1991].

Tides and surges have a long wavelength compared to the water depth in shallow water regions, and are therefore usually modeled using the shallow-water equations. In Chapter 3, I use tidal equations of motion to provide an analytical model to augment our insight of surge-tide propagation in estuaries. Because dredging of channels affects the depth to wavelength ratio, secular changes in tidal estuaries over the past century can influence both tidal and storm surge characteristics [e.g., Talke, et al., 2014].

Large surge events are uncommon, and historical data are limited. Thus, recovery of $19^{\text {th }}$ and early $20^{\text {th }}$ century tide data is needed for reanalysis of extreme events and historical storms [Woodworth and Blackman, 2002; Talke and Jay, 2013, 2017] and for determination of secular trends in tides, storm tides, and surges. In Chapter 2 and 3, I use recovered tide data from the U.S. National Archives and the National Oceanographic and Atmospheric Administration (NOAA) to look at how long-term tidal dynamics have been affected by anthropogenic channel changes. Unlike tides, which approximately repeat every day, each storm and surge is unique. Therefore, deductions about possible longterm changes in storm surges are difficult to draw, either analytically or statistically. Moreover, basic questions such as whether a long-period or quick moving storm will produce larger surge in inland regions, cannot easily be determined from empirical data only, due to this lack of repeatability. 
Previous studies of estuarine tidal dynamics can be used to interpret surge and storm tide dynamics, because both tides and surges are long waves. Therefore, I suggest that new insights can be gained into the behavior of surge in tidal estuaries by using idealized analytical and numerical model which are based on models developed for tides (Chapter 3 and 4). Figure 1-1 shows the marine, river, and intermediate section of an estuary and conceptualize the importance of tides, river flow, and surge in flood water along an idealized estuary.

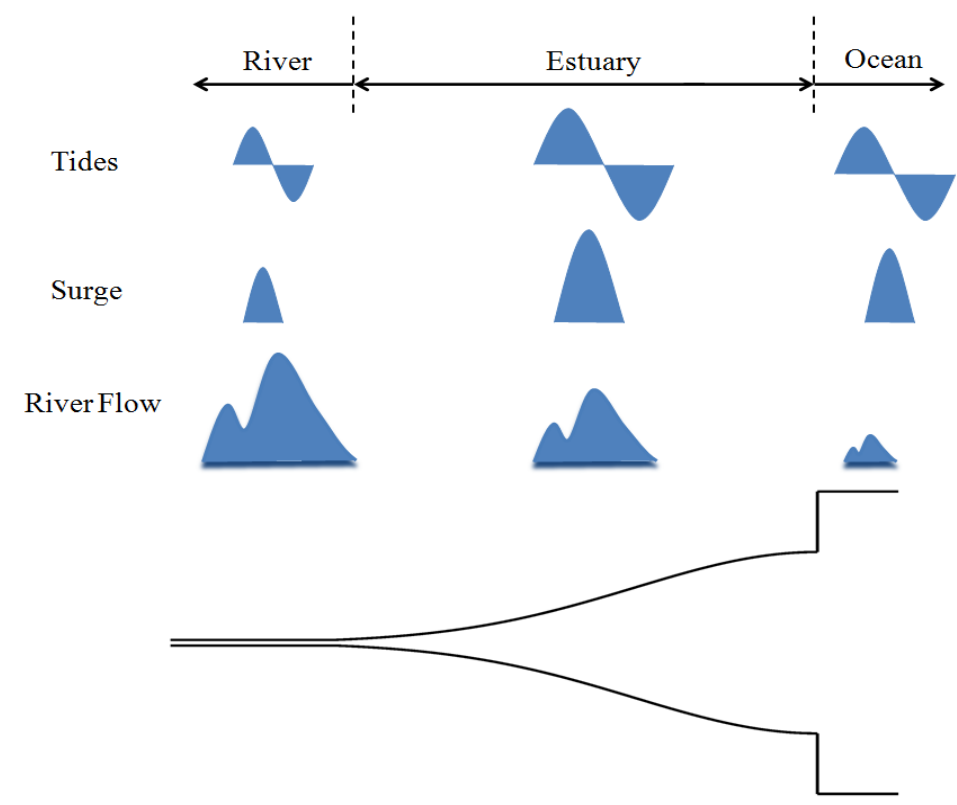

Figure 1-1: Conceptual model of flood water components in an idealized tidal estuary.

\subsection{Motivation}

The tides in many estuaries and harbors around the world display evidence of altered amplitudes and phases. For instance, the greater diurnal tidal range (GDR) in Philadelphia (PA) has increased by about $20 \%$ since 1900 (from 1.7 to $2.05 \mathrm{~m}$ ), while the 
GDR in Wilmington (NC) has increased $85 \%$ from 0.84 to $1.55 \mathrm{~m}$ since the $1880 \mathrm{~s}$ [DiLorenzo et al., 1993; Woodworth, 2010; Familkhalili and Talke, 2016].The amplitudes of both semidiurnal and diurnal tides have increased in the eastern Pacific as the amplitude of the largest diurnal $\left(K_{l}\right)$ constituent in Astoria has increased by $9 \%$ century $^{-1}$, while the amplitude of semidiurnal $\left(M_{2}\right)$ constituent has increased by $\sim 7 \%$ century $^{-1}$ since 1854 in San Francisco Bay [Jay, 2009]. The Ems estuary is another example of remarkable change in tidal range, with an increase of $1.5 \mathrm{~m}$ between 1980 and 2005 in the tidal river [Chernetsky et al., 2010]. Possible factors causing these changes include reduced wetland areas, sea level rise, coastal and estuarine topography changes (especially dredging), and altered river flow [Talke et al., 2014; Orton et al., 2015; Wamsley et al., 2010; Kukulka and Jay, 2003b; Familkhalili and Talke, 2016].

The need for more insight into how bathymetry changes (i.e., depth), surge characteristics (i.e., amplitude, time scale, asymmetry and its relative phase to tide), and river flow can alter storm surge, motivates this study. This investigation extends our knowledge about the tide-surge propagation along tidal estuaries by analyzing important factors that determine water flood distribution.

\subsection{Organization of the Thesis}

Figure 1-2 provides an overview to the content, structure of this dissertation, and process of addressing research questions. In Chapter 2, I investigate how storm surge and tidal magnitudes may be changing due to channel deepening over the past 130 years. An idealized numerical model (Delft-3D) based on the Cape Fear River Estuary (NC), which 
is characterized by strong tidal currents and a wide tidal range, is developed and applied to investigate the importance and the effects of changing channel depth from $7 \mathrm{~m}(1880 \mathrm{~s})$ to $15.5 \mathrm{~m}$ (modern) and hurricane conditions on storm tides and surges. To model storm conditions, I develop parametric wind and pressure forcing with different intensities that represent tropical depression, tropical storm, and hurricane categories 1-5, (SaffirSimpson hurricane scale). The focus of this study is to show that bathymetry changes (i.e. increased depth and narrower width) caused by dredging and channel modification can cause long term changes to the magnitudes and phases of tides. Therefore, storm surge magnitude and timing relative to tides in estuaries will also be influenced by the effects of friction and depth changes.

In Chapter 3, I investigate the effects of surge characteristics on its spatial pattern of amplitude. The focus of this investigation is to provide a perspective on: a) the effects of channel deepening on tides and storm surge, b) the effects of surge characteristics (i.e., amplitude and time scale) on surge propagation, and c) the importance of surge asymmetry and its relative phase to greater semi-diurnal tide constituent $\left(M_{2}\right)$ on surge amplitude along an estuary. To address these questions, I develop an idealized one dimensional analytical model based on known tidal theory and validate the model with an idealized two dimensional, depth-averaged numerical model (Delft-3D) with a constant depth and convergent cross-sectional profile. The analytical model helps to elucidate storm surge dynamics along a river. I next implement a sensitivity study using a range of non-dimensional numbers and explore different values of channel depth and surge amplitude, time scale, and relative phase to show how the location of maximum change 
in surge amplitude propagates upstream. This means that the damping and amplification of surge within an estuary due to bathymetric changes and surge characteristics altered over time as the channel deepened.

In Chapter 4, I investigate the spatial and temporal variability of compound flooding, the effects of convergence length scale of an estuary, and the frictional effects of river flow through analytical and numerical modeling. This study addresses the timely and important question about how and why the contribution of tides, surge, and river flow to peak water level has changed spatially, but also over secular time scales. I use the verified analytical model from Chapter 3 and develop a numerical model to study the parameter space of compound flooding (river flow, tides, and storm surge) in the SJRE and show how prominent factors change spatially from the coast to upstream of an estuary. Results suggest that changes in surge propagation along an idealized estuary are a function of channel depth, surge time scale and amplitude, relative phase of the tides, and river flow effects. 


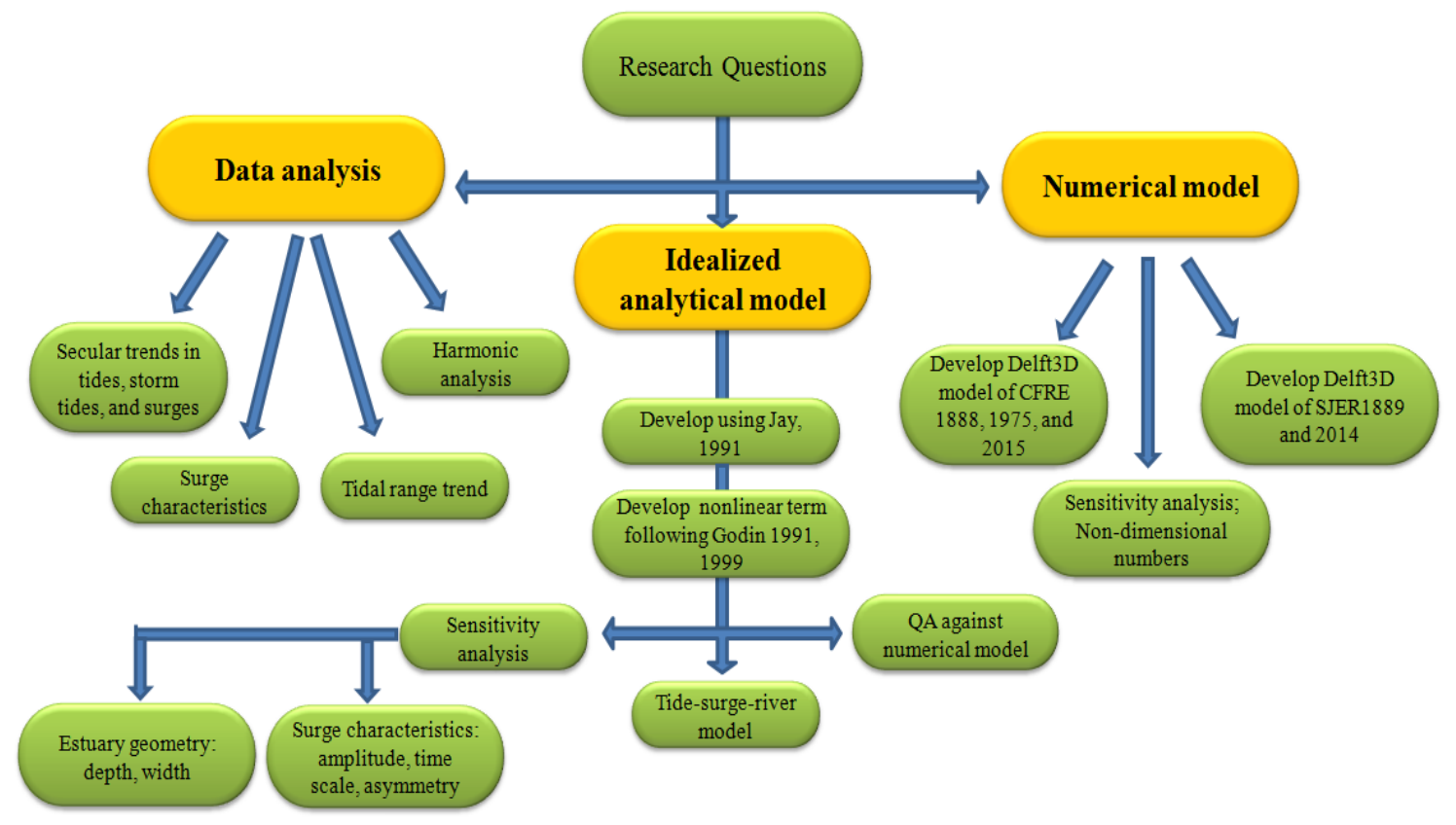

Figure 1-2: An overview of the structure of this dissertation. 


\section{Chapter 2 Idealized Modeling of Storm Surge}

This chapter has been published: Familkhalili, R. and Talke, S., (2016): The effect of channel deepening on tides and storm surge: A case study of Wilmington, NC, Geophys. Res. Lett., 43, 9138-9147, doi:10.1002/2016GL069494.

Estuaries play important environmental and commercial roles in human life. More depth in navigation channels means that ships can have more draft -the depth a ship sinks to when loaded- and navigate with more cargo which brings millions of dollars benefit. Therefore channels have been dredged and deepened over time to provide larger depths for larger ships. In 2017, the Port of Los Angeles/Long Beach increased the shipping channel depth from $65 \mathrm{ft}$ to $66 \mathrm{ft}$ with a future goal of $69 \mathrm{ft}$. The foreign trades of the U.S. ports were valued to be $\$ 1.6$ trillion in total of exports and imports in 2017 [National Ocean Service, 2018].

In this investigation I develop an idealized model of estuarine surge propagation, tide-surge-river interaction for improved understanding of extreme water level along the estuary. There is concern about the effects of climate change and sea-level rise on flood hazard, this contribution, while focused on a single location, is a reminder that local alteration may also play a significant role in evolving risk. 
The magnitude and consequences of local development in estuaries have often been under-appreciated, due to a paucity of historical water-level data and perhaps because concern for climate change has focused attention onto storm properties, rather than changing local bathymetry. By extending the time horizon back more than 50 years, I am able to show that tide range in Wilmington, NC has approximately doubled since the 1880 s, a remarkable statistic. I have used this insight to test and confirm the hypothesis that secular changes to tidal dynamics can imply that storm surge properties and risk have changed as well. To my knowledge, this hypothesis has never been explicitly tested using a retrospective modeling approach, perhaps because of the difficulties of developing and verifying historical $19^{\text {th }}$ century models. Also an idealized model with a Gaussian width variation is a new approach (as opposed to simply using a funnel shape) and allows for a width expansion followed by convergence (a typical estuary behavior).

\subsection{Introduction}

Storm surges, when combined with astronomical tides and wind waves, can cause enormous flood waters [e.g., Wolf and Flather, 2005; McRobie et al., 2005]. As sea level increases due to climate change and other factors, the same storm surge produces larger extreme water levels that will worsen the flood hazard [e.g., Kemp and Horton, 2013].

Since much of the densely populated Atlantic coastline lies less than $3 \mathrm{~m}$ above mean sea level [CCSP, 2008], assessing and explaining long-term changes to storm surge is vitally important. At least two approaches are typically used to model storm tides and 
analyze storm surge, defined here as the difference between the measured and predicted tide. Fully resolved, 2D or 3D hydrodynamic models with realistic meteorological forcing and coastal bathymetry are useful for understanding the effects of individual events on specific landscape features [e.g., Orton et al., 2012; Colle, 2003]. On the other hand, idealized, parametric hurricanes with simplified wind and pressure fields are often used to develop sensitivity studies that investigate the effects of changing meteorological and hydrodynamic variables and non-linear interactions [e.g., Shen and Gong, 2009]. Idealized models require less computational time and reduce complexity, simplifying analysis and interpretation of physical processes. This enables an ensemble-based approach, in which a large parameter space is tested to help assess hazard probability [e.g., Rumpf et al., 2009].

Though the effects of storm characteristics and tide-surge interaction have been investigated in storm surge models [e.g., Peng et al., 2004; Shen et al., 2006], the effect of changing coastal and estuarine topography, which occurs over decadal and secular time scales, has been much less investigated. Nonetheless, diking and changing wetland cover is known to influence flood hazard [e.g., Wamsley et al., 2010] by altering hydraulic roughness and estuary width. Likewise, changes to wetland area are known to influence flood hazard [e.g., Wamsley et al., 2010]. Similarly, Talke et al. [2014] hypothesized that increasing storm tides and storm surge magnitudes in New York Harbor could (in part) be explained by increased harbor depths. Building on these ideas, Orton et al. [2015] showed that restoring channel depths to historical norms in Jamaica 
Bay, New York Harbor, decreased the magnitude of hurricane-induced surge; interestingly, changes in wetland cover were much less important than depth changes.

While the effects of long-term bathymetric change on storm surge are little investigated, the effects of altering depth, cross-sectional area, convergence, and other bathymetric properties on estuary tides have long been investigated using idealized models [e.g., Friedrichs and Aubrey, 1994; Jay, 1991; Lanzoni and Seminara, 1998; Prandle, 2003].

For a given tidal frequency, tidal amplitudes decrease upriver when frictional effects dominate over the funneling effect caused by decreasing width; by contrast, strong convergence can produce increasing amplitude when friction is relatively weak. Significantly, the frictional damping in the linearized tidal equations is proportional to bottom roughness, but inversely proportional to water depth [Friedrichs and Aubrey, 1994]. Therefore, over long time scales, depth changes to estuaries alter the balance of inertial effects, friction, and convergence. When combined with resonance effects, reduced friction has been observed to increase tidal range by more than $3 \mathrm{~m}$ at the landward end of some estuaries [Chernetsky et al., 2010; Talke and Jay, 2013]. Since both storm surge and tides are long waves, with a wavelength large compared to the depth, I hypothesize that surge will also be influenced by the competing effects of friction, depth changes, and convergence.

Over the past 130 years, successive deepening of the Cape Fear River Estuary (CFRE) has occurred and mean depths have approximately doubled. Recently recovered tide data from the U.S. National Archives and the National Oceanographic and Atmospheric Administration (NOAA) enables a long-term look at how tidal dynamics are 
affected by direct, anthropogenic changes. Because much of the estuary approximates a funnel-shaped geometry, an idealized modeling approach to understand first-order system physics and sensitivities is justified. In turn, a parametric model of hurricane wind and pressure forcing is applied to the idealized bathymetry to determine how broad-band long waves react to secular changes in depth. Results suggest a simple, but profound lesson: locations in which tide waves have been amplified are also vulnerable to increases in storm surge and flood risk, to a degree that is related to changed tidal dynamics.

\subsection{Study Domain}

My study site is the Cape Fear River Estuary (CFRE) region in North Carolina that has experienced significant hurricanes over the past 100 years. Hurricane Hazel (1954) and Hurricane Fran (1996), made landfall as CAT-4 and CAT-3 hurricanes, respectively, producing $0.96 \mathrm{~m}$ and $1.7 \mathrm{~m}$ surge at Wilmington. Other significant surge events include an unnamed 1944 event (0.72m surge), an unnamed 1945 event (0.66m), Hurricane Floyd (1999; 1.14m), Hurricane Charley (2004; 1.39 m), and Hurricane Hanna (2008; $1.47 \mathrm{~m})$. The CFRE is an important nursery for juvenile fish, crabs, shrimp, and other biological species [Xia et al., 2008]. Therefore, improved prediction of extreme events impacts on CFRE system will be important to efforts to protect marine life and environments, as well as to better engineering design of infrastructures that can change the economic situations of local residents. 
The Cape Fear River is a relatively shallow river $(\sim 322 \mathrm{~km})$ with a discharge that varies between $\sim 10$ and $3800 \mathrm{~m}^{3} / \mathrm{s}$, with an average annual flow of $\sim 270 \mathrm{~m}^{3} / \mathrm{s}$ that flows into the North Atlantic Ocean. The Cape Fear River has 23,581 $\mathrm{km}^{2}$ watershed and forms near Moncure, where the Deep River and the Haw River converge (Figure 2-1). About $22 \mathrm{~km}$ above Wilmington, the Black River joins the Cape Fear and another river, the Northeast Cape Fear River enters the system at Wilmington [Becker et al., 2010; Xia et al., 2008]. There is a port at Wilmington which is approximately at Rkm 47, at the junction of the Northeast Cape Fear and Cape Fear River, which shows that navigation is an economic driver for this estuary. Tides propagate about $100 \mathrm{~km}$ upstream from the estuary mouth (Rkm 0) [Giese et al., 1985] because the CFRE has a relatively open mouth that allows tidal currents to propagate well into the system (Figure 2-1). Like many river estuaries on the East Coast and worldwide (e.g., the Delaware) [see Lanzoni and Seminara, 1998], the CFRE is approximately funnel shaped over a large part of its domain. 


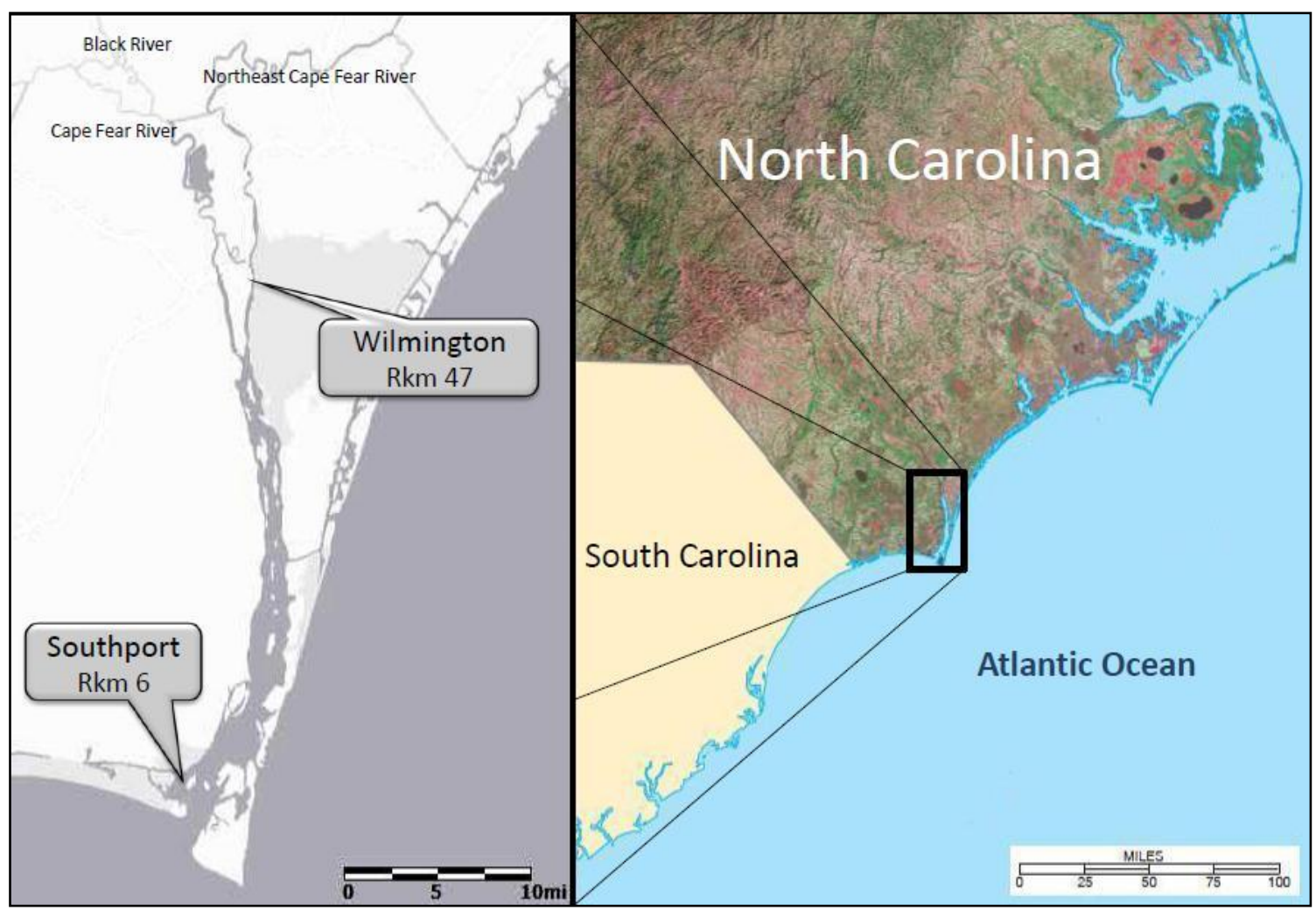

Figure 2-1: Cape Fear River Estuary, [USGS, The National Map, http://www.nationalatlas.gov] and tide gauge locations at Wilmington (NOAA Station ID: 8658120) and Southport (NOAA Station ID: 8659084).

\subsubsection{Hydraulics Evolution of the Cape Fear River Estuary}

Over the past 130 years, the shape and flow characteristics of the CFRE have changed dramatically. Table 2-1 shows the CFRE has been under continuous development work since early 1830 s. In the mid- $19^{\text {th }}$ century, the controlling depth at the bar $(\mathrm{Rkm} 0)$ and in the estuary varied between $3-5$ m relative to mean low water (MLW) [USACE COE, 1873]. Initial efforts to control flow began in the 1820s, but large scale diking and jetty construction only began around 1870, with significant dredging 
beginning in 1881 [USACE COE, 1915]. Continued work increased the channel depth to $9.1 \mathrm{~m}$ by $1932,11.6 \mathrm{~m}$ by 1971 , and $13.5 \mathrm{~m}$ by 2001 , relative to MLW [Welch and Parker, 1979; Olsen, 2012]. The inlet width and channel width were widened to $\sim 120$ and $90 \mathrm{~m}$ in 1913, from $\sim 80 \mathrm{~m}$ in the 1880s [Welch and Parker,1979]. The modern (2015) shipping channel is maintained at a depth of $15.5 \mathrm{~m}$ relative to MSL (14.8 m relative to MLW) and a width of $180 \mathrm{~m}$.

Table 2-1: Chronology of navigational developments in the CFRE [Welch and Parker, 1979]

\begin{tabular}{|c|c|c|}
\hline $\begin{array}{l}\text { Date Work } \\
\text { Completed }\end{array}$ & Description of Work in the CFRE & $\begin{array}{l}\text { Ocean entrance and } \\
\text { River Channel, } \\
\text { Depth and Width } \\
\text { [ft] }\end{array}$ \\
\hline $1829-1889$ & $\begin{array}{l}\text { Several engineering works undertaken to increase the depths of } \\
\text { lower CFR for navigation. Improvements include construction of } \\
\text { contraction jetties in the } 8 \text {-mile river reach immediately below } \\
\text { Wilmington; closure of New Inlet through the construction of } \\
\text { New Inlet Dam; dredging of the river channel shoals. River's } \\
\text { navigation channel between the ocean entrance and Wilmington } \\
\text { developed to a depth of } 16 \mathrm{ft} \text { and a width of } 270 \mathrm{ft} \text { by } 1889\end{array}$ & $\begin{array}{l}16 \text { by } 270 \text { river } \\
\text { channel (by } 1889 \text { ) }\end{array}$ \\
\hline 1907 & $\begin{array}{l}\text { River channel dimensions increased to a depth of } 20 \mathrm{ft} \text { and width } \\
\text { of } 270 \mathrm{ft} \text { by dredging. Mooring basin excavated at Wilmington }\end{array}$ & $\begin{array}{l}20 \text { by } 270 \text { river } \\
\text { channel }\end{array}$ \\
\hline 1913 & $\begin{array}{l}\text { Ocean entrance channel dredged to a depth of } 26 \mathrm{ft} \text { and width of } \\
400 \mathrm{ft} \text {. River channel dredged to a depth of } 26 \mathrm{ft} \text { and width of } 300 \mathrm{ft} \\
\text { at Wilmington }\end{array}$ & $\begin{array}{l}26 \text { by } 400 \text { ocean } \\
\text { entrance, } 26 \text { by } 300 \\
\text { river channel }\end{array}$ \\
\hline 1916 & $\begin{array}{l}\text { Anchorage basin dredged at Wilmington, having a length of about } \\
2000 \mathrm{ft} \text {, a width of about } 1000 \mathrm{ft} \text {, and a depth of } 26 \mathrm{ft}\end{array}$ & $\begin{array}{l}26 \text { by } 400 \text { ocean } \\
\text { entrance, } 26 \text { by } 300 \\
\text { river channel }\end{array}$ \\
\hline 1926 & $\begin{array}{c}\text { Ocean entrance channel dredged to a depth of } 30 \mathrm{ft} \text { and a bottom } \\
\text { width of } 400 \mathrm{ft}\end{array}$ & $\begin{array}{l}30 \text { by } 400 \text { ocean } \\
\text { entrance, } 26 \text { by } 300 \\
\text { river channel }\end{array}$ \\
\hline 1930 & $\begin{array}{c}\text { Excavation of Snows Cut connected at Atlantic Intracoastal } \\
\text { Waterway (AIWW) with CFR }\end{array}$ & $\begin{array}{l}30 \text { by } 400 \text { ocean } \\
\text { entrance, } 26 \text { by } 300 \\
\text { river channel }\end{array}$ \\
\hline 1932 & $\begin{array}{c}\text { River channel dimensions increased by dredging to a depth of } 30 \mathrm{ft} \\
\text { and bottom width of } 300 \mathrm{ft} \text {. A turning basin having a width of } \\
\text { about } 600 \mathrm{ft} \text { excavated at Wilmington. Work accomplished } \\
\text { between } 1931 \text { and } 1932\end{array}$ & $\begin{array}{l}30 \text { by } 400 \text { ocean } \\
\text { entrance, } 30 \text { by } 300 \\
\text { river channel }\end{array}$ \\
\hline 1948 & $\begin{array}{l}\text { River channel extended } 1.25 \text { miles north of Wilmington for the } \\
\text { Hilton railroad bridge to an upstream point in the Northeast CFR. } \\
\text { Extension had channel depth of } 25 \mathrm{ft} \text { and bottom width of } 200 \mathrm{ft} \text {. } \\
\text { Work accomplished in winter of } 1948\end{array}$ & $\begin{array}{l}30 \text { by } 400 \text { ocean } \\
\text { entrance, } 30 \text { by } 300 \\
\text { river channel to } \\
\text { Hilton Bridge, }\end{array}$ \\
\hline
\end{tabular}




\begin{tabular}{|c|c|c|}
\hline 1949 & $\begin{array}{c}\text { Ocean entrance and river channel dimensions increased to a depth } \\
\text { of 32ft and bottom width of 400ft. Work accomplished between } \\
1947 \text { and } 1949\end{array}$ & $\begin{array}{c}25 \text { by } 200 \text { river } \\
\text { channel above } \\
\text { Hilton Bridge }\end{array}$ \\
\hline $\begin{array}{c}32 \text { by } 400 \text { ocean } \\
\text { entrance, } 32 \text { by } 400 \\
\text { river channel to } \\
\text { Wilmington }\end{array}$ \\
\hline 1952 & $\begin{array}{c}\text { Carolina Beach Inlet opened through barrier beach by earth- } \\
\text { moving equipment and explosives. Work accomplished summer } \\
1952\end{array}$ & $\begin{array}{c}32 \text { by } 400 \text { ocean } \\
\text { entrance, } 32 \text { by } 400 \\
\text { river channel }\end{array}$ \\
\hline 1955 & $\begin{array}{c}\text { Navigation facilities dredged at Military Ocean Terminal Sunny } \\
\text { Point. Basins dredged to a width of 800ft and depth of 34ft. } \\
\text { Entrance channel dredged to a width of 300ft and depth of 34ft. } \\
\text { Work accomplished between } 1953 \text { and } 1955\end{array}$ & $\begin{array}{c}32 \text { by } 400 \text { ocean } \\
\text { entrance, } 32 \text { by } 400 \\
\text { river channel to } \\
\text { Wilmington }\end{array}$ \\
\hline 1958 & $\begin{array}{c}\text { Ocean entrance dimensions increased to depth of 35ft and bottom } \\
\text { width of 400ft. River channel dimensions to Wilmington increases } \\
\text { to a depth of 34ft and bottom width of 400 ft. Work accomplished } \\
\text { between 1956 and 1958 }\end{array}$ & $\begin{array}{c}35 \text { by } 400 \text { ocean } \\
\text { entrance, 34 by } 400 \\
\text { river channel to } \\
\text { Wilmington }\end{array}$ \\
\hline 1970 & $\begin{array}{c}\text { River channel dimensions increased to a depth of 38ft and bottom } \\
\text { width of 400ft. Work accomplished between 1965 and 1970 }\end{array}$ & $\begin{array}{c}35 \text { by } 400 \text { ocean } \\
\text { entrance, 38 by } 400 \\
\text { river channel to } \\
\text { Wilmington }\end{array}$ \\
\hline 1971 & $\begin{array}{c}\text { Ocean entrance dimensions increased to depth of } 40 \mathrm{ft} \text { and width } \\
\text { of 500ft. Work accomplished between 1970 and 1973 }\end{array}$ & $\begin{array}{c}40 \text { by } 500 \text { ocean } \\
\text { entrance, 38 by } 400 \\
\text { river channel }\end{array}$ \\
\hline
\end{tabular}

\subsubsection{Data Sources}

Hourly tide data used to validate the idealized tidal model were obtained from the National Oceanographic and Atmospheric Administration (NOAA) for Southport, NC (1976-1988 and 2006-2008) and Wilmington, NC (1935-2015). Nineteenth and early twentieth century hourly tabulations were photographed at the U.S. National Archives [see Talke and Jay, 2013] and digitized, including hourly data from Wilmington (18871888, 1890-1891, 1908-1912) and Southport (1923-1924). Further, hourly records from Southport (1933-1954) were recovered from the National Centers for Environmental 
Information (https://www.ncdc.noaa.gov/EdadsV2) and digitized. Harmonic constituents obtained from 12 short-term gauges are also used [Welch and Parker, 1979].

Figure 2-2 demonstrates that the yearly averaged greater diurnal tidal range (GDR) in Southport has increased by $0.07 \mathrm{~m}$ since the $1920 \mathrm{~s}$, but that Wilmington GDR has increased from 0.84 to $1.55 \mathrm{~m}$ since the $1880 \mathrm{~s}$. A nodal correction was applied by fitting a sinusoid with an 18.6 year period to the observed tide range, and subtracting this curve from the original signal. The results suggest that oceanic processes and alterations at the estuary entrance have produced little change in Southport tides. By extension, the tides at Wilmington have been strongly affected by local changes in the estuary such as the increase in channel depth from $7 \mathrm{~m}$ to $15.5 \mathrm{~m}$.
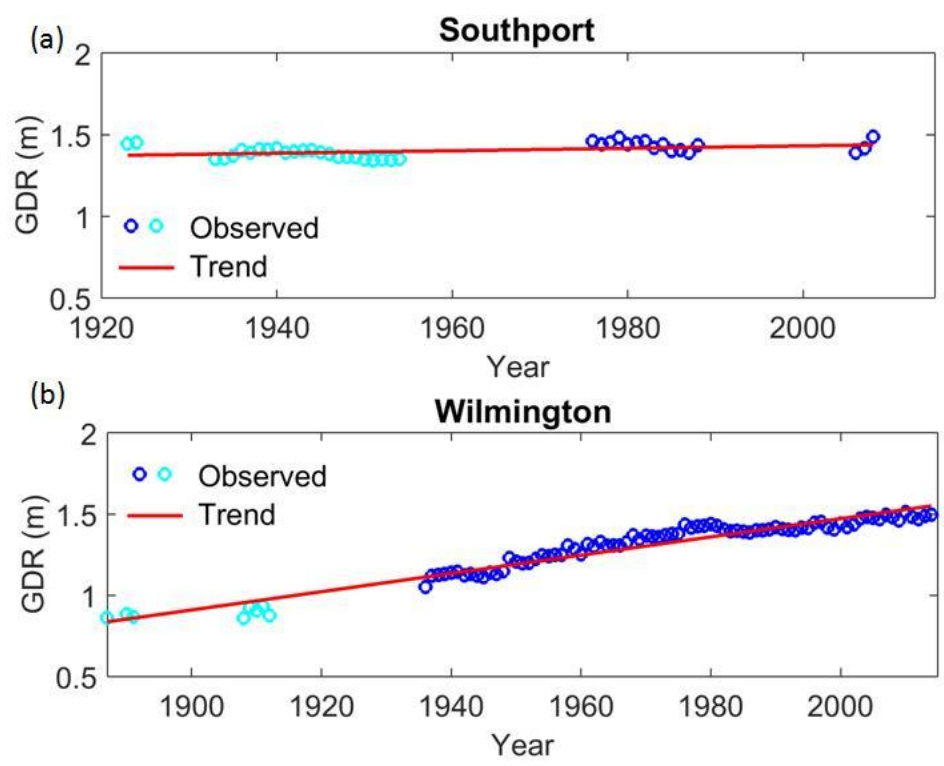

Figure 2-2: Yearly averaged GDR at (a) Southport and (b) Wilmington. Data recovered and digitized from archival sources plotted in cyan and data obtained from NOAA plotted in blue. 


\subsection{Model Configuration}

A depth-averaged Delft-3D numerical model [Booij et al., 1999] is developed with idealized depth and width variations that approximate the natural system in a leastsquares sense (Figure 2-3). The along-channel variation in width is modeled as a Gaussian curve, which allows for an initial expansion in width between Rkm 0 and 12 and an exponential decrease between Rkm 12 and 50 (Figure 2-3d). The channel crosssection is modeled as a Gaussian curve (Figure 2-3c) and is constrained to approximate the cross-sectional area as a function of river kilometer (see Figure 2-6), allowing for both channel and shallow subtidal areas. The width convergence length-scale between Rkm 12 and 50 for the historic (1888) and modern (1975 and 2015) models is $17 \mathrm{~km}$ and $20 \mathrm{~km}$, respectively (see Figure 2-6). Channel depths of $7 \mathrm{~m}, 13.25 \mathrm{~m}$, and $15.5 \mathrm{~m}$ relative to mean sea level are applied for the 1888, 1975, and 2015 conditions, respectively. To allow damping of the tidal wave, the river is modeled with a constant width of $120 \mathrm{~m}$ and a constant depth of $4 \mathrm{~m}$ (for 1888) and 5m (for 1975 and 2015) for $150 \mathrm{~km}$ upstream of Rkm 50. 
(a)

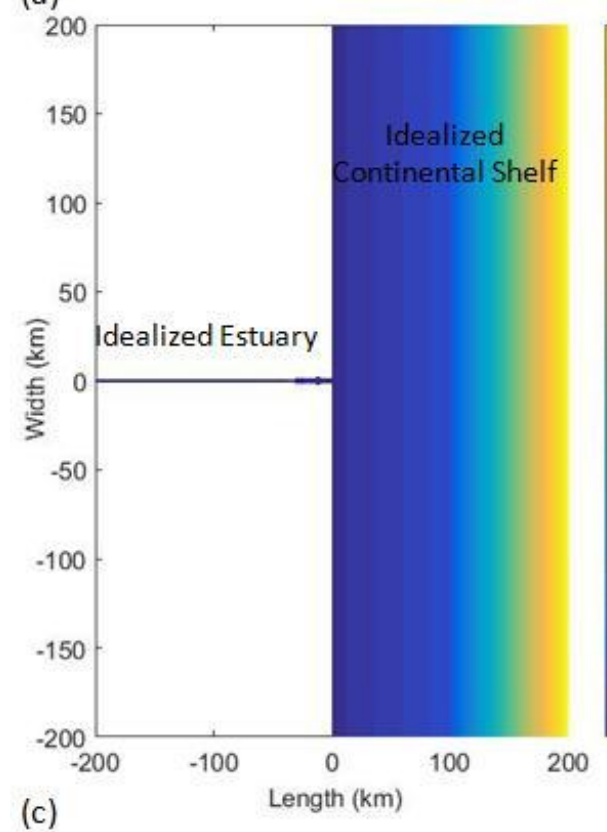

(c)

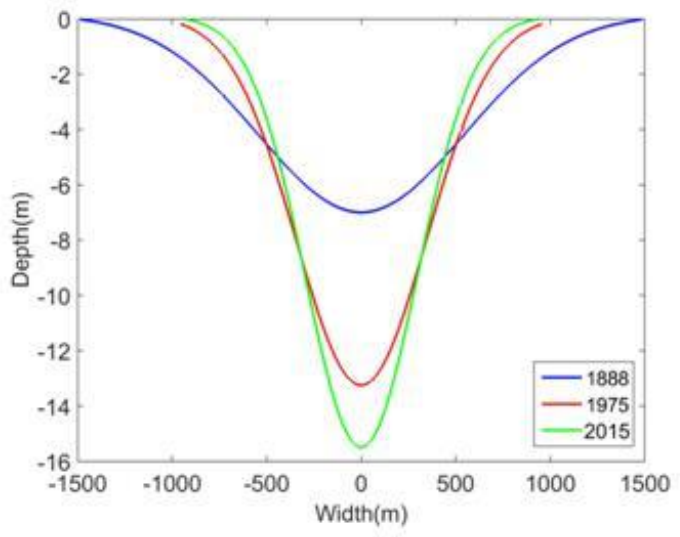

(b)

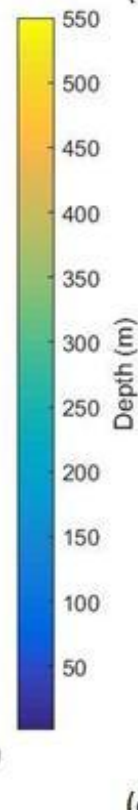

(d)
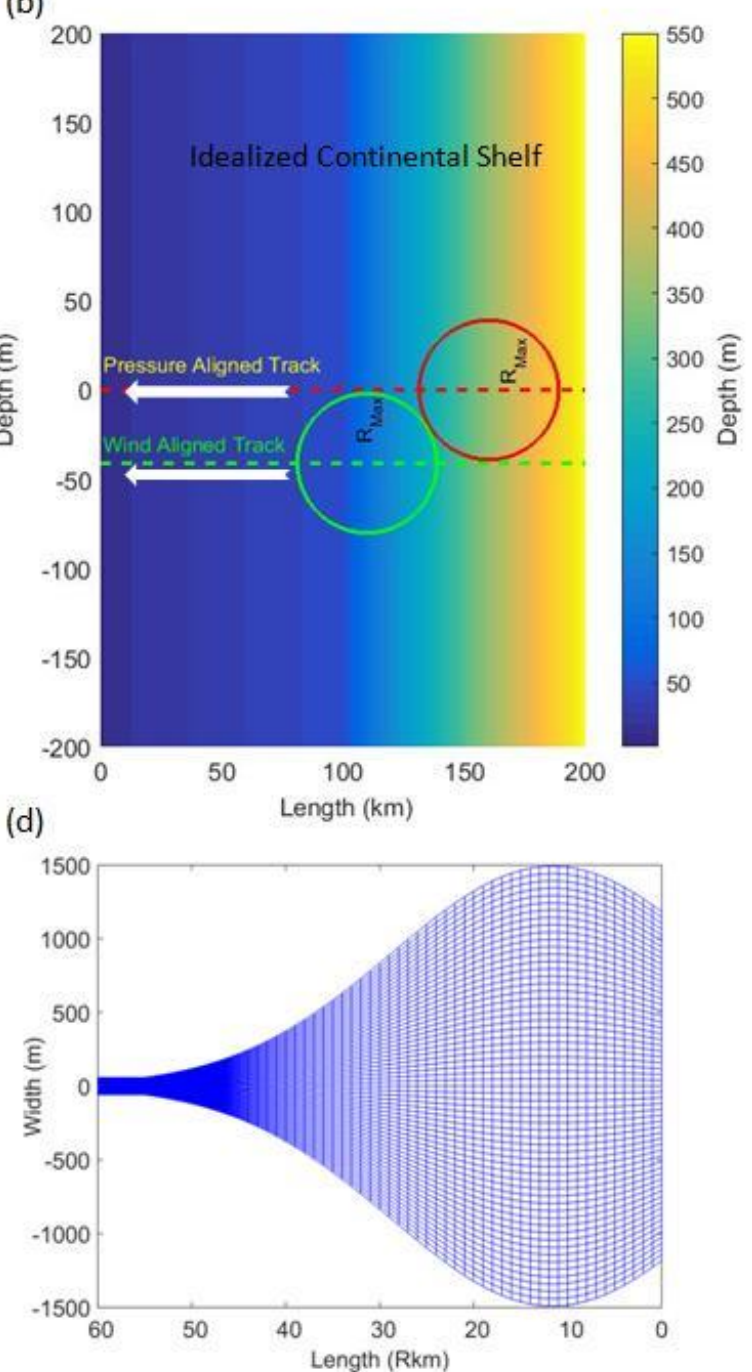

Figure 2-3: (a) Idealized model bathymetry (b) the plan view of TC tracks on the continental shelf, which move from right to left (c) Idealized channel cross-section at the mouth, and (d) the plan view of the first $60 \mathrm{~km}$ of estuary grid.

Continental shelf topography is approximated from modern bathymetric measurements [Olsen, 2012] and slopes linearly downward from the coast to a depth of $550 \mathrm{~m}$ at $200 \mathrm{~km}$ offshore. Coastal geometry has been simplified to a straight coastline, 
and the estuary orientation has been made perpendicular to the coast. The length and width of the continental shelf model are $200 \mathrm{~km}$ and $400 \mathrm{~km}$, respectively, which was found thru sensitivity studies to be adequate for simulating storm surge; doubling the domain size resulted in a less than $1 \%$ change in storm surge results. As shown below, the good agreement between measured and modeled tidal constituents validates the idealized approach. A total of 62 grids in the lateral direction and 273 in the alongchannel direction are used in the estuary, and 113 and 140 along the continental shelf.

\subsection{Idealized Model}

Depth changes and width convergence along the CFRE are used to create the bathymetry files. To estimate an idealized CFRE bathymetry, 23 cross-sectional profiles of depth were digitized in $2 \mathrm{~km}$ increments from an 1888 topographical map published by the U.S. Coast and Geodetic Survey, and a smooth, idealized bathymetry was fit to the

cross-sections (Figure 2-4, 2-5). A digital elevation model (DEM) of Cape Fear from 1975 was obtained from NOAA, and the 2015 channel depth was estimated from Olsen [2012]. 


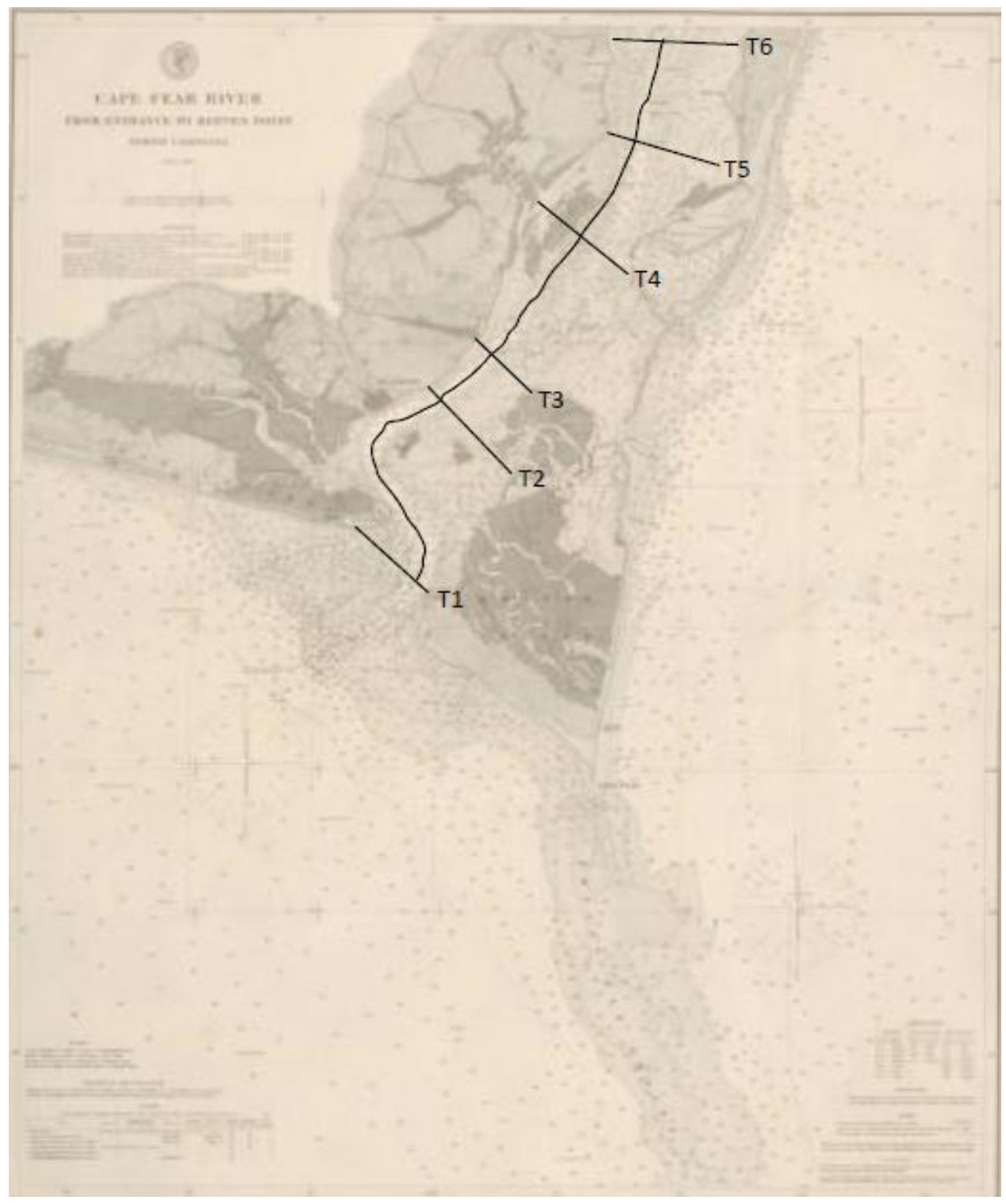

Figure 2-4: 1888 topographical map of the Cape Fear River, channel, and location of crosssectional profiles (T1-T6) that are in $1.5-6 \mathrm{~km}$ increments with an average of $3.5 \mathrm{~km}$. It is assumed that cross-sections are perpendicular to the channel direction (part one). 


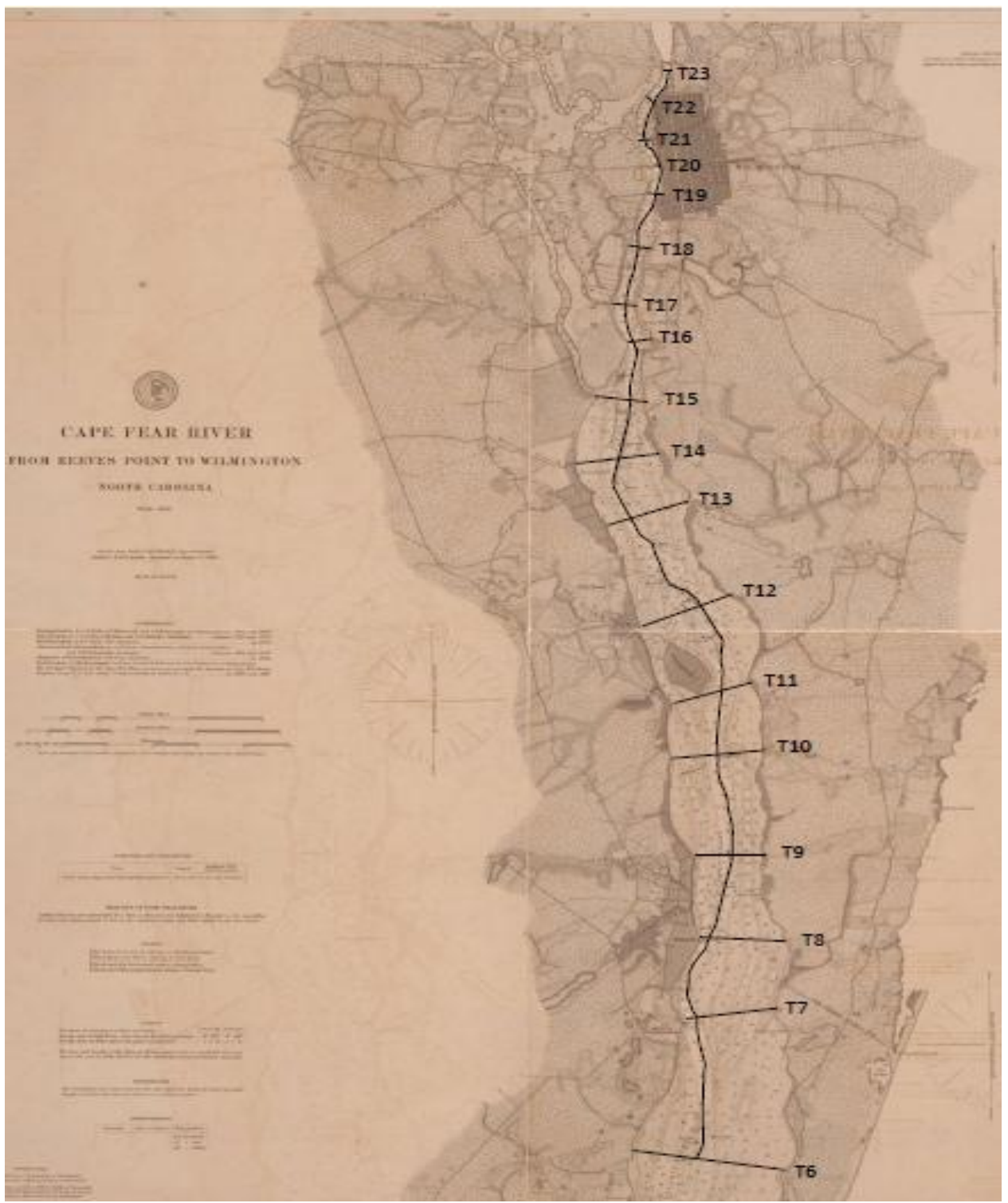

Figure 2-5: 1888 topographical map of the Cape Fear River and location of cross-sectional profiles (T6-T23) that are in $1.7-3.5 \mathrm{~km}$ increments with an average of $1.7 \mathrm{~km}$. It is assumed that crosssections are perpendicular to the channel direction (part two). 
Figure 2-4 and 2-5 show the 1888 topographical map of the CFRE published by the U.S. Coast and Geodetic Survey and obtained via the University of North Carolina's online library (http://www2.lib.unc.edu/dc/ncmaps/cgs_chartnumber.html). Black lines numbered T1 to T23 show the location of cross-sectional profiles that I used to estimate an idealized CFRE bathymetry (Figure 2-6a, b). Each cross-section was drawn perpendicular to the thalweg (channel direction) and was selected on the main branch of the Cape Fear River. A small NW branch of the river and the Brunswick River are neglected due to their small reach compared to the main channel. The width of channel is $2500 \mathrm{~m}$ at the mouth, increases to $3400 \mathrm{~m}$ at $\mathrm{Rkm} \mathrm{17}$, and decreases upstream to about 200m at Wilmington (Rkm 47).
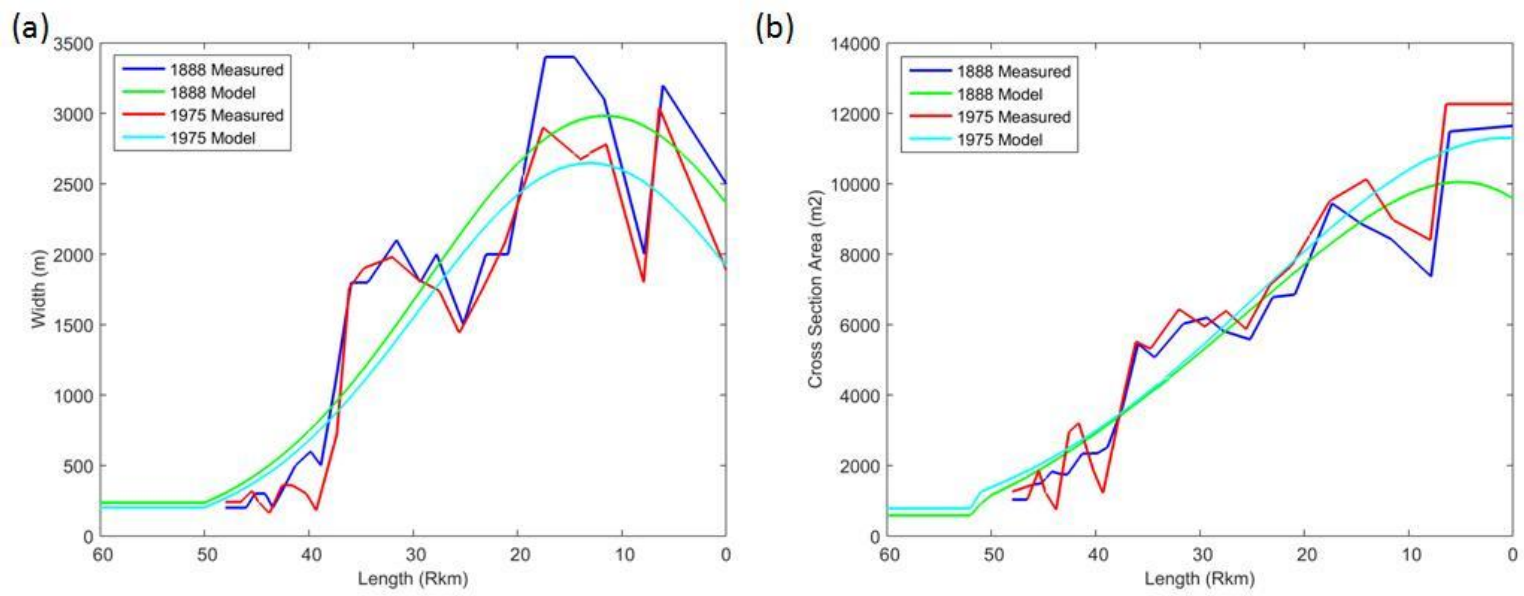

Figure 2-6: Observed and modeled (a) width and (b) cross sectional area along the channel. Zero is at the river entrance and positive direction is landward to the left of the graph. 
Figure 2-6 shows the observed and modeled width and cross sectional area in the CFRE as a function of Rkm. A Gaussian curve was fit to the observed width and crosssectional area variation using a least-squared approach; depth was held constant and reflects the published navigational channel depth. Compared to historical conditions, the modern cross-sectional area is $0-20 \%$ larger than historically, but the width is $0-20 \%$ smaller. This analysis of bathymetry results in an expanding width between Rkm 0 and 12 and an approximately exponentially converging width between Rkm 12 and 50 . Upstream of Rkm 50, the estuary is modeled with a constant width and cross-sectional area.

\subsubsection{Boundary Conditions}

Meteorological forcing for the model is imposed on the system using surface boundary conditions. This atmospheric forcing includes wind and pressure perturbation. The idealized hydrodynamic model is forced at the seaward boundary by $M_{2}, S_{2}, N_{2}$ (semidiurnal), and $K_{1}, O$, and $P_{1}$ (diurnal) tidal constituents derived from the Oregon State University Tidal Inversion Software (OTIS) package [Egbert and Erofeeva, 2002]. These are sufficient to the first order to obtain the tide surge interaction. River forcing at the landward end was set to total discharge of $268 \mathrm{~m}^{3} / \mathrm{s}$, representing the historic average of river discharge.

River discharge measurements from the United States Geological Survey (USGS) confirm that flood events generally do not coincide with hurricane storm surge. Since river discharge is generally small during hurricane events, I assume-to first order-that the 
system is well mixed [see Becker et al., 2010] and that nonlinear interactions between the river and storm tide are negligible. A barotropic modeling approach is therefore justified.

\subsubsection{Meteorological Forcing}

The meteorological inputs are sea level pressure and wind fields developed following the parametric model of Holland [1980]. Central pressure is one of the most important parameters in defining the intensity of a storm. The meteorological forcing during a tropical cyclone is:

$$
\begin{gathered}
P=P_{c}+\left(P_{n}-P_{c}\right) \exp \left(-A / r^{B}\right) \\
V_{W}^{\prime}=\left[A B\left(P_{n}-P_{c}\right) \exp \left(-A / r^{B}\right) /\left(\rho r^{B}\right)\right]^{1 / 2}
\end{gathered}
$$

where $\rho$ is the air density, $P_{c}$ is the hurricane central pressure (Table 2-2), $P_{n}$ is the ambient pressure, $A$ and $B$ are scaling parameters, $P$ is the atmospheric pressure at radius $r$, and $V_{W}^{\prime}$ is the wind velocity. The parameter $A$ is defined by $A=\left(R_{\max }\right)^{B}$, where $R_{\max }$ represents the distance from the storm center to the location of maximum wind and $B$ is a constant with values between 1 and 2.5 [Holland, 1980]. Following Hsu and Yan [1998], I apply an $R_{\max }$ of $34,34,34,46,51,48$, and $47 \mathrm{~km}$ to represent a Tropical Depression (TD), Tropical Storm (TS), and hurricane categories 1-5, (Saffir-Simpson hurricane scale), respectively. The maximum wind speed and the center pressure ranged from $11.75 \mathrm{~m} / \mathrm{s}$ and $998 \mathrm{mbar}$ (TD) to $78.8 \mathrm{~m} / \mathrm{s}$ and $910 \mathrm{mbar}$ (CAT-5) (Table 2-2). The parameter $B$ is defined to be 2.25 . 
Table 2-2: Definition of the typical sustained wind speed and minimum surface pressure for different categories of tropical cyclones. The typical range is given in parentheses [National Oceanic and Atmospheric Administration, National Hurricane Center].

\begin{tabular}{lcc}
\hline Category & Maximum Wind & Minimum Surface \\
& Speed $(\mathrm{m} / \mathrm{s})$ & Pressure $(\mathrm{mbar})$ \\
\hline Tropical Depression & $11.75(\leq 17)$ & $998($ Non $)$ \\
Tropical Storm & $26.26(18-32)$ & $990($ Non $)$ \\
1 (Weak) & $37.14(33-42)$ & $980(>980)$ \\
2 (Moderate) & $45.49(43-49)$ & $970(979-965)$ \\
3 (Strong) & $55.71(50-58)$ & $955(964-945)$ \\
4 (Very Strong) & $66.96(59-69)$ & $935(944-920)$ \\
5 (Devastating) & $78.80(\geq 70)$ & $910(<920)$ \\
& & \\
\hline
\end{tabular}

\subsubsection{Wind Drag}

Many studies have investigated the relation of wind sea-surface drag and wind speed [e.g., Smith 1980; Powell et al., 2003]. The drag coefficient $C_{D}$ increases as the wind speed increases in open oceans. But under extreme wind conditions this relationship is unrealistic and results in overestimation of sea momentum transfer and higher water levels. Therefore, a reduction in the wind drag coefficient at higher wind speeds greater than $30 \mathrm{~m} / \mathrm{s}$ is proposed, based on observations and experiments. Most of the surge is caused by friction between the strong winds of the storm and the ocean surface. It is the 
wind stress that transfers momentum from the atmosphere to the water. The wind drag coefficient varies as wind speed rises due to hurricane conditions. Wind stress $T$ is calculated:

$$
T=\rho_{a} C_{D} U_{10}^{2}
$$

where $\rho_{a}$ is the density of air, $U_{10}$ is wind speed at $10 \mathrm{~m}$ above the sea surface, and $C_{D}$ is the wind drag coefficient. Jarosz et al. [2007] showed that that $C_{D}$ peaks at a wind speed near $32 \mathrm{~m} / \mathrm{s}$ and then steadily decreases as the wind speed continues to rise. Powell et al. [2003] showed that tropical cyclones include logarithmic mean wind profiles and that $C_{D}$ is much less than previously thought in winds above $40 \mathrm{~m} / \mathrm{s}$. They showed drag coefficient of 0.0026 as saturation value for extreme winds of higher than $35 \mathrm{~m} / \mathrm{s}$. Donelan et al. [2004] measurements suggest the drag coefficient of 0.0025 as saturation level for wind speeds which exceed $33 \mathrm{~m} / \mathrm{s}$. Therefore, the wind drag coefficient is modeled using the Yelland and Taylor [1996] equation for $U_{10}$, and is capped at 0.003 for wind speeds larger than 30m/s [see Powell et al., 2003; Donelan et al., 2004].

\subsection{Model Calibration and Validation}

A preliminary data analysis of hourly water levels recently discovered from tide gauges spaced along the Cape Fear River was done to calibrate the idealized model. The idealized model was calibrated by adjusting the Chézy bed-friction coefficient until the spatial variation in tidal constituents (the dominant semidiurnal $M_{2}$ ), over a 40day run matched observations from 1976 (Figure 2-7b). The measured tidal amplitude (red circles 
in Figure 2-7b) are obtained from 12 short-term gauges along the river from Southport to Wilmington [see Welch and Parker, 1979]. A Chézy coefficient of 23 and 65 was applied for the estuary and the continental shelf, respectively, and yielded a root-mean-squareerror (RMSE) of $0.013 \mathrm{~m}$, or approximately $2 \%$ of the $M_{2}$ amplitude at the river mouth.

The results indicate a good fit between model results and data. The relatively large bed friction within the estuary likely compensates for un-modeled roughness features such as marsh vegetation and/or variations in bathymetry.

Then, the spatially constant bed-friction coefficients were applied to the historic (1888) and modern $(1975,2015)$ models. Harmonic analysis [e.g., Leffler and Jay, 2009] shows that the modeled constituents for the 1888 and 2015 conditions compare favorably with tide records in Wilmington and Southport (Figure 2-7a). Therefore, despite simplifications, my idealized model reproduces the observed secular trends in the CFRE and is capturing the first order behavior of long waves in the real system. 

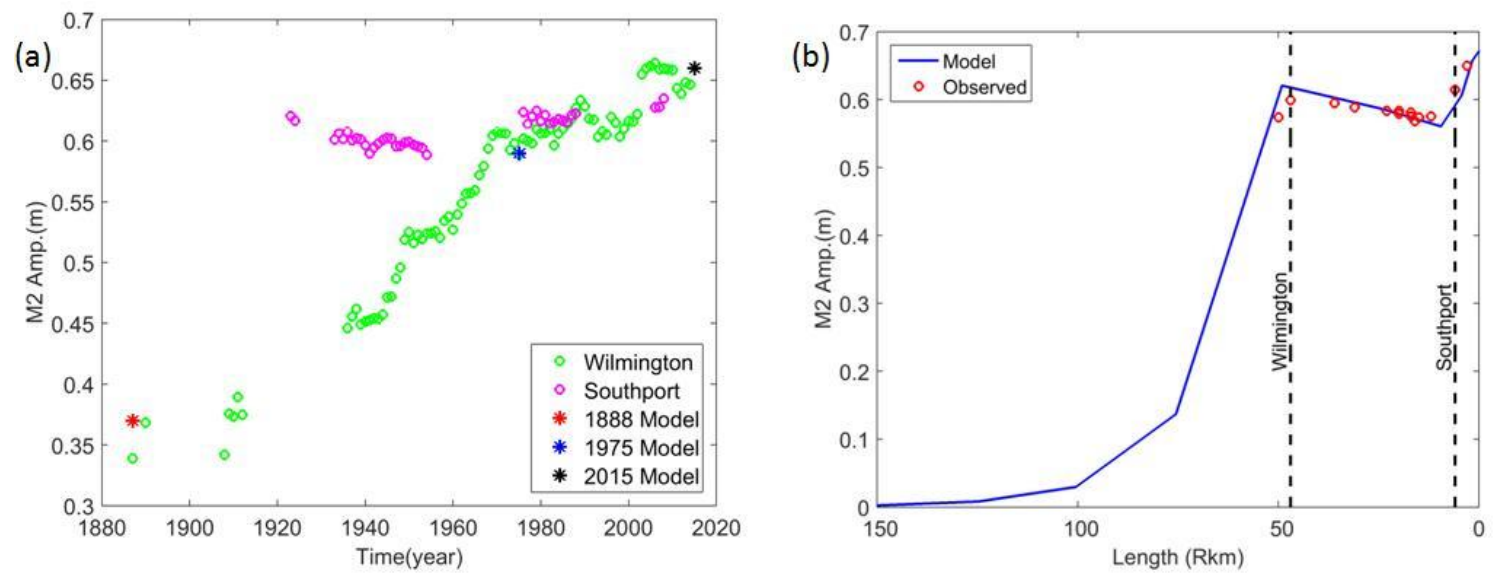

Figure 2-7: (a) Measured and modeled $M_{2}$ amplitude at Wilmington and Southport over time and

(b) variation of modeled $M_{2}$ along the idealized 1975 estuary, compared against measurements.

Figure 2-8 shows the track of significant TCs that have approached the CFRE within $60 \mathrm{~km}$ of the CFRE entrance since 1910 (see inset circles in Figure 2-9). The subset of TCs which approximate wind-aligned or pressure-aligned tracks (see Figure 23b) are labeled with an arrow. 


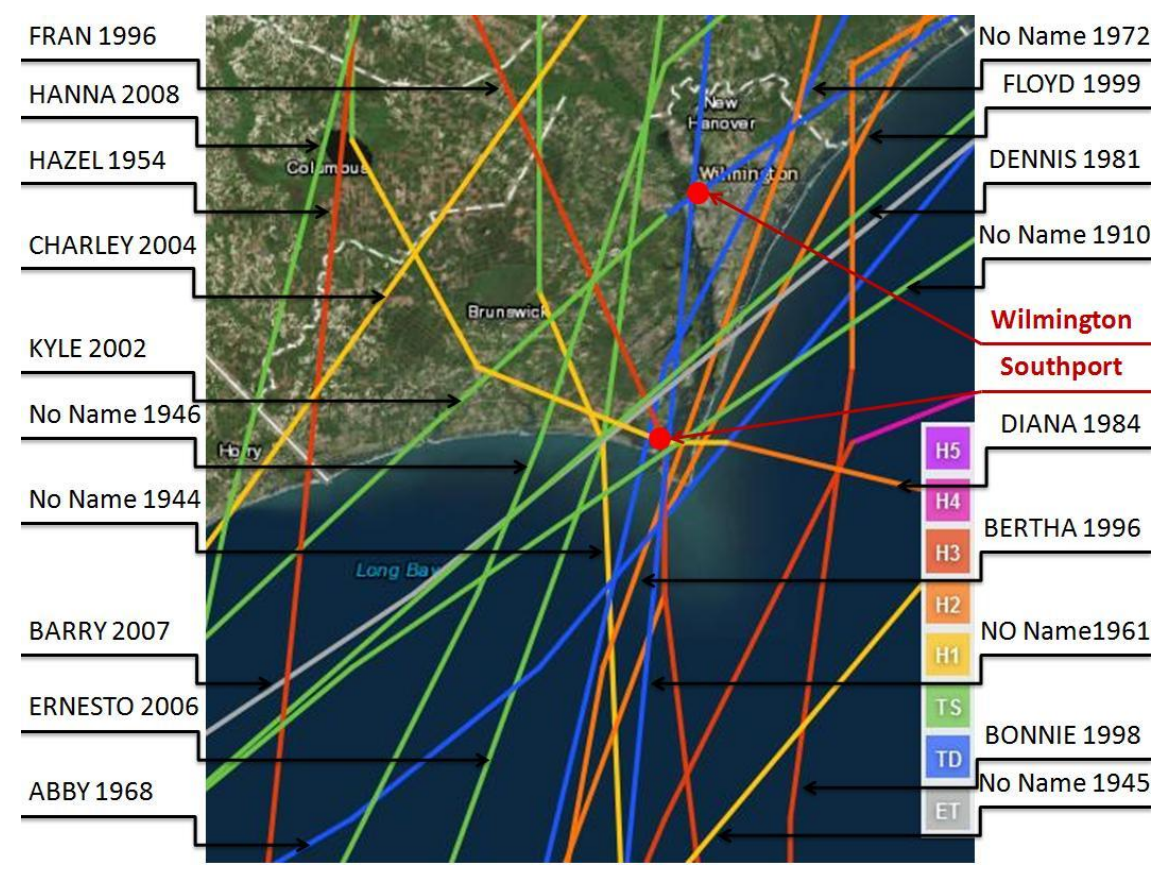

Figure 2-8: Significant tropical cyclone (TC) tracks within $60 \mathrm{~km}$ of the river entrance with approximate wind-aligned or pressure-aligned tracks.

\subsection{Sensitivity Analysis}

To investigate changing conditions, a total of 546 model runs were carried out on the calibrated models, representing three time periods (1888, 1975, and 2015), seven storm intensities (from TD to CAT-5), two storm tracks, and 13 tidal phases (spaced over a tidal cycle). Because tidal phases affect estuary depth (e.g., high or low tide) and current direction (either opposed or collinear with wind-induced currents), I assess the effect of these non-linear tide-surge interactions by re-running storms in 13 hourly shifted increments. The parametric storms were applied during mean tidal conditions (halfway between spring and neap). Two storm tracks are modeled: wind aligned, in which the 
maximum wind speed coincides with and travels along the estuary center axis, and pressure-aligned, in which the eye of the hurricane coincides with and travels along the estuary center axis (Figure 2-3b). Storm surge was estimated from the modeled storm tide by subtracting out the tide from the calibration runs.

\subsection{Results and Discussion}

Significantly, the frictional damping in the linearized tidal equations is proportional to bottom roughness, but inversely proportional to water depth [Friedrichs and Aubrey, 1994]. Therefore, over long time scales, depth changes to estuaries alter the balance of inertial effects, friction, and convergence. Since both storm surge and tides are 'long waves', with a wavelength large compared to the depth, I hypothesize that surge will also be influenced by the competing effects of friction, depth changes, and convergence.

Analysis of archival data indicates that the $M_{2}$ amplitude in Wilmington has nearly doubled over the past century, from $\sim 0.35 \mathrm{~m}$ in the late $19^{\text {th }} /$ early $20^{\text {th }}$ century to $\sim 0.65 \mathrm{~m}$ today (Figure 2-7a). Over a similar period, the $M_{2}$ amplitude near the coast (Southport) has increased only slightly. Similarly, tidal range in Wilmington has doubled to $1.55 \mathrm{~m}$ since the $1880 \mathrm{~s}$, with a much smaller increase of $0.07 \mathrm{~m}$ observed in Southport since the 1920s (see Figure 2-2). Clearly, the divergence in observed tidal amplification in these locations suggests that changes to the estuary physics, rather than the ocean, explains most of the secular changes at Wilmington. In fact, the observed changes in tides 
are reproduced by changing only the depth and width of the modeled channel (Figure 2$3 c)$.

Since saving the whole model results with all sub domains requires large amount of storage space, considering the number of runs, I save the results at specific stations which are located along the river channel and spread into the continental shelf. For this section I focus on Wilmington station data at $\mathrm{Rkm} 47$ which consists of total water level that is the results of the sum of the meteorological surge and astronomical tide. Figure 2-9 shows modeled storm tide and storm surge at Wilmington ( $\mathrm{km} 47)$ produced by seven different TC strengths and two different tracks. The vertical dashed lines indicate barometric pressure and peak wind speeds of the modeled TC on the continental shelf domain. The fill areas around the mean shows the range of results obtained from 13 hourly spaced tidal phases. Red, magenta, and green circles show measured TCs from 1980-present, 1950-1980, and pre-1950, respectively, and include (1) Hurricane Hanna (2008), (2) Hurricane Barry (2007), (3) Hurricane Ernesto (2006), (4) Hurricane Charley (2004), (5) Hurricane Kyle (2002), (6) Hurricane Floyd (1999), (7) Hurricane Bonnie (1998), (8) Hurricane Bertha (1996), (9) Hurricane Fran (1996), (10) Hurricane Diana (1984), (11) Hurricane Dennis (1981), (12) unnamed (1972), (13) Hurricane Abby (1968), (14) unnamed (1961), (15) Hurricane Hazel (1954), (16) unnamed (1946), (17) unnamed (1945), (18) unnamed (1944), and (19) unnamed (1910). Vertical scales are different between wind and pressure-aligned graphs. The horizontal magenta dashed lines in Figures 2-9a and 2-9b represent the National Weather Service threshold for moderate flooding in Wilmington of $2.04 \mathrm{~m}$. 
The reduced dissipation in the system could decrease the damping of storm surge within the estuary. Therefore, the amplification of tides due to less friction may be an indicator of increased surge. Idealized TC runs also suggest that a deeper system will produce a greater storm tide and storm surge, for the same meteorological forcing (Figure 2-9). For the 'wind aligned' scenario with 1888 depths, storm surges are modeled to be $0.7+/-0.15$ and $3.8+/-0.25 \mathrm{~m}$ for a CAT-1 and CAT-5, respectively (Figure 2-9a), where the maximum variance is caused by different timing relative to tidal phase. By contrast, the deeper, wider 2015 scenario produces storm surges which vary between $1.2+/-0.45$ to 5.6+/-0.6 m for a CAT-1 and CAT-5, respectively (Figure 2-9a). Compared to 1888, the modeled CAT-5 storm tide in 2015 increased by $1.65+/-0.25 \mathrm{~m}$ and $0.95+/-0.18 \mathrm{~m}$ in the 'wind-aligned' and 'pressure aligned' scenarios, respectively (Figures 2-9c and 2-9d). Overall, storm surge and storm tide heights increased between the 1888 and 2015 models for all modeled TCs, such that there is almost no overlap in the range of modeled heights. A less drastic change is modeled between the 1975 and 2015 scenarios, likely due to a smaller proportional increase in depth. For reference, the National Weather Service considers a storm tide of $2.04 \mathrm{~m}(6.7 \mathrm{ft})$ to be the threshold for moderate flooding in Wilmington. Hence, modeling results suggest that the number of storms that can cause significant surge and flooding has likely increased over time. Measurements at Wilmington qualitatively support this conclusion; the largest 5 storm surge on record all occurred since 1980 (Figures 2-9c and 2-9d). 

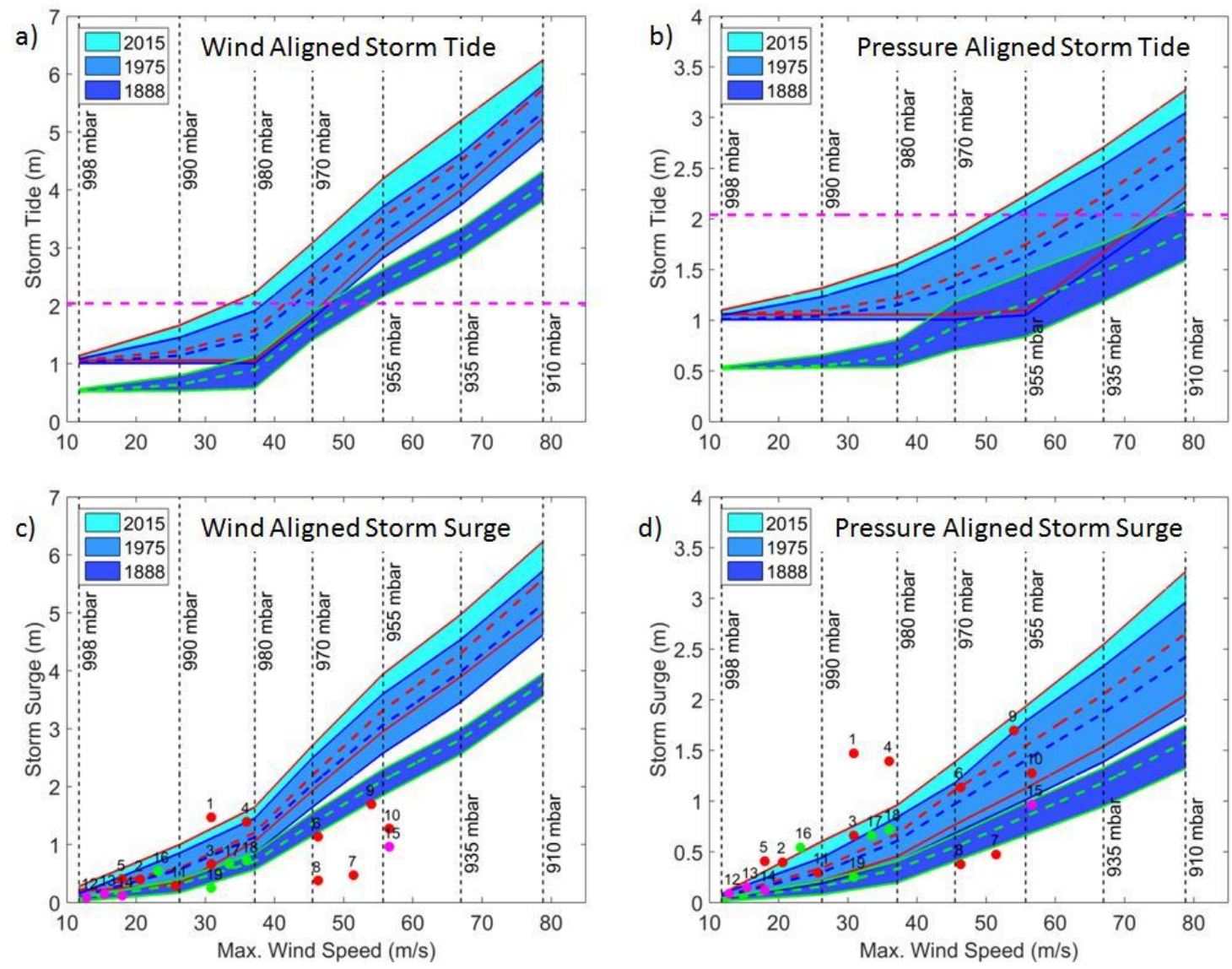

Figure 2-9: (a-d) Modeled storm tide and storm surge at Wilmington (Rkm 47) produced by seven different TC strengths, varying from TD to CAT-5.

Several factors drive increased storm tides in the modern simulations. First, increases in mean high water (MHW) have resulted in a larger possible storm tide, independent of meteorological forcing. This effect is especially prominent for low-energy storms like tropical depressions, in which the increase in the peak water level from 0.55 to $1.05 \mathrm{~m}$ between the 1888 and 2015 scenarios is almost entirely driven by larger tides (Figures 2-9a and 2-9b). A large tide range also contributes to the greater variability in storm tide heights observed in modern model runs. 
I also posit that both tides and storm tides have increased because channel deepening reduces the hydraulic resistance to incoming long waves [e.g., Chernetsky et al., 2010]. In analytical models of tide propagation, the friction term in the momentum equation is linearized to be proportional to $C_{D} /_{H}$, where $C_{D}$ is the linearized drag coefficient and $H$ is the depth [e.g., Jay, 1991; Friedrichs and Aubrey, 1994]. Hence, doubling depth over the past century has a similar dynamic effect on a tide wave as halving friction. Since the estuary is strongly convergent upstream of Rkm 12, an incoming wave is characterized by a balance between smaller cross-sections (tending to amplify) and friction (tending to damp). Increased depth alters this balance and helps explains why both tides and storm tides have amplified over time. Scaling of momentum terms in model results also indicate that inertial effects $(d u / d t)$ are important, and have become more prominent over time. Unlike some estuaries such as the Ems [Chernetsky et al., 2010], traditional quarter wave resonance does not appear to play a role here since the deep channel is only $50 \mathrm{~km}$ long, smaller than the quarter wave wavelength. However, sensitivity studies suggest that wave celerity and $M_{2}$ phase change at the transition from the shipping channel $(15.5 \mathrm{~m}$ depth) to the river channel $(5 \mathrm{~m})$ upstream of Wilmington, suggesting that some wave reflection is occurring that may contribute to observed water levels.

Compared to historical events, the modeled storm surge from wind-aligned conditions often exceeds observed magnitudes at Wilmington (Figure 2-9c), particularly for larger storms. Since no historical storm tracks are exactly wind aligned, and storms 
often lose power near the shore, this result is not unexpected (see Figure 2-8). On the other hand, some measured events exceed the pressure-aligned model experiments (Figure 2-9d), which shows that the order of magnitude of simulation results (Figure 2-9) is plausible. The overall consistency with actual tide and storm tide measurements demonstrates that the model experiments likely capture the correct historical trend. The wind-aligned scenario can be interpreted as the worst-case scenario: though most historical storms approach the CFRE at some angle and have made landfall elsewhere, a perpendicular approach is not implausible (as hurricane Sandy showed in NY). When meteorological forcing in the estuary is included, sensitivity studies suggest that overall storm tide magnitudes increase, and that the differences between the 1888 and 2015 scenarios decrease by as much as $0.35 \mathrm{~m}$ in a CAT- 5 event. Therefore, preliminary results suggest that the local contribution to surge has decreased over time (due to increasing depth), but not enough to compensate for the amplification in the externally forced wave.

Nonetheless, because an idealized modeling approach was used, results should be interpreted as an indication that significant change has occurred in both tides and storm tides, not as definitive magnitudes. A fully realized numerical model that includes more complex bathymetry, variable friction linked to bed types, more realistic storm forcing, overland flow and flooding effects, and periodic estuary stratification is required to fully assess changed flood risk. In particular, large scale overland flooding (the levee-break scenario) may reduce the predicted storm surge heights in the extreme scenarios, and hence the modeled relative change over time. An ensemble of storm tracks and storm characteristics should be modeled to fully understand how the worst-case scenario has 
changed over time. Nonetheless, results validate the hypothesis that direct anthropogenic interventions are the primary cause of both changed tidal and storm-surge dynamics in the CFRE. Since I did not consider the natural, pre-1850 condition of a 3-5m deep estuary, historical changes may be more extreme than suggested.

\subsection{Conclusions}

In this study I develop an idealized numerical model to investigate how changing channel depths affect tides and storm surge in a system. The alterations in tidal characteristics indicate that local changes in the system, particularly channel deepening, have increased the propagation of tides into the system and alteration in the non-linear frictional properties of a system that reduced the dissipation. Model results suggest that tide propagation into the system has been strongly affected by increases in channel depth from $7 \mathrm{~m}$ to $15.5 \mathrm{~m}$ over the last 130 years, leading to a doubling of tidal range in Wilmington. The decreased hydraulic roughness affects hurricane storm surge as well: Synthetic parametric tropical cyclones (with peak winds from $11.75 \mathrm{~m} / \mathrm{s}$ to $78.80 \mathrm{~m} / \mathrm{s}$ ) applied to different depth scenarios suggest that the same storm making landfall today will produce significantly larger water levels than in the $19^{\text {th }}$ century. Further investigation with realistic bathymetry is warranted to constrain the change in flood hazard in Wilmington, NC. Since many harbors worldwide have been deepened since the $19^{\text {th }}$ century, and because many locations worldwide exhibit substantial trends in tidal 
constituents [Woodworth, 2010; Mawdsley et al., 2015], it is probable that a secular change in storm surge risk has also occurred in other estuaries. 


\section{Chapter 3 Analytical Modeling of Storm Surge ${ }^{1}$}

Numerical modeling of storm surge has been the subject of many researches [e.g., Brandon et al., 2014; Familkhalili and Talke, 2016]. Generally, 2D or 3D hydrodynamic models are either directly forced by meteorological forcing or observed water levels from tide gauges. Realistic meteorological forcing and coastal bathymetry have been used for understanding the effects of individual events on specific landscape features [e.g., Brandon et al., 2014; Orton et al., 2012; Bertin et al., 2012; Colle, 2003], while idealized geometry and parametric hurricanes with simplified wind and pressure fields are often used to develop sensitivity studies that investigate the effects of changing meteorological and hydrodynamic variables [e.g., Shen and Gong, 2009; Familkhalili and Talke, 2016]. Since numerical models are typically calibrated for an existing bathymetric configuration and for a selected set of storms [e.g., Orton et al., 2016], sensitivity tests that incorporate and compare a multitude of geometric configurations are challenging. Idealized analytical models that rely on fundamental underlying physics simplify the bathymetric conditions and are able to circumscribe a much larger parameter space and provide insight into physical processes.

\footnotetext{
${ }^{1}$ Familkhalili, R., Talke, S., Jay, D. (2019): Tide-Storm Surge Interactions in Highly Altered Estuaries: How Channel Deepening Increases Surge Vulnerability, submitted to JGR
} 
In this chapter I describe an analytical model that enhances our insight of surgetide propagation in estuaries. The analytical model is fast and simple, which allows for sensitivity analyses that investigate the effects of different systems geometries (e.g., depth and width) and changing surge and tidal characteristics on surge-tide propagation. My analytical solution is different from earlier studies which usually solve the propagation of one dominant tidal constituent (e.g., $M_{2}$ ), by considering the interaction of surge and tide. I investigate the effects of channel depth, surge amplitude and time scale, and relative phase of surge to tide on surge tide amplitudes along a weakly convergent estuary.

\subsection{Introduction}

As global sea-level rises, there is increasing concern that increased depth may amplify tide amplitudes and alter phases at the estuary scale [Cai et al., 2012; Ross et al., 2017; Holleman and Stacey, 2014]. Similarly, there is a growing recognition that local bathymetric changes such as channel deepening can significantly alter tide, circulation, and transport patterns within estuaries [e.g., Chernetsky et al., 2010; Jay et al., 2011; de Jonge et al., 2014; Chant et al. 2018; van Rijn et al., 2018]. Since storm surge caused by wind occurs over a similar time scale and with similar amplitude as a tide wave, changes in estuary bathymetry also affect surge magnitudes and flood risk [e.g., Talke et al., 2014; Orton et al., 2015]. Most dramatically, a doubling of channel depth in the Cape Fear Estuary (NC) since 1880s resulted in a doubling of tide range and a large $(1.8 \mathrm{~m})$ increase 
in the modeled surge due to the worst-case scenario hurricane [Familkhalili and Talke, 2016]. In the Hudson River, tides at Albany (NY) have approximately doubled since 1930 due to dredging [Schureman, 1934; Ralston et al., 2019] and were modeled to produce a significant increase in storm surge magnitudes. On the other hand, the tide range in New York harbor has changed only slightly since the mid- $19^{\text {th }}$ century [Talke et al., 2014], and modeling suggested that historical channel deepening only altered tide range within the harbor by $0.1 \mathrm{~m}(\sim 7 \%)$ [Ralston et al., 2019].

Hence, long wave amplitudes at some locations within estuaries appear to be quite sensitive to changing conditions, while others seen relatively impervious to change. Since altered tide and storm surges have implications for flood hazard, a better understanding of how and why storm surge magnitudes vary within an estuary has obvious practical importance. Here, I use a well-known analytical approach that has previously been used for tides [e.g., Jay 1991; Jay and Flinchem, 1997] and apply the tools and lessons of tide analysis to gain new insights into how and why storm surge magnitudes change within an estuary.

Storm surge is a meteorologically-forced long-wave generated by storm winds, and interacts with storm waves and astronomical tides in coastal regions to produce flood waters [e.g., Wolf and Flather, 2005; McRobie et al., 2005]. The magnitude and time scale of a storm surge within an estuary depend on the intensity, size, and path of the storm [Peng et al., 2004; Xia et al., 2008; Rego and Li, 2010; Orton et al., 2016], the geometric properties of the estuary [Familkhalili and Talke, 2016; Orton et al., 2015], and non-linear frictional interactions with other hydrodynamic processes, including river 
flow, astronomical tides, and wind waves [Maskell et al., 2013]. At the same time, the storm surge modifies the hydrodynamic processes with which it interacts, for example, shifting the phase [Horsburg and Wilson, 2007] and altering the amplitude [Arns et al., 2017] of the tide wave. Quantifying such effects, however, remains challenging and is typically assessed by simulating storm surge in a numerical model that is run with and without tides [Shen et al., 2006]. The difference between the modeled storm surge waves is then attributed to non-linear tide-surge interaction, but this approach cannot determine how much the tide (or surge) wave has been altered.

I suggest that new insights can be gained into the behavior of surge in estuariesand its nonlinear interaction with tides - by approximating its behavior using analytical models developed for tides. Tides and surge have similar time scales, are long-waves described by the shallow-water equations and may, therefore, be amenable to similar solution methodologies. Extensive studies have analytically investigated the influence of geometrical variations of estuaries (e.g., depth, cross-sectional area, and convergence) on tidal propagation [e.g., Dronkers, 1964; Jay, 1991; Friedrichs and Aubrey, 1994; Lanzoni and Seminara, 1998; Godin, 1999; Kukulka and Jay, 2003]. Moreover, a subset of analytical models have investigated the interaction between two or three tidal constituents, or between tides and river flow [e.g., Giese and Jay, 1989; Jay and Flinchem, 1997; Godin, 1999; Toffolon and Savenije, 2011]. Here, I argue that insights into tide-surge interactions can be obtained by a three constituent tide model, in which two of the constituents model the surge and the remaining constituent models the primary $M_{2}$ tidal frequency. 
If surge can be approximated as the sum of tide waves, the tidal literature can guide analysis of surge propagation within estuaries, and help explain the effects of changing geometry (such as depth). Tidal theory explains wave dynamics in estuaries a balance between inertia (acceleration and deceleration effects), amplification (due to the convergence), damping (due to bottom friction), and energy exchange between frequencies. At any given tidal frequency, tidal amplitudes decrease upriver when frictional effects dominate over the funneling effect caused by decreasing width; by contrast, strong convergence can produce increasing amplitude when friction is relatively weak. Therefore, changing the balance between bed friction, convergence, and river flow helps determine whether tidal amplitudes reduce, increase, or remain constant along a convergent estuary [e.g., Jay, 1991].

Since large surge events are uncommon and associated historical data are limited, $19^{\text {th }}$ and early $20^{\text {th }}$ century tide data recovery is vital and help to reanalyze extreme events and to determine secular trends in tides, storm tides, and surges [Woodworth and Blackman, 2002; Orton et al., 2016; Talke and Jay, 2013, 2017]. Unlike tides, which repeat every day, the characteristic of each storm is unique. Therefore, direct deductions about possible long-term changes are challenging to make, either analytically or statistically, though longer records make conditional sampling possible [Talke et al., 2014, 2019; Dangendorf et al., 2014]. Moreover, basic questions such as whether a longperiod or quick moving storm produce larger surge in inland regions, cannot easily be determined from empirical data due to lack of repeatability. 
In this chapter, I develop an analytical model of surge based on the three constituent tide models used by [Jay and Flinchem, 1997; Parker, 1991; Buschman et al., 2009]. I first use empirical data to justify the use of two sinusoidal constituents to model surge effects, and quantify the range of time scales and amplitudes of surge that is typically observed in a representative coastal-plain estuary on the U.S. East Coast, the Delaware Bay. Since a significant portion of Delaware Bay is funnel shaped, and the increase in tide magnitudes due to channel dredging is well established [DiLorenzo et al., 1993], my modeling approach is well suited for understanding whether surge amplitudes have changed over time due to altered bathymetry. Next, I develop an analytical model by linearizing friction using the Godin [1991, 1999] approach, which involves using Chebyshev polynomials and trigonometric identities to derive terms with combinations of frequencies. I employ a multi-section approach and determine the friction term iteratively to account for along-channel variation of width and effective friction. To show that results are reasonable, the analytical model is then validated against an idealized numerical model that is run using the same configuration. The resulting model is fast, simple, and enables the quick sampling of a large parameter space. I demonstrate the explanatory power of the model by showing how four important parameters- the estuary depth and the surge amplitude, time scale, and asymmetry—affect the spatial damping (or amplification) of the surge wave. 


\subsection{Methods}

\subsubsection{Analytical Model}

Computer simulations are widely used to model storm surge in specific coastal areas [e.g., Orton et al., 2012] or in idealized geometry [e.g., Familkhalili and Talke, 2016], but analytical models are transparent, quick to run and enable the investigation of both individual parameters and their non-linear interaction [e.g., Chernetsky et al., 2010]. Using these models, the analytical effects of changing parameters (e.g., depth) can be found for different types of systems and different boundary forcing.

Here I outline the theoretical basis of a three-constituent tide model, closely following the approach of Jay [1991] and Giese and Jay [1989]. One-dimensional long wave propagation along a channel in an idealized estuary is described by the crosssectionally integrated equations for conservation of mass and momentum [e.g., Jay, 1991]. For details see Appendix A.

$$
\begin{gathered}
\underbrace{\frac{\partial Q}{\partial t}}_{\begin{array}{c}
\text { Local } \\
\text { acceleration }
\end{array}}+\underbrace{\frac{\partial}{\partial x}\left(\frac{Q^{2}}{A}\right)}_{\begin{array}{c}
\text { Convective } \\
\text { acceleration }
\end{array}}+\underbrace{g A \frac{\partial \xi}{\partial x}}_{\begin{array}{c}
\text { Pressure } \\
\text { gradient }
\end{array}}+\underbrace{b T}_{\text {Friction }}=0 \\
\underbrace{\frac{\partial Q}{\partial x}}_{\begin{array}{c}
\text { Water } \\
\text { transport }
\end{array}}+\underbrace{b \frac{\partial \xi}{\partial t}}_{\begin{array}{c}
\text { Temporal water } \\
\text { surface elevation }
\end{array}}=0
\end{gathered}
$$

where $Q$ is cross-sectionally integrated flow, $t$ is time, $x$ is the longitudinal coordinate measured in landward direction ( $x=0$ at the mouth, see Figure $3-1), b$ is width, $g$ is acceleration due to gravity, $A$ is channel cross-section, $\xi$ is elevation of the tide water 
level, $T$ is the bed stress divided by water density. Cross-sectionally integrated flow $(Q)$ is equal to $\left(Q_{R}+Q_{T}\right)$ (that is summation of river flow $Q_{R}$, invariant in time and space, and tidal transport $\left.Q_{T}(x, t)\right)$. The conceptual plan of the model of tidal wave is shown in Figure (3-1). I consider a constant depth and assume that the width of the channel is an exponentially decreasing function of the longitudinal coordinate $x$, which approximates a typical mid-latitude coastal plain estuary:

$$
b=B_{c}+\left(B_{0}-B_{c}\right) e^{\left(-\frac{x}{L_{e}}\right)}
$$

where $B_{0}$ is the width at the estuary mouth, $B_{c}$ is a constant that models the river width in the landward part of the domain, and $L_{e}$ is the convergence length scale (i.e., the length over which the width decreases by a factor of e).

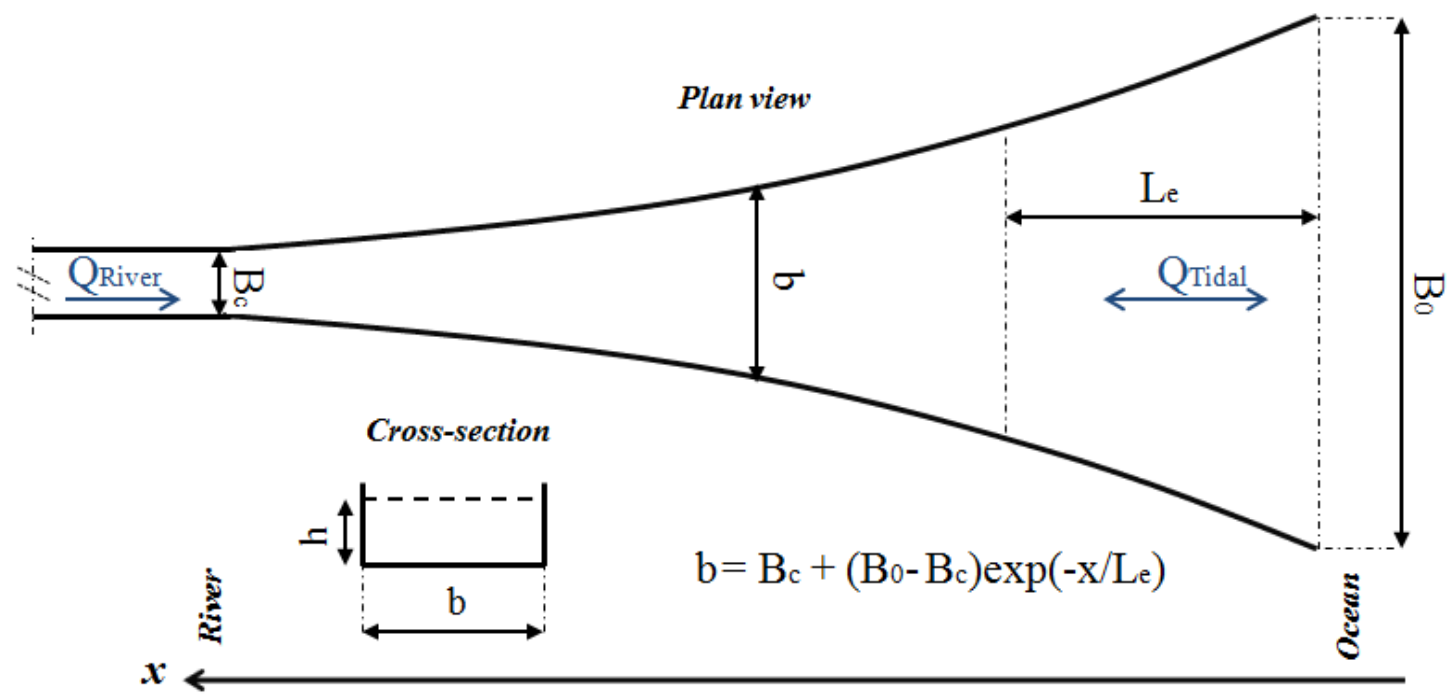

Figure 3-1: The conceptual plan view and cross-section area of the model. 
I assume that the tidal amplitude to depth ratio $\left(\frac{\xi}{h}\right)$ is small and river flow $\left(Q_{R}\right)$ is constant, since variability from a storm-driven river freshet typically occurs a day or more after the storm [e.g., Divoky et al., 2005], depending on watershed characteristics. Subtracting the time derivative of the momentum equation (Eq 3-1) from the spatial derivative of the continuity equation (Eq 3-2), and using $Q=Q_{R}+Q_{T}$, results in a wave equation that describes the wave propagation along a channel without tidal flats [Kukulka and Jay, 2003]:

$$
\begin{aligned}
& \underbrace{\frac{\partial^{2} Q_{T}}{\partial x^{2}}}_{\begin{array}{c}
\text { Pressure } \\
\text { gradient }
\end{array}}-\underbrace{\frac{1}{b} \frac{\partial b}{\partial x} \frac{\partial Q_{T}}{\partial x}}_{\begin{array}{c}
\text { Pressure gradient and } \\
\text { convergence }
\end{array}}-\underbrace{2 \frac{1}{g h} U_{R} \frac{\partial^{2} Q_{T}}{\partial x \partial t}+2 \frac{1}{g h} U_{R} \frac{1}{A} \frac{\partial A}{\partial x} \frac{\partial Q_{T}}{\partial t}}_{\text {Convective acceleration }} \\
& -\underbrace{\frac{1}{g h} \frac{\partial^{2} Q_{T}}{\partial t^{2}}}_{\text {Local acceleration }}-\underbrace{\frac{b}{g h} \frac{\partial T}{\partial t}}_{\text {Friction }}=0
\end{aligned}
$$

where $b$ is the width, $h$ is the depth, $g$ is the acceleration due to gravity, and $A$ is the channel cross-section. The non-linear frictional interaction is represented by $T=\frac{\tau}{\rho}=$ $C_{d}|u| u$, where the velocity $u$ is the summation of river flow $u_{R}$ and the tidal flow $u_{T}$, and $C_{d}$ is the drag coefficient. To compare the results of the analytical model with an idealized numerical model (see section 3.2), the drag coefficient is converted to a Chézy coefficient $C_{h}$ using $C_{d}={ }^{g} / C_{h}{ }^{2}$, where $g$ is the gravitational constant. An analytical solution for equation (Eq 3-4) is possible after assuming a sinusoidal solution and linearizing the quadratic friction term. 
Although the width of the continental shelf and the propagation speed, width, and storm-track influence storm surge time scale and magnitudes [e.g., Orton et al., 2016], I neglect such complexity. Instead, I consider coastal-generated surge as a boundary condition and investigate how surge behaves in the estuary, once generated. Furthermore, I neglect the Coriolis acceleration, assume no overland flooding, and consider that tidal transport is one dimensional. These processes are left for future study.

\subsubsection{Linearizing the Frictional Term}

In this study, I linearize the nonlinear term following the Godin [1991a, b, 1999] approach, in which the frictional term, $u|u|$, is represented analytically with Chebyshev polynomials [Dronkers, 1964]. The expansion is expressed as:

$$
\frac{u|u|}{U_{(x)}^{2}} \approx A u^{\prime}+B u^{3}+C u^{15}+\ldots
$$

where $U_{(x)}$ is the maximum value of the current at point $x$ (i.e., the sum of the amplitudes of all waves), and $u^{\prime}$ is a non-dimensionalized velocity that is defined as $\frac{u}{\left|U_{(x)}\right|}$ [Doodson, 1956; Godin, 1991a, b; see Appendix B for more info]. A combination of the first $\left(u^{\prime}\right)$ and third $\left(u^{\prime 3}\right)$ expansion terms is typically sufficient to obtain an accurate approximation [Godin, 1991a, 1999; Figure 3-2], and I use this approach here. As an example, Figure 3-2 shows that the combination of three tidal harmonics $\left(D_{1}, D_{2}\right.$ and $\left.D_{4}\right)$ produces an asymmetric bed stress $u|u|$ over a tidal period, and is well approximated by 
Chebyshev polynomials (red line). The dashed blue line in Figure 3-2 shows $u|u|(\mathrm{m} / \mathrm{s})^{2}$, which is the square of $u(\mathrm{~m} / \mathrm{s}$, green line), with the direction of the stress retained.

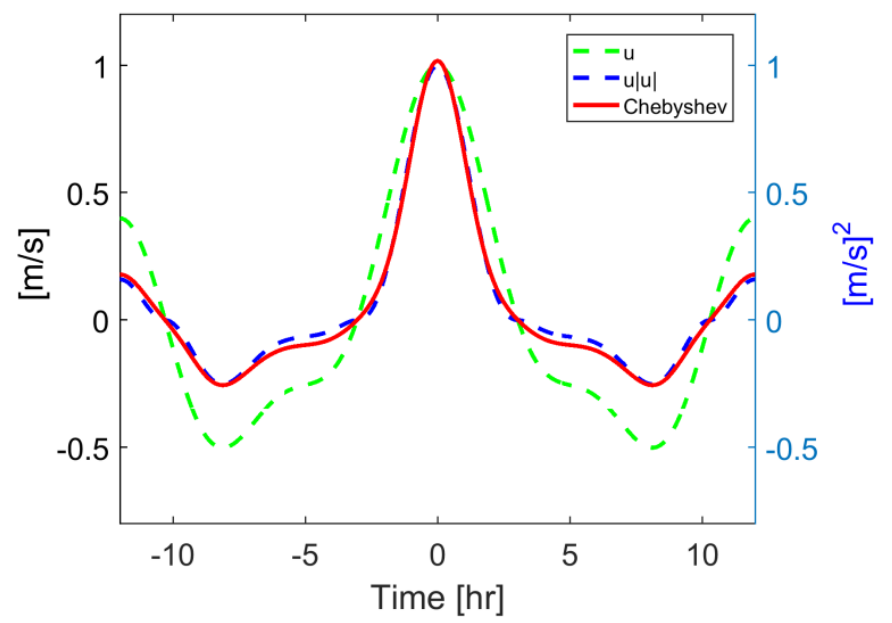

Figure 3-2: Example of an approximation to $u|u|$ by Chebyshev polynomials for the case of three sinusoidal constituents $\left(6,12\right.$, and 24 hour period), i.e., $u_{(x, t)}=u^{\prime}=0.3 \cos (\omega t)+0.5 \cos (2 \omega t)+$ $0.2 \cos (4 \omega t), U_{(x)}=1$. The green line represents the velocity flow $u[\mathrm{~m} / \mathrm{s}]$, while the blue line represents the square of the velocity, $u|u|\left[(\mathrm{m} / \mathrm{s})^{2}\right]$. The Chebyshev approximation (red-line) well represents $u|u|$.

For a 3-tide constituent model with river flow, I first assume a solution of the form (see also Appendix B):

$$
u^{\prime}=u_{0}^{\prime}+u_{1}^{\prime} \cos \left(\omega_{1} t+\phi_{1}\right)+u_{2}^{\prime} \cos \left(\omega_{2} t+\phi_{2}\right)+u_{3}^{\prime} \cos \left(\omega_{3} t+\phi_{3}\right)
$$

where $u_{0}^{\prime}, \quad u_{1}^{\prime}, \quad u_{2}^{\prime}$ and $u_{3}^{\prime}$ are dimensionless velocity amplitudes, $\omega_{1}, \omega_{2}, \omega_{3}$ are frequencies, and $\phi_{1}, \phi_{2}, \phi_{3}$ are phases. I substitute Equation (3-6) into the expansion $A u^{\prime}+B u^{\prime 3}$, which results in a friction term with 24 terms. I further simplified by applying trigonometric identities based on the Chebyshev expansion (for example, $\cos ^{3} x=\frac{1}{4}(3 \cos x+\cos 3 x)$; see Appendix B for a full list and the solution). The 
resulting expansion is a linear sum of sine waves which includes terms containing the original forcing frequencies but also additional terms that contain higher harmonics (overtides). For the simple case that $u_{0}^{\prime}=u_{2}^{\prime}=u_{3}^{\prime}=0$, I show in the Appendix B that the linearization of bed stress produces a harmonic at three times the frequency of the original wave; for example, the standard $M_{2}$ tide wave produces an $M_{6}$ harmonic. When a mean flow is present, the $M_{4}$ harmonic is produced. When $u$ is a function of two, three, or more sinusoidal constituents, the same expansion is used and leads to many additional overtides (harmonics) with frequencies that are sums and differences of the parent (driving) frequencies. The amount of energy transferred to higher harmonics controls the damping of constituents within a domain; the more that energy is transferred to overtides, the larger the amount of energy lost from the parent wave. As I show later, the amount of energy loss -the damping in the estuary- is strongly influenced by parameters such as depth. From a mathematical viewpoint, the nonlinear term, $(u|u|)$ has been linearized, enabling the development of analytical or semi-analytical solutions to the forcing equation, given appropriate boundary conditions and geometry [see e.g., Chernetsky et al., 2010].

The novel aspect of my model is that I represent storm surge as the summation of two sinusoidal "tide" constituents, while retaining primary tidal forcing from the $D_{2}$ tide (e.g., $u_{M_{2}}$ ). Hence, my model is primarily valid in locations with primarily semidiurnal or diurnal forcing (e.g., the U.S. East Coast and U.S. Gulf Coast, respectively). In section 3.2.2, I investigate the validity of representing storm surge as the sum of a primary 
sinusoid $\left(u_{S u_{P r i}}\right)$ and a smaller, typically higher frequency harmonic $\left(u_{S u_{S e c}}\right)$, where I employ $S u$ to denote a surge constituent.

\subsubsection{Multi Segment Approach}

The linearization described above is often applied by choosing a representative velocity scale that best approximates the range of velocity amplitudes found within the entire domain. A better approach, which takes into account the spatial variation in the representative velocity scale, is to split the model domain into multiple segments [Dronkers, 1964]. Here, I divide up the estuary into 25 segments, where width and depth are estimated by mathematical functions (e.g., constant and exponential) [e.g., Prandle and Rahman, 1980; Jay, 1991]. This approach effectively divides the model domain into $N=25$ linear problems, with $2 N$ boundary conditions. At the seaward boundary, I apply 3 sinusoids which represent the amplitude and phase of tides and surge, while at the landward boundary I apply a no reflection condition. A constant discharge (here, $u_{r}=0$ ) is specified at the landward boundary; hence, I investigate the often-observed situation in which river flow exerts a small or negligible influence on estuarine water levels during storm events, because the flood hydrograph often occurs many days after a storm surge [e.g., Orton et al., 2012; Ralston et al., 2013; Familkhalili and Talke, 2016; Ross et al., 2017]. I leave the more complex case of compound flooding to further study. The 2(N-I) internal boundary conditions are obtained implicitly from the solution from neighboring segments, or from the applied boundary condition (outer segment). This approach allows the reflection caused by changing width on wave celerity to form in the system and I am 
able to detect the reflection effects on tide. To solve the system of $2 \mathrm{~N}$ linear equations, I apply a Gaussian-elimination technique in which the initial value for tidal current $\left(u_{x}\right)$ and frictional term is estimated at each segment. By matching the solutions at the internal and external boundaries with these estimates, the final wave amplitudes ( $\xi$ ) and discharges $(Q)$ are calculated repeatedly until the results do not vary by more than one percent.

\subsubsection{Decomposing the Surge Signal}

A primary assumption used in my analytical model is that storm surge can be decomposed into and represented by a limited number of sinusoidal waves. I test whether this is possible by fitting two and three sinusoidal waves with variable amplitude, frequency, and phase to measured surge waves at Lewes, DE (NOAA Station ID 8557380: 1936-2018). This station is chosen because of its location at the mouth of the

Delaware River Estuary, the type of coastal-plain, convergent estuary that is the focus of this study [see e.g., DiLorenzo et al., 1993; Ross et al., 2017; Lee et al., 2017]. I define surge to be the residual that is left after removing annual mean sea-level and the predicted tide (using t-tide; see Leffler and Jay, 2009; Pawlowicz et al., 2002) out of the measured hourly water level. To ensure event independence, I required that surge events be at least four days apart. Because the tidal propagation speed is altered by the higher water levels during a storm, the actual astronomical tide arrives slightly before the predicted tide, potentially resulting in a calculated surge wave that contains a residual tide-signal [Horsburgh and Wilson, 2007]. While unavoidable in this type of analysis, my choice of 
a coastal station minimizes this signal, since the proportional depth changes on the continental shelf are relatively small. As shown below, most of fitted surge waves are not at the $D_{2}$ frequency, suggesting that any residual tide energy does not generally dominate our surge signal.

Since surge is a non-repeating wave, some approximations regarding the processing are unavoidable. Here, I limit myself to storm surge waves with amplitudes $>0.5 \mathrm{~m}$ and fit sinusoids to the portion of the wave that exceeds a threshold of $0.3 \mathrm{~m}$ (see Figure 3-3). I find that this threshold excludes most non-storm related water level fluctuations, while retaining sufficient data to produce a statistically significant fit. Next, a non-linear least-squares fit is used to estimate the terms in the following equation:

$$
S u=C_{1}+S u_{P r i} \operatorname{Cos}\left(\omega_{P r i} t+\phi_{P r i}\right)+S u_{S e c} \operatorname{Cos}\left(\omega_{S e c} t+\phi_{S e c}\right)
$$

where $S u$ is the surge amplitude, $\omega$ is the frequency of the surge wave and is inversely related to time scale $T\left(\omega=\frac{2 \pi}{T}\right), \phi$ is the phase, and $C_{l}$ is an arbitrary offset that $\mathrm{I}$ find is $\sim 0.45 \mathrm{~m}$ on average, of which $0.3 \mathrm{~m}$ is the arbitrary threshold. The primary and secondary waves are denoted by the pri and sec subscripts, respectively. Because 7 parameters are being estimated, I require that a minimum of 10 points is fit to ensure statistical validity. A third sinusoidal wave with different frequency, phase, and amplitude was not found to significantly improve the fit to data. Only statistically significant fits with $R^{2}>0.85$ are retained for my analysis. Of 453 surge events that were $>0.5 \mathrm{~m}$ from between 1936 and 2018, I am able to fit $78 \%$ with a two-wave sine model at a statistically significant level with an average RMSE of $0.045 \mathrm{~m}$ and an average $R^{2}$ of 0.91 . 
An example fit using two sinusoidal waves is shown in Figure 3-3. As shown, the primary sinusoid (blue line) approximates the amplitude and time-scale of the surge, while the secondary sinusoid represents much of the higher frequency variability. Fitting a third sinusoid to this particular surge (not shown) results in a slightly better fit (correlation of $R^{2}=0.98$ vs $R^{2}=0.97$ and smaller root mean square error of 0.03 vs $0.04 \mathrm{~m})$; however, fitting two waves is still able to approximate the time scale and amplitude of an event. I note that the fits are only valid for the time period in which surges are over the threshold value of $0.3 \mathrm{~m}$. Therefore, in post-processing of analytical results I only consider this time period, though I model the entire wave periodically.

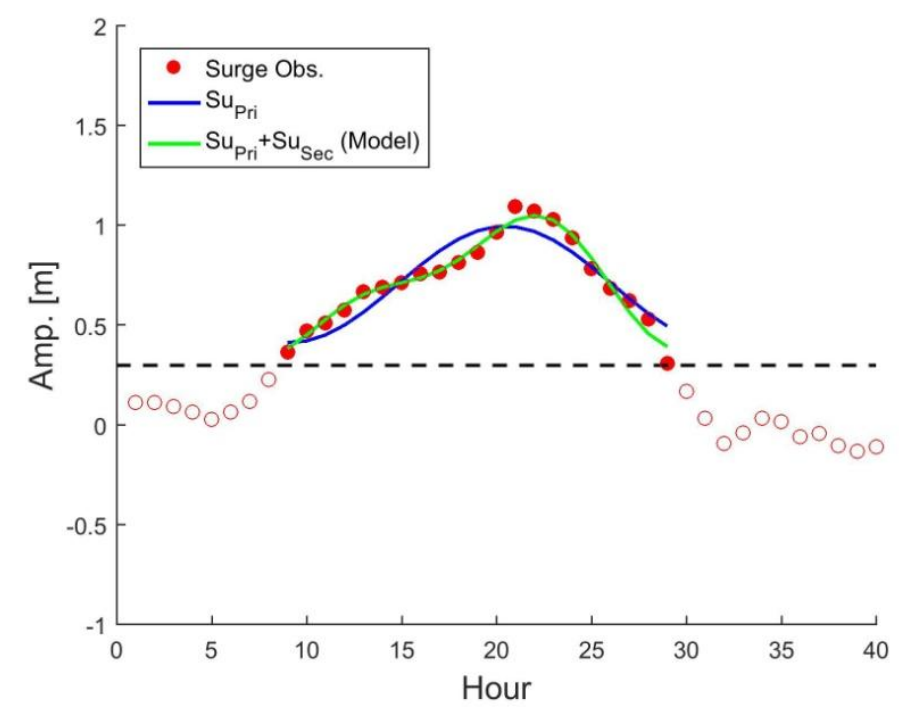


Figure 3-3: Decomposing surge into different sinusoidal waves, red circles represent surge and calculated by subtracting predicted tide from measured water level and blue line is the one sine-wave fit, green is two sine-wave fit that is the sum of $S u_{P r i}$ and $S u_{S e c}$. Black dashed line shows the $0.3 \mathrm{~m}$ threshold. Periods of $S u_{P r i}$ and $S u_{S e c}$, are $22.6 \mathrm{hr}$, and $10.9 \mathrm{hr}$, respectively.

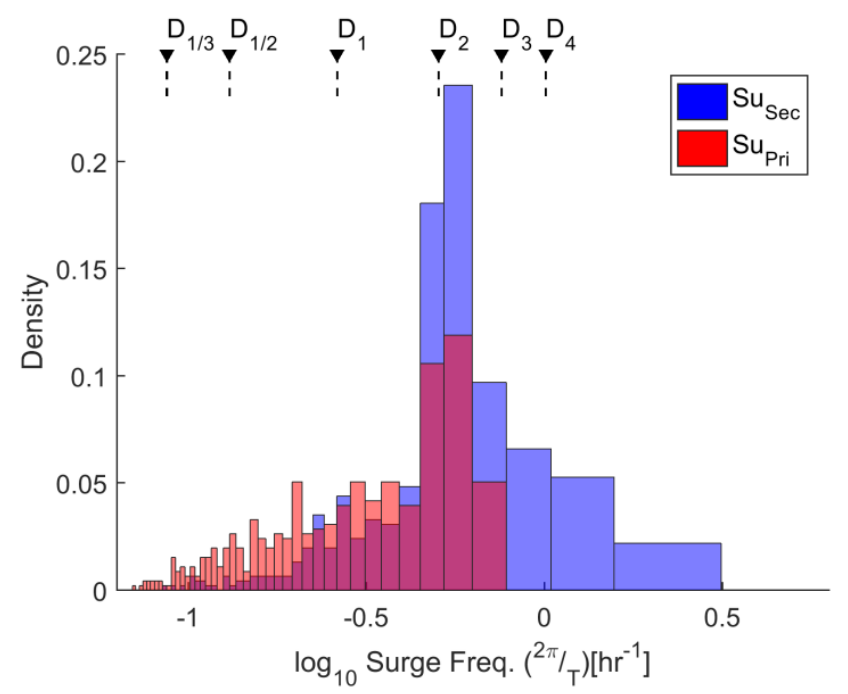

Figure 3-4: Probability distribution of multi waves fit. The hourly tide data is obtained from the National Oceanographic and Atmospheric Administration (NOAA) for Lewes, DE (Station ID 8557380: 1936-2018).

Results show that the time period of the primary surge wave ranges from $8 \mathrm{hr}$ to $89 \mathrm{hr}$ i.e., from a time scale that is $\sim 2 / 3$ of the primary $M_{2}$ tidal period of $12.42 \mathrm{hr}$ to one that is $>6$ times larger $\left(D_{1 / 3}\right)$ (Figure 3-4). Each bin width corresponds to $2 \mathrm{hr}$ time period of surge and vertical dash-lines show $D_{1 / 3}\left(1 / 3\right.$ cycle per day) to $D_{4}$ (4 cycle per day). Most surge events have time scales similar to tides (Figure 3-4), and approximately $\sim 60 \%$ of surge events have periods from 1-3 times the $M_{2}$ period (average surge period is $\sim 29.2 \mathrm{hr}$ ). The average period of the secondary surge wave, $S u_{S e c}=16.1 \mathrm{hr}$, is roughly one half the primary period (Figure 3-4). The distribution of time periods is asymmetric, 
however, the median time scale for the primary and secondary surge waves $(23.6 \mathrm{hr}$ and 12.2hr) is shorter than the average time scale. Analysis results further suggest that the ratio of the primary to secondary surge amplitude $\left(\gamma=S u_{P r i} /_{S u_{S e c}}\right)$ ranges from 0.8 to 9.5, with a mean value of 2 (Figure 3-5a). Thus, the primary surge wave is generally larger than the secondary wave.

Similarly, the time scale of the primary sine wave is generally larger than the secondary wave, with $80 \%$ of secondary waves having a period that was between $1 / 2$ and $1 / 7^{\text {th }}$ the time scale of the primary wave (Figure $3-5 b$ ). Interestingly, the most common ratio-i.e., the mode- between the primary and secondary surge period is two. Hence, the plurality of surge waves follow a pattern also seen for tides, that is of a primary wave (e.g., $\left.M_{2}\right)$ which is linked to a smaller wave $\left(M_{4}\right)$ of exactly twice its frequency, probably thru the generation of non-linear frictional overtides. Borrowing from the tidal literature [e.g., Friedrichs and Aubrey, 1988; Chernetsky et al., 2010], I therefore define a relative phase between the primary surge (frequency $\omega$ ) and a secondary surge (frequency $2 \omega$ ) as $\left(2 \phi_{S u_{P r i}}-\phi_{S u_{S e c}}\right)$. The more general formula to calculate the relative phase is $\left(\alpha \phi_{\text {Lower freq. }}-\phi_{\text {Higher freq. }}\right)$, where $\alpha$ is the ratio of $\left(\omega_{\text {Higher freq. }} / \omega_{\text {Lower freq. }}\right)$.

Therefore, Figure 3-5c represents the relative phase of primary and secondary surge wave by subtracting the higher frequency from the lower. As described in the literature, the value of the relative phase determines whether the wave is slow rise (i.e., ebb dominant with a long flood and a short ebb; largest for relative phase $=270^{\circ}$ ) or fast rise (i.e., short 
flood and long ebb; largest for relative phase $=90^{\circ}$ ). Results for surge (Figure 3-5c) show that the relative phase of surge waves varies between zero and 360, i.e., that storm surge can be either fast rise (0-180) or slow rise (180-360). However, close inspection shows a marked preference for a relative phase near 0 or 180 , which represents a symmetric wave (Figure 3-5c). I use this result in my analytical modeling, and test the most common conditions; symmetrical, flood dominant, and ebb dominant surge waves in which the relative phase is set to zero, 90 , and 270 , respectively, and the primary surge frequency is one half the secondary frequency.

Finally, I note that my tide/surge model differs from traditional 3-tide models, in that $M_{2}$ is not necessarily the dominant amplitude. Figure $3-5 d$ shows that $\sim 60 \%$ of the surge waves have an amplitude greater than $M_{2}=0.6 \mathrm{~m}$, with $5 \%$ more than twice as large. As shown in the tidal literature [e.g., Jay et al., 1990, 2015; Godin and Gutierrez, 1986], the dominant tidal constituent typically influences a smaller constituent more than vice versa; for example, $M_{2}$ produces more damping in the $S_{2}$ wave in an estuary than the other way around. Hence, the ratio of surge to tide amplitude likely influences the pattern of damping and constituent attenuation within an estuary. The frequency of the wave matters as well, since lower frequency waves exhibit less damping, hence, the wide range of surge time scales becomes an important consideration (see section 3.5). To conclude, Figures 3-4 and 3-5 help define a parameter space that I use to model surge $\left(S u_{P r i}\right.$ and $\left.S u_{S e c}\right)$ and tides. 

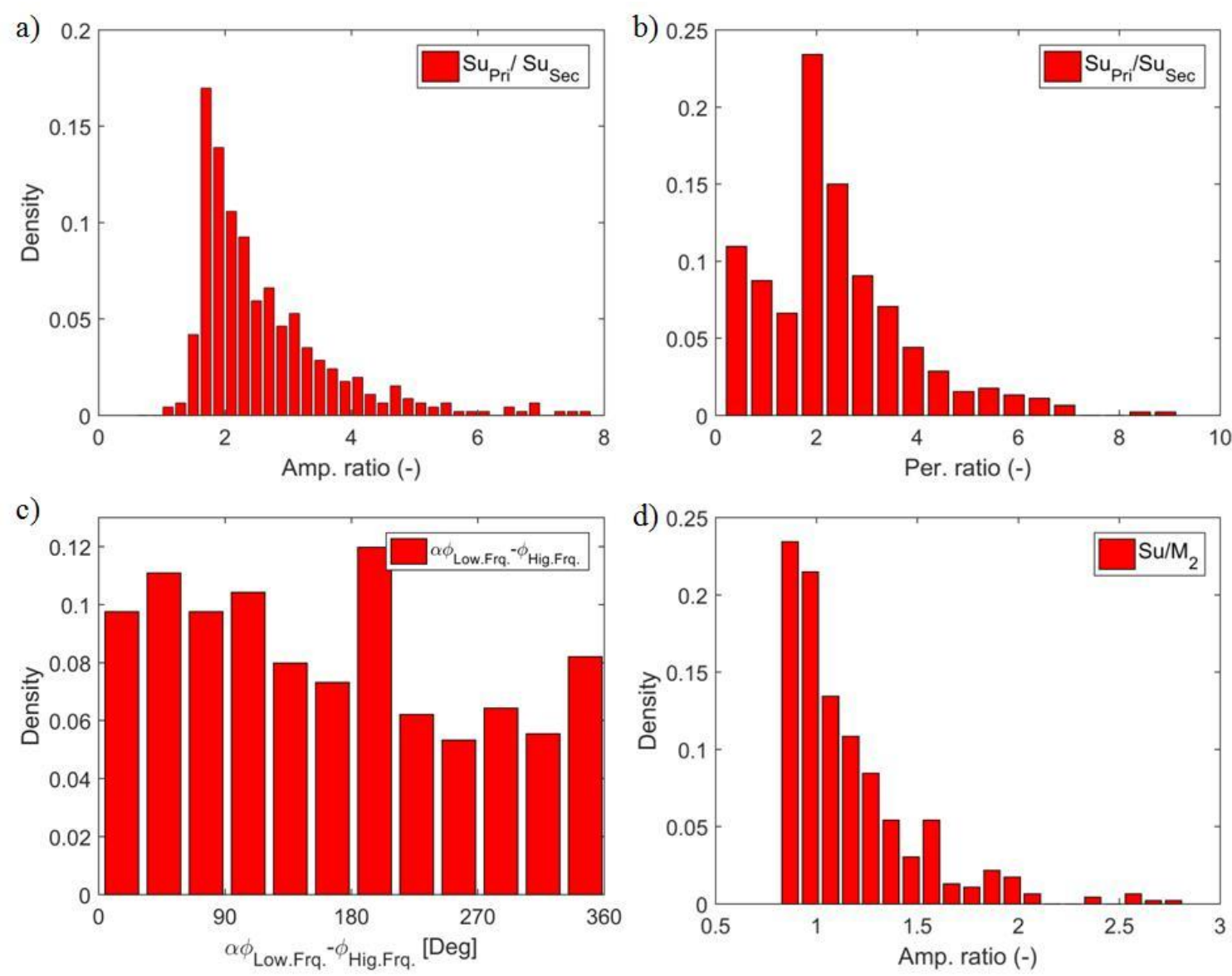

Figure 3-5: Probability distribution of ratio of surge-primary to surge-secondary (a) amplitude, (b) time scale, (c) relative phase, and (d) ratio of $S u_{P r i}$ period to $M_{2}$

\subsection{Numerical Modeling}

The multi-segment, linearized model described in section 3.1 is validated against a depth-averaged idealized Delft-3D numerical model that is similar to the one employed in Familkhalili and Talke [2016]. The estuary width and cross-sectional area are allowed to converge exponentially $\left(B_{0}=5 \mathrm{~km}, L_{e}=80 \mathrm{~km}\right)$ in a way that follows the [DiLorenzo et al., 1993; Lanzoni and Seminara, 1998; Cai et al., 2012; Familkhalili and Talke, 2016] 
analytical models for a weakly-convergent estuary; upstream of Rkm 200, a constant width channel $\left(B_{c}=400 \mathrm{~m}\right)$ is used to simulate the tidal river up to $\mathrm{Rkm} 300$, as a way to eliminate reflections at the upstream boundary. A Chézy coefficient of 25 is applied for the estuary. This parameter space corresponds to strongly dissipative and weakly convergent estuaries [Lanzoni and Seminara, 1998]. This simplified geometry, while commonly used [DiLorenzo et al., 1993, Friedrichs and Aubrey, 1994; Chernetsky et al., 2010], ignores the width expansion often observed (looking upstream) in the outer portion of estuaries, and the effect of large intertidal and subtidal flats. Hence, the model results are most applicable to the exponentially convergent portion of estuaries upstream of an outer bay. I note however that the effect of topographic variations is approximated through use of an appropriate average depth and friction coefficient, such that the barotropic wave height progression is well calibrated [Familkhalili and Talke, 2016]. For

testing purposes, I force both the numerical and semi-analytical model by the $K_{1}, M_{2}$, and $M_{3}$ tidal constituents at the seaward boundary and employ a spatially constant bottom friction coefficient. I run the model for 40-days to account for start-up time and include $K_{1}, M_{2}$, and $M_{3}$ cycles. The results of numerical modeling are analyzed using harmonic analysis [e.g., Leffler and Jay, 2009].

\subsection{Model Calibration and Validation}

I validate the performance of my semi-analytical, linearized tide-surge model against other analytical models of tides [e.g., Toffolon and Savenije, 2011; Jay, 1991] and 
an idealized Delft-3D numerical model (section 3.3). Because of the large number of terms (24 terms) in my expansion for friction (see Appendix B) increases the probability of introducing a mathematical or programming error, I first check that my analytical tide model can reproduce the results of simpler, published 1-constituent models and agrees well with the Delft-3D model. Two types of analytical model are tested; the simple single-segment (SS) model, and a multi-segment (MS) model in which the domain is split into 25 segments. As described in section 3.2.1.2, the use of multiple segments enables spatially variable velocity scale $\left(U_{(x)}\right)$ and convergence rate to be applied, improving the local validity of the Chebyshev expansion. Using only 1 constituent with no river flow, my analytical model agrees well with both the Delft-3D model, the Jay [1991] approach, and the Toffolon and Savenije [2011] solution for a variety of amplitudes and frequencies (see Figure 3-6a for an example with $M_{2}$ ). In each case, the multi-section model more closely resembles the numerical model than the single section model, demonstrating that this approach improves the observed spatial variability (Figure 3-6a). Overall, the oneconstituent test validates my derivation of geometric and frictional effects in a one tide model, but does not yet validate non-linear interactions between terms. To validate the three wave model, I next compare against the Delft-3D model with identical geometry and boundary conditions (Figure 3-6b). 
a)

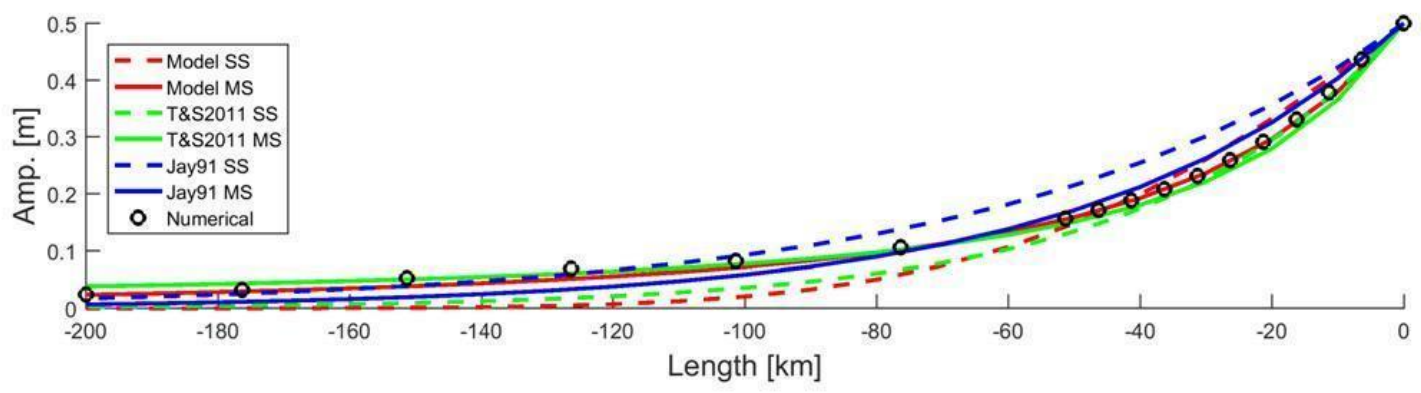

b)

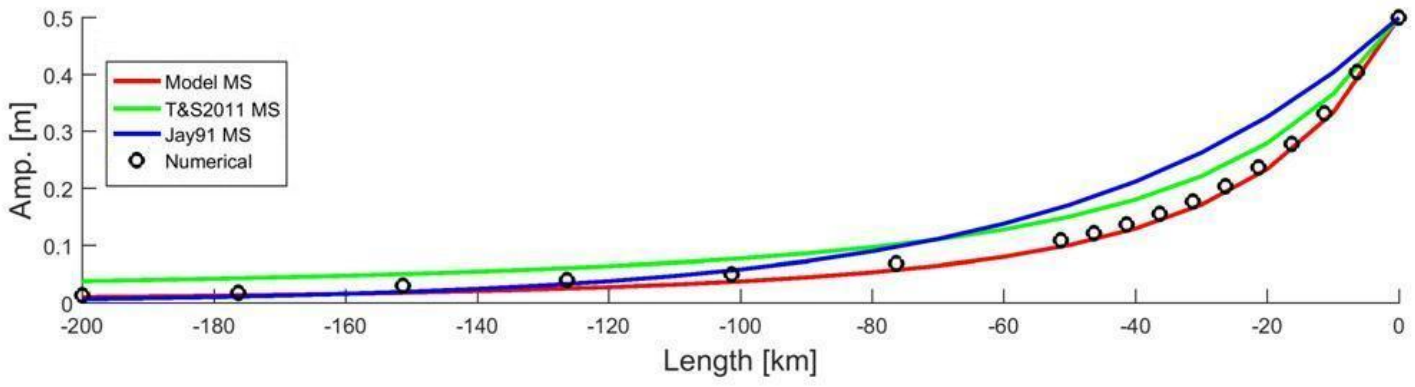

Figure 3-6: Evolution of dominant tidal constituent $\left(M_{2}\right)$ in a $5 \mathrm{~m}$ deep convergent estuary for (a) single tide and (b) three tides model with no river flow. The ocean/estuary boundary is at Rkm 0 , SS means single-segment, and MS refers to multi-segment model.

Figure 3-6b shows how the amplitude of the $M_{2}$ wave evolves spatially in my 3tide model under forcing by the $K_{1}, M_{2}$, and $M_{3}$ constituents at the open ocean boundary at $\mathrm{Rkm} 0$ (river flow is neglected; see solid red line). The amplitudes are $0.25,0.5$, and $0.25 \mathrm{~m}$ for $K_{1}, M_{2}$, and $M_{3}$ respectively; while the $M_{3}$ constituent is typically small in an estuary $(<0.01 \mathrm{~m})$, I make it artificially large such that the test model more closely replicates my parameter space (the $M_{2}$ tide plus two sinusoids for surge). As shown, my 3-tide analytical and numerical models closely agree, particularly for the multi-segment model, and validate my approach. Interestingly, the 1-constituent models (Jay91 and T\&S2011), re-plotted in Figure 3-6b from Figure 3-6a, overestimate the $M_{2}$ amplitude. 
Effectively, adding more constituents increases the frictional damping of $M_{2}$, resulting in a spatially variable decrease in $M_{2}$ amplitude that is maximal around Rkm 50. I show below that this same process occurs of constituent interaction and enhanced damping will also occur when surge is approximated by a tide constituent, to a degree that is related to the relative amplitude of the surge wave and $M_{2}$.

\subsection{Parameter Space}

I use my validated, semi-analytical surge-tide model to investigate the effects of estuary depth, surge wave time-scale, amplitude, and relative phase on the spatial evolution of water levels in estuaries. As shown in Table 3-1, I apply a semi-diurnal $\left(D_{2}\right)$ tide with a period of $12 \mathrm{hr}$ (approximately equal to the $M_{2}$ tide period) and amplitude of $0.5 \mathrm{~m}$, and neglect the effects of river flow. The following parameters are held constant; convergence length of $80 \mathrm{~km}, S u_{S e c}$ amplitude of $0.25 \mathrm{~m}$. The parameters in Table $3-1$ are varied individually, with other parameters held constant, yielding a total of 160 analytical model runs. The semi-analytical solution takes $\sim 0.25$ minutes on a desktop computer, enabling the parameter space to be quickly tested. 
Table 3-1: Parameter space used in modeling

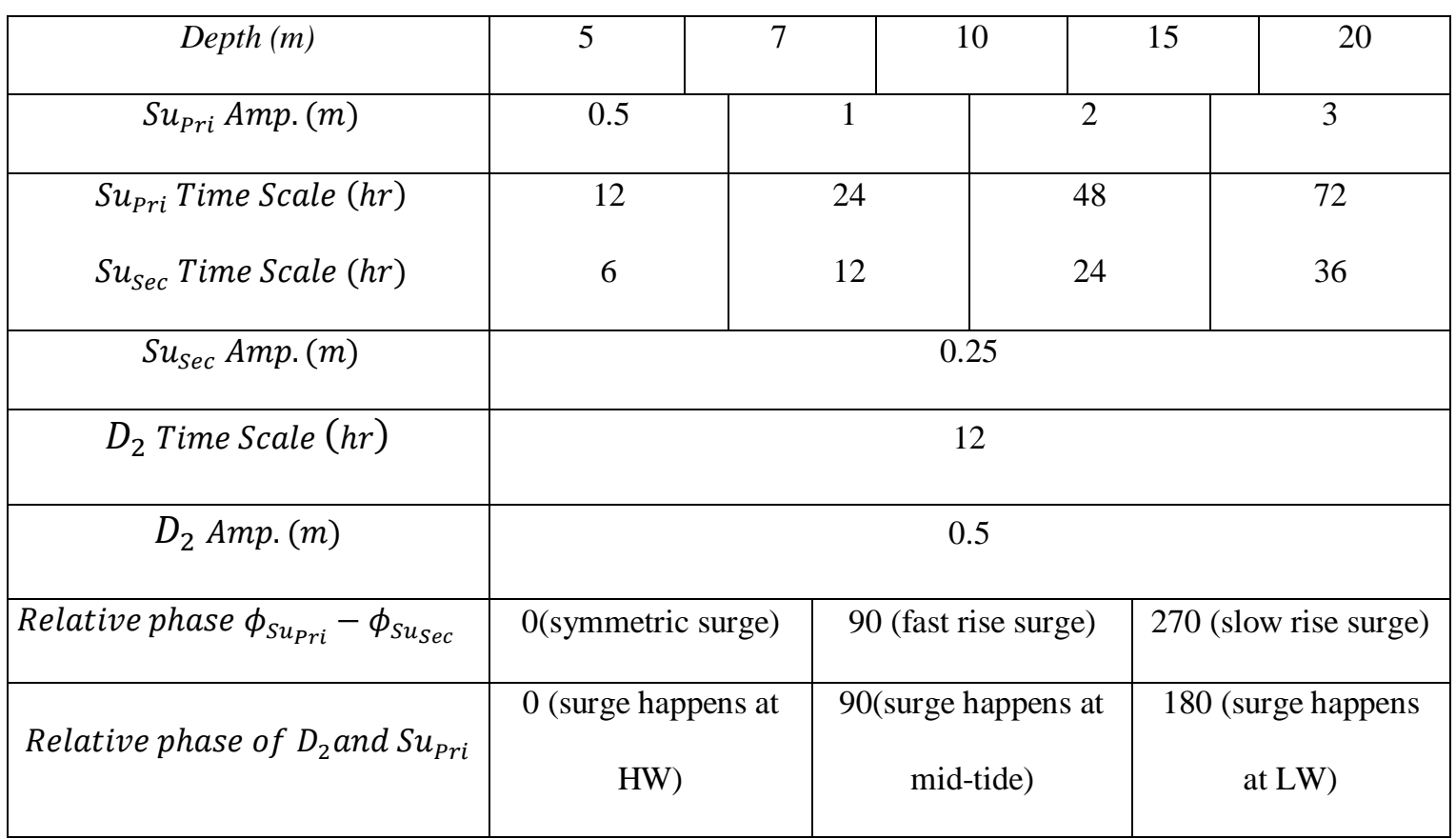

The parameters in Table 3-1 are presented in dimensional form, for ease of interpreting results relative to real estuaries and tide/surge scenarios; however, I note that varying each of these parameters also traces out a non-dimensional parameter space; in the figures I use both dimensional and non-dimensional parameters, where appropriate. Independent non-dimensional variables and their range of values that are used in my sensitivity analysis (based on Table 3-1) include the ratio of surge amplitude to $D_{2}$ tide $\left(\gamma=\frac{A m p \cdot S u_{P r i}}{A m p \cdot D_{2}}\right)$, the ratio of $S u_{P r i}$ time scale to $D_{2}$ period $\left(\Omega=\frac{\text { Period } S u_{P r i}}{\text { Period } D_{2}}\right)$, and the friction scale $\left(\psi=\frac{C_{d} \xi \omega^{2} L_{e}^{3}}{g h^{3}}\right)$ which stems from scaling (non-dimensionalizing) Equation (3-4) (see Appendix C). Parameter $\psi$ suggests that increasing depth and wave time scale $(1 / \omega)$, or decreasing amplitude $\xi$, has a similar effect as decreasing the drag coefficient 
(see section 3-6). Other parameters that are varied include the surge/surge amplitude ratio $\left(\frac{A m p \cdot S u_{P r i}}{A m p \cdot S u_{S e c}}\right)$, the $\left(\frac{\text { Tide Amp. }}{\text { Channel Depth }}\right)$ ratio, the relative phase of storm surge (which drives the surge asymmetry), and the relative phase of surge and tide (which drives the timing of surge relative to $\mathrm{HW} / \mathrm{LW}$ ). For plotting purposes, I also define the following non-dimensional numbers: a normalized amplitude $\left(\delta=\frac{A m p \cdot S u_{P r i}}{\text { Max. surge Amp. }}\right)$ and a dimensionless coordinate system of $L_{*}=x / L_{e}$, where $L_{*}$ is normalized length. Additional non-dimensional parameter related to this study (see section 3-2-2) include: surge/surge period ratio $\left(\frac{\text { Period } S u_{P r i}}{\text { Period } S u_{S e c}}\right)$, which is set aside for future study.

Table 3-2: Non-dimensional parameter space

\begin{tabular}{|c|c|c|}
\cline { 2 - 3 } \multicolumn{1}{c|}{} & Minimum & Maximum \\
\hline$\gamma\left(\frac{\text { Amp. Su }}{\text { Amp. } D_{2}}\right)$ & 1 & 6 \\
\hline$\Omega\left(\frac{\text { Period } \text { Su }_{P r i}}{\text { Period } D_{2}}\right)$ & 1 & 6 \\
\hline$\delta\left(\frac{\text { Amp. Su } u_{P r i}}{\text { Max.Surge Amp }}\right)$ & 0 & 1 \\
\hline$\psi\left(\frac{C_{d} \xi \omega^{2} L_{e}^{3}}{g h^{3}}\right)$ & $\sim 0.03$ & $\sim 70$ \\
\hline
\end{tabular}

\subsection{Results and Discussion}

The parameter space described above (section 3-5) is used to investigate the spatial pattern of surge amplitude along the channel for different variables. Figure 3-7 shows the spatial pattern of damping that occurs when the amplitude of a surge wave with a time scale of $12 \mathrm{hr}$ is varied between 0.5 and $3 \mathrm{~m}(\gamma=1$ to 6$)$. These results reflect 
conditions in which the frictional interaction is likely to be largest: a symmetric surge with a phase lag of zero degrees relative to the $D_{2}$ wave (such that the surge comes in with the flood tide, and leaves with the ebb).

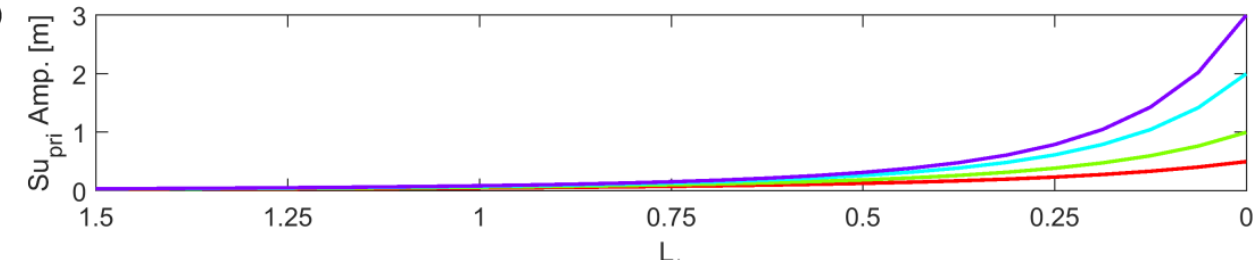

b)

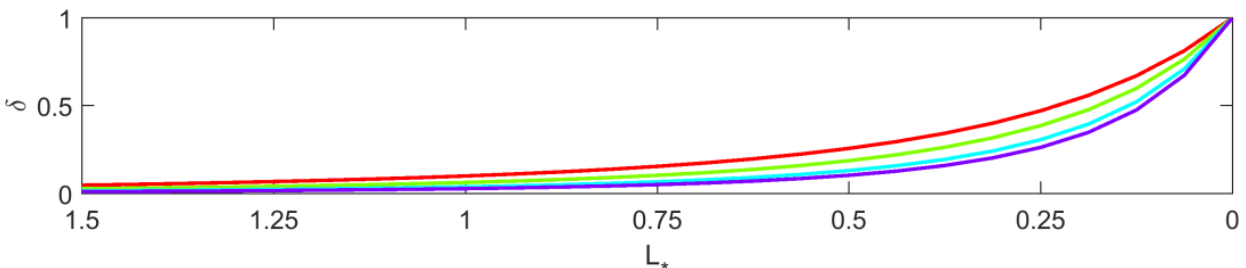

c)

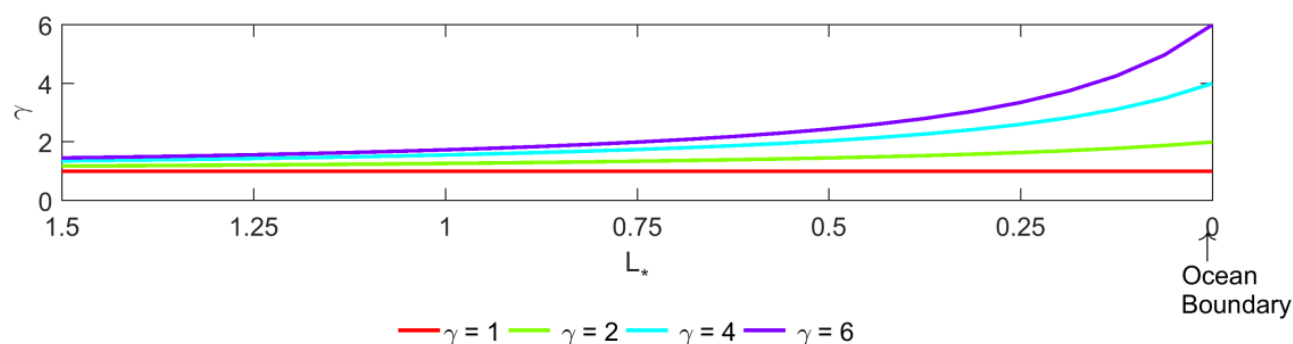

Figure 3-7: Importance of $S u_{P r i}$ amplitude for four different amplitudes relative to $D_{2}$ tide at the ocean boundary, $\gamma=\frac{A m p \cdot S u_{P r i}}{A m p \cdot D_{2}}=1,2,4$ and 6, (a) surge amplitude, (b) normalized amplitude $\delta=$ $\frac{A m p . S u_{P r i}}{\text { Max. surge Amp. }}$, and (c) surge amplitudes relative to $D_{2} . L_{*}=x / L_{e}$ is normalized length. I assume that $D_{2}$ has period of $12 \mathrm{hr}(\Omega=1)$ for simplicity of parameter space used in modeling.

For the chosen parameters, the spatial progression in surge amplitude closely follows the pattern of the $D_{2}$ tide between the ocean $\left(L_{*}=0\right)$ and the landward boundary (Figure 3-7). The e-folding scale for damping of surge amplitudes ranges from $0.4 L_{*}$ to $0.25 L_{*}$ with the smallest values (quickest damping) occurring for larger amplitude wave 
(Figure 3-7b). The slope of the amplitude decay $\left(d \delta / d L_{*}\right)$ progressively decreases in the landward direction (Figure 3-7b) for all surge amplitudes, but the rate of decay remains largest (and the ratio of amplitude to the boundary amplitude is smallest) for the largest surge $(\gamma=6)$. Physically, the larger velocity in a big surge event induces more damping, and the rate of surge amplitude reduction within the estuary increases for larger surge (Figure 3-7c). Further, about $75 \%$ of damping for $0.5 \mathrm{~m}$ surge occurs seaward of $0.5 L_{*}$, while $\sim 90 \%$ damping occurs there for the largest surge $(\gamma=6)$.
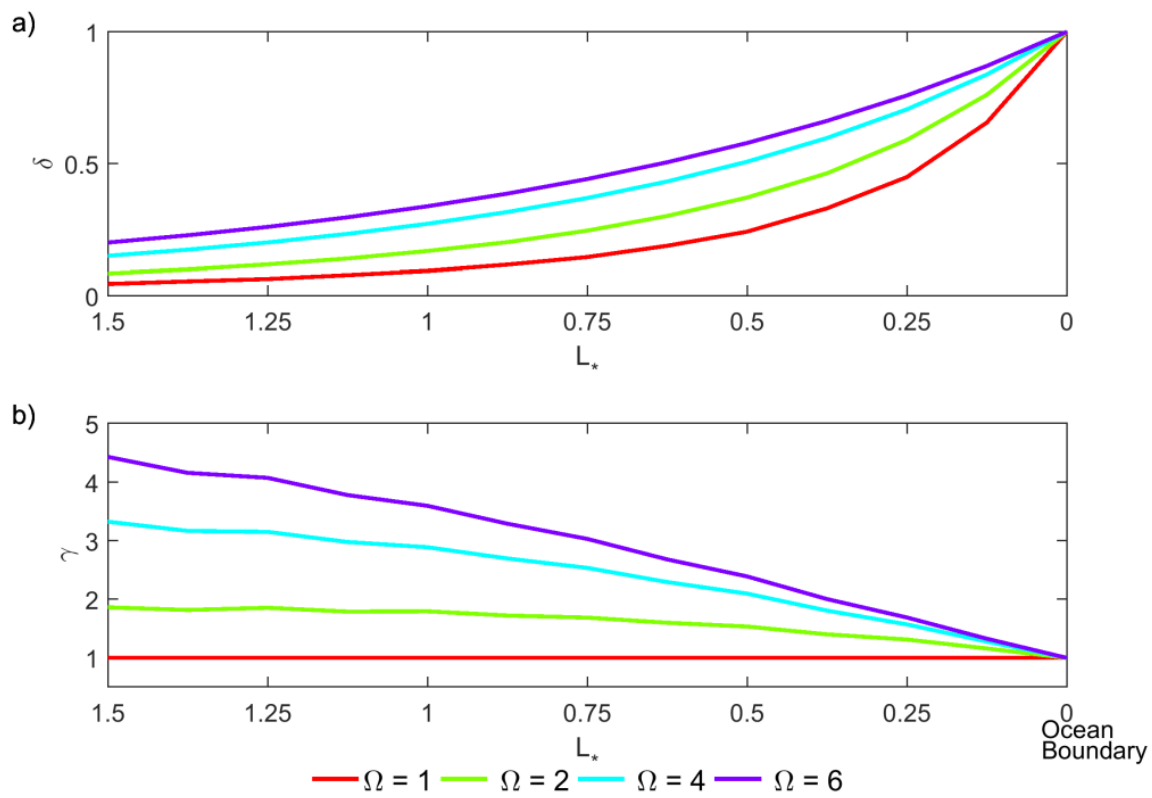

Figure 3-8: The influence of surge period on surge-tide propagation along an idealized estuary for four different periods $\Omega=\frac{\text { Period } S u_{P r i}}{\text { Period } D_{2}}=1,2,4$, and 6. (a) normalized amplitude and (b) relative amplitude to $D_{2} . L_{*}=x / L_{e}$ is normalized length, relative to the length-scale of convergence. 
The influence of storm surge period on non-linear tide-surge interaction is tested by modeling a set of surge primary waves with periods from $12 \mathrm{hr}$ to $72 \mathrm{hr}$ (Table $3-1$; Figure 3-8). As theory predicts, increasing the time scale (decreasing the frequency) of a surge wave produces a progressively lower rate of spatial decay, and therefore larger upstream amplitudes (Figure 3-8a). For the same boundary amplitude, in other words, long-period surges produce the largest estuary and fluvial amplitudes, with implications for flood risk [see e.g., Orton et al., 2015]. The largest difference in amplitude between a $12 \mathrm{hr}(\Omega=1)$ and $72 \mathrm{hr}(\Omega=6)$ surge occurs at $\sim 0.5 L_{*}$, i.e., at roughly half the e-folding length-scale for geometric convergence and similar to the e-folding length-scale for damping (Figure 3-8a). Hence there exists in the estuary a region which is much more vulnerable to flooding from a long-period surge than a short period surge, everything else being equal.

Similarly, the amplitude ratio between the primary surge component and $D_{2}$ (set equal to one at the ocean boundary) increases in the upstream direction for a slow moving storm (Figure 3-8b). Specifically, the $72 \mathrm{hr}$ time-scale surge becomes more than a factor of four larger than $M_{2}$ between the normalized length $L_{*}=0$ and $L_{*}=1.5$, while smaller time-scale surges (48hr and $24 \mathrm{hr}$ time-scale) amplify by 3.4 and 1.8 ratio relative to $D_{2}$ tide (Figure 3-8b). The physical reason for the slower decay of long-period surges is suggested by scaling but also found by examining my solution, which shows that longer time-scale surges have a lower velocity, leading to less frictional damping. For example, the ratio of $S u_{P r i}$ velocity to $D_{2}$ velocity at the ocean boundary $\left(L_{*}=0\right)$ ranges from 1 to 0.44 for $\Omega=1$ to 6 , respectively. 

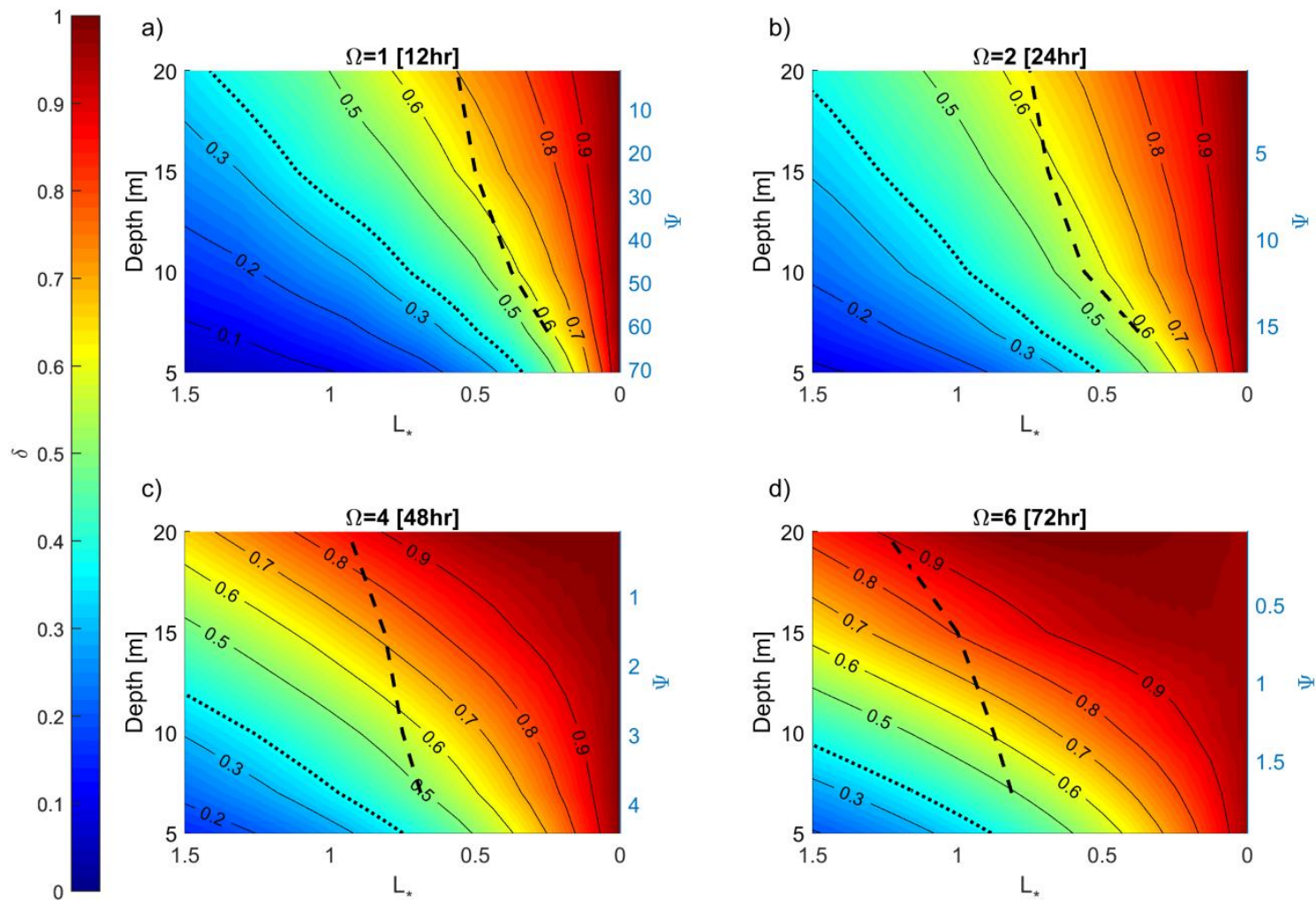

Figure 3-9: The influence of surge time scale and channel depth on surge-tide propagation along an idealized estuary. The color scaling represents the normalized amplitude $\delta$ and equals one at the ocean boundary, $L_{*}=0$. Each plot represents a different time scale for the primary surge component, from 12 to 72hr. For a configuration with no reflection effects, $\delta$ decreases into the estuary (left direction). The black, dashed-line represents location of maximum change relative to the $5 \mathrm{~m}$ depth condition and the black dotted-line represents the location of the e-folding scale of normalized amplitude. Note that the friction number $\psi$ associated with each depth is plotted on the right hand side of each plot.

Idealized surge-tide model runs also suggest that the primary surge amplitude decays less quickly in a deeper channel as it moves upstream (Figure 3-9), with an effect that depends on surge time scale. Hence, a $12 \mathrm{hr}$ surge wave in a $5 \mathrm{~m}$ deep estuary under 
default parameters (Table 3-1) decays to $1 / \mathrm{e}$ its boundary value at $L_{*}=0.35$; by contrast, a slow surge wave with a $72 \mathrm{hr}$ time scale decays to $1 / \mathrm{e}$ at $L_{*}=0.85$ (see dotted lines in Figure 3-9a and 3-9d). Effectively, the slow wave propagates twice as far. As depth increases, the e-folding scale for damping moves upstream (to the left) at a slower rate for the $12 \mathrm{hr}$ than the $72 \mathrm{hr}$ storm; essentially, the larger friction in a fast surge wave ( $\psi=1$ to 70 in Figure 3-9a) continues to damp the wave, relative to a slow wave $(\psi=0.3$ to 2 in Figure 3-9d). The more common 24 and 48hr times scales (see Figure 3-4) show an intermediate behavior (Figure 3-9). Since channel deepening reduces the hydraulic drag to incoming long waves (tides and surge; effectively, a decreased friction parameter), Figure 3-9 is consistent with the hypothesis that both tides and storm surge have increased due to channel deepening over decadal and secular time scales [e.g., Chernetsky et al., 2010; Cai et al., 2012; de Jonge et al., 2014; Familkhalili and Talke, 2016]. Moreover, as depth increases, surge propagates further upstream. As an example, Figure 3-9a shows that a $12 \mathrm{hr}$ surge wave with $\Omega=1$ decays to $50 \%$ of its boundary value by $L_{* 50}=0.23$ for $\psi=70$ (5m depth), but at $L_{* 50}=1$ for $\psi=1$ ( $20 \mathrm{~m}$ depth).

The increased intrusion of surge as depth is increased is shown by the contours in Figure 3-9, which all slant left. The amount of leftward tilt indicates the degree of sensitivity to increased surge magnitudes. When contours are nearly vertical, a change in depth $\Delta h$ has little effect on surge magnitudes. Therefore, storm surge (and tides) at the estuary boundary are little affected by channel deepening. By contrast, the largest percentage change in amplitude is observed far upstream $\left(L_{*}>1\right)$ where the contours are most tilted. However, because magnitudes are small, the absolute change is small. 
Figure 3-9 therefore shows that the increase in surge amplitude for an incremental increase in depth is a function of location. At $L_{*}=0$ there is no change, by definition. Within the estuary, the sensitivity at a given $L_{*}$ to a depth change $\Delta h$ is given by the width of the contours; a small contour width in the $y$ direction indicates a large increase in magnitude as depth is increased. Careful examination shows that the contour spacing decreases as $L_{*}$ increases from $L_{*}=0$, up to a location of maximum sensitivity to $\Delta h$ (black dashed line). Further upstream, the sensitivity to a $\Delta h$ diminishes (in an absolute sense), given the smaller amplitudes in the upstream domain. The largest amplitude change therefore typically occurs in the mid-estuary region [see also Talke et al., 2019]. This location of maximum change is typically around $L_{*}=0.5$ for $\Omega=1$ and 2 , or about half the e-folding lengthscale of damping, and increases as surge time-scale increases (see Figures 3-9 and 3-10).

Figure 3-10 shows that the location of maximum sensitivity to channel deepening $\left(L_{* \max }=L_{\max } / L_{e}\right)$ is a strong function of depth, surge time scale, and the phasing of the surge relative to the tide. When the wave is strongly affected by friction (large $\psi$, i.e., small depth and small time scale), the location of maximum change occurs relatively near the coast, $L_{*} \max \sim 0.3-0.6$, shown by the blue coloring in Figure 3-10. For waves less impacted by friction (larger depth, low frequency), the location of maximum change moves far upstream, sometimes exceeding the e-folding length-scale for width convergence (red coloring, Figure 3-10). Some variation in $L_{* \max }$ also occurs depending on whether the peak surge occurs at the same time as high water (Figure 3-10a), occurs during the mid-tide (Figure 3-10b), or occurs at low water (Figure 3-10c). In general, 
$L_{* \max }$ occurs more seaward in Figure 3-10a than it does in Figure 3-10c. This is a consequence of non-linear frictional interaction. When the total velocity due to tides and surge $\left(u_{t}+u_{s}\right)$ is maximal, as when surge and tides come in at the same time (Figure 310a), the frictional effects are larger; when tide and surge velocity are more opposed, as when the ebb tide opposes the incoming surge (peak surge at low water; Figure 3-10c), frictional effects are less. Hence, altering tide/surge phase has similar effects as changing the friction parameter $\psi$.

The region of maximum sensitivity to change moves upstream as an estuary is deepened. As an example, Figure 3-10a shows that $L_{* \max }$ of a $12 \mathrm{hr}$ surge wave $(\Omega=1)$ increases from $L_{* \max } \sim 0.25$ for a $7 \mathrm{~m}$ depth to 0.58 for a $20 \mathrm{~m}$ depth. As shown by Talke et al. [2019], the upstream movement occurs because the e-folding damping length-scale (the length-scale at which amplitudes are 1/e the boundary value) increases as the friction parameter $\psi$ decreases. For a simple, tide-only model, it can be shown that the peak change occurs at $\sim 1 / 2$ the damping length-scale [see Talke et al., 2019]. While the inclusion of multiple wave frequencies and phases alters the actual location of $L_{*} \max$, the general rule that $L_{* \max }$ is related to the damping length-scale holds. 

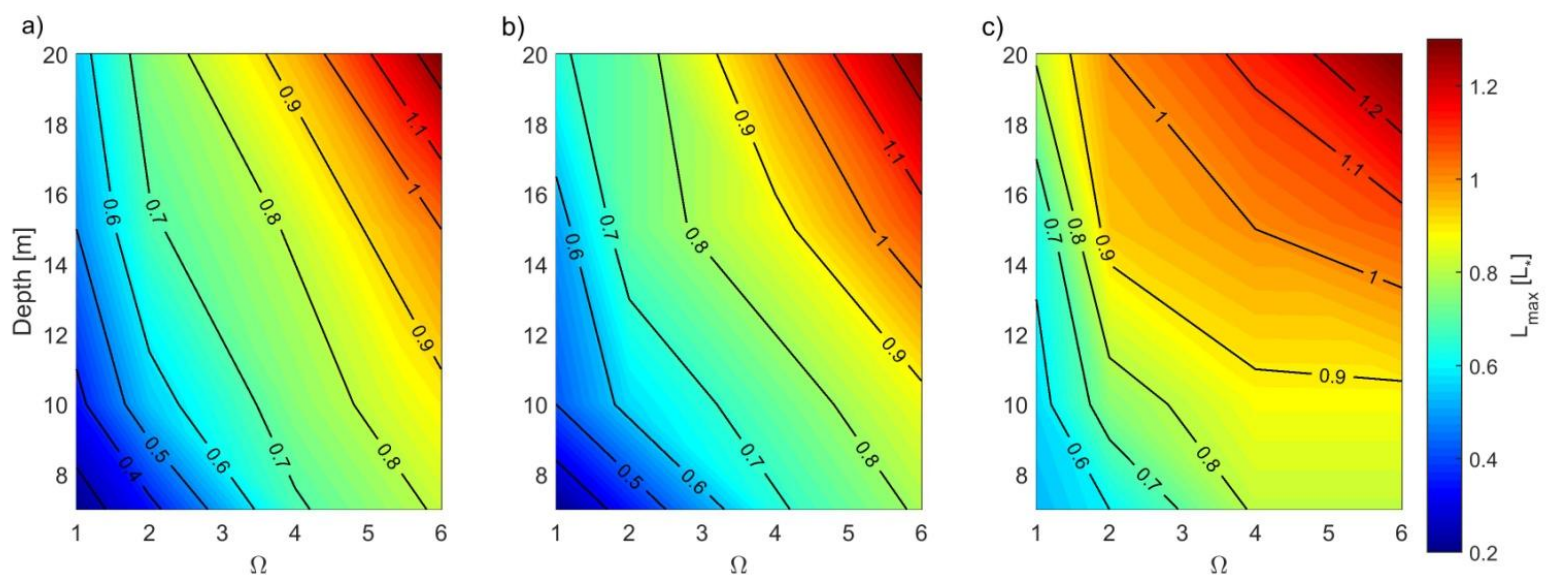

Figure 3-10: Location of maximum change of surge waves $\left(L_{* \max }\right.$, that occurs for depths of 7 to $20 \mathrm{~m}$ relative to an original depth of $h=5 \mathrm{~m}$ ) for symmetric surge (relative phase of $S u_{P r i}$ and $S u_{S e c}$ is set to

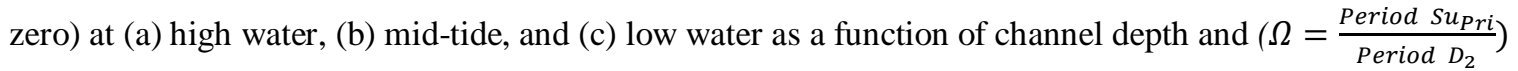

The shape of the storm surge wave, as captured by the relative phase of the primary and secondary surge constituent, can also alter the time history of frictional effects. This also results in a different spatial pattern of surge amplitude change as an estuary is deepened. Figure 3-11 shows the effect of changing depth from $5 \mathrm{~m}$ to $7-20 \mathrm{~m}$ for fast-rise and slow-rise storm surge for the case that the secondary surge frequency is twice the primary (in analogy to $M_{2}-M_{4}$ flood and ebb-tide asymmetry, as previously discussed). In a fast-rise storm surge, the relative phase of $S u_{P r i}$ and $S u_{S e c}$ equals $90^{\circ}$ and the incoming surge rises faster than it falls, leading to the greatest currents before peak surge; in a slow-rise surge, the relative phase of $S u_{P r i}$ and $S u_{S e c}$ is $270^{\circ}$, the rise is slower than the fall, and the greatest currents occur after peak surge. Note that, in keeping with previous cases, I have kept the relative phase of $M_{2}$ and $S u_{P r i}$ to zero. Results show that the location of maximum change $\left(L_{* \max }\right)$ is more variable for a fast rise surge 
wave than a slow rise surge wave, due to larger changes in total velocity $\left(u_{r}+u_{s}\right)$ as a channel is deepened. Figure $3-11$ a shows that for a $12 \mathrm{hr}$, fast-rise surge $(\Omega=1), L_{*} \max$ varies from $\sim 0.35(7 \mathrm{~m} \mathrm{depth})$ to 0.68 (20 $\mathrm{m} \mathrm{depth)}$; for a slow rise surge, $L_{*} \max$ varies from $\sim 0.55$ (7m depth) to 0.8 (20m depth) (Figure 3-11b). Essentially, as intuition might suggest, Figure 3-11 shows that larger velocities during the rising surge are effective at moving the location of maximum change seaward, due to larger damping. By comparison, velocities after peak surge matter less to the spatial pattern of surge amplitude, and therefore the spatial pattern of change.
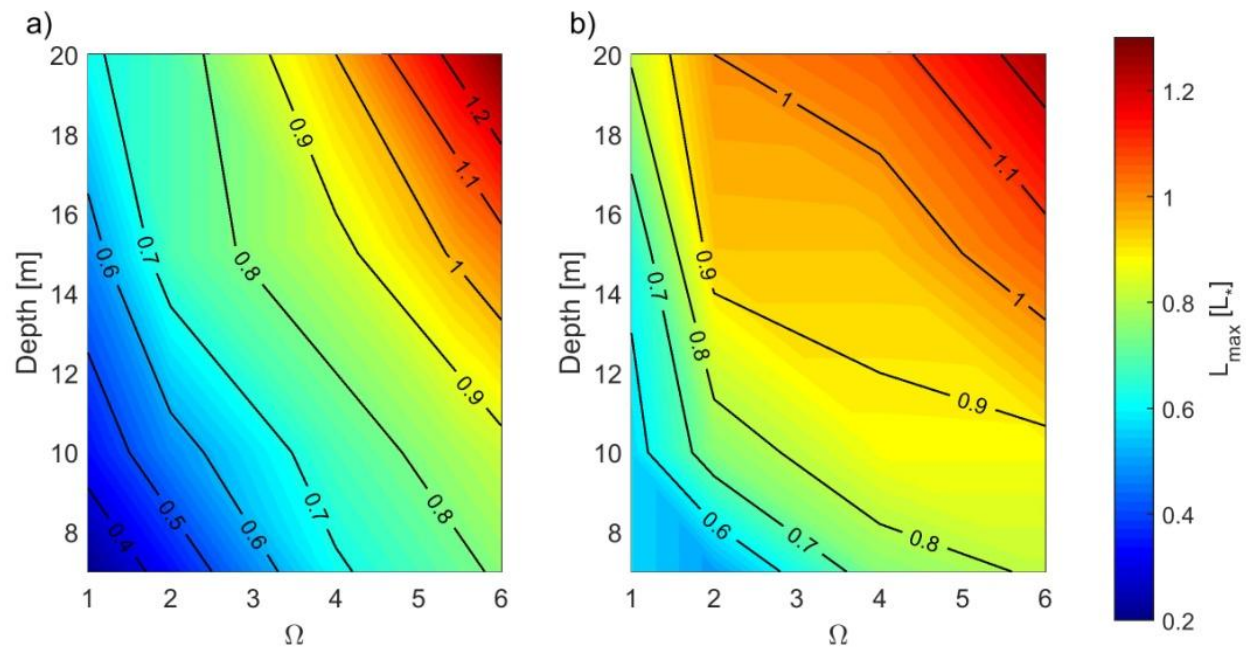

Figure 3-11: The effects of surge asymmetry for (a) fast-rise and (b) slow-rise surge on the location of maximum change of surge $\left(L_{* \max }\right)$ for different channel depths and $\left(\Omega=\frac{\text { Period. } \text { Su }_{\text {Pri }}}{\text { Period. } D_{2}}\right)$ with $\gamma=\frac{A m p \cdot S u_{P r i}}{A m p \cdot D_{2}}=1$ and $S u_{S e c} A m p \cdot=0.25 \mathrm{~m}$. 
One practical implication of Figures 3-10 and 3-11 is that channel deepening likely exerts a different effect on each storm surge, since each occurs with a different time scale and different tide and surge amplitudes and phases. Maximal effects are observed much closer to the coast on fast surge (small $\Omega$ ) than slow surge (Figure 3-10). Since the average storm surge time scale is between $\Omega=2$ and $\Omega=3$ (Figure 3-4), and many estuaries have changed from 5-6m to roughly 10-12m depth (e.g., Cape Fear Estuary; Familkhalili and Talke, 2016), there is a zone from $L_{*} \max \sim 0.5$ to $L_{* \max } \sim 0.9$ within a weakly convergent estuary (with no reflection effects) which is most prone to altered storm surge (see also Figure 3-11). Maximal $M_{2}$ tide change occurs somewhere closer to the coast that surge, since its time period $(\Omega=1)$ is slightly less.

\subsection{Conclusion}

I have developed a conceptual numerical model and a novel analytical modeling approach to assess the effects of different storm surge types on different idealized estuarine geometries, using an approach previously applied to tides. The semi-analytical model for surge-tide propagation, based on a 3-tide constituent model, agrees well with

the 1-constituent analytical models of Jay [1991] and Toffolon and Savenije [2011], and is able to reproduce constituent interaction found in a 2D numerical model. Hence, some of the model assumptions (such as constant depth, small amplitude, and linearized friction) do not exert a strong influence on results. I also show that modeling surge using two sinusoidal constituents is a reasonable approximation to empirically measured storm 
surge and water levels, and use these results to estimate typical magnitudes, time scales, and phasing of surge waves (Figures 3-4 and 3-5). Future improvements might include using more realistic wave-forms to model surge, applying more realistic depth and width variations, and in general considering environmental variability and forcing that is neglected here. Nonetheless, the advantage of my relatively simple tide model is that I can use insights from the tide literature to improve our understanding of how other long waves such as surge evolve within tidal estuaries.

Hence, from the analytical model we gain insights into the effects of estuary configurations (depth) and storm characteristics (amplitude, time-scale, and relative phase) on the spatial pattern of surge damping. Considering the sensitivity of storm surge to time scale and depth, results suggest that the largest temporal change over time due to anthropogenic channel deepening will occur for estuaries with (a) a large surge to $D_{2}$ ratio (i.e., large $\gamma$ ), (b) large frequency surge waves (i.e., smaller $\Omega$ ), and (c) a large percentage depth change. Therefore, results suggest that sea-level rise may also alter storm surge amplitudes, similar to studies that have suggested that tide amplitudes are sensitive to sea-level rise [Holleman and Stacey, 2014; Ross et al., 2017; Lee et al., 2017; Garel and Cai, 2018]. My results also suggest that weakly convergent estuaries (the parameter space studied here) have a region of enhanced sensitivity to change that is generally located around half the e-folding damping length-scale for a particular wave frequency, but is modified by frictional interaction with other waves (e.g., the $D_{2}$ tide), which in turn are set in part by the amplitude ratio and surge timing (phase) and asymmetry. Results therefore suggest that storm surges may respond in a variety of ways 
to a perturbation in depth caused by dredging or sea-level rise. Nonetheless, because storm surge magnitudes, time scales, and relative phases have a quantifiable distribution (Figures 3-4 and 3-5), a given storm-climate is likely to produce a determinable distribution of responses in any particular estuary. This has an implication for hazard assessments, which typically use either empirical data [e.g., Talke et al., 2014] or an ensemble of storms [Lin et al., 2012; Orton et al., 2016] at a particular location to assess return periods and infer system-wide, long-term non-stationarity.

Hence, the presence of a region of maximum change for $\Delta h$ in my results suggests that non-stationarity will vary spatially due to dredging and sea-level rise effects. This analytical insight therefore suggests that future modeling studies of surge should assess spatially varying risk due to sea-level rise and bathymetric change, rather than focusing on the change at a specific location (usually a specific tide gauge). Moreover, the placement of a tide gauge within an estuary impacts the degree to which it is able to assess changing conditions; stated differently, the absence of evidence of non-stationarity in a tide gauge record does not necessarily constitute evidence of absence, if the tide gauge is placed non-optimally. Other factors such as the individuality of storm events also complicate empirical studies [see e.g., Familkhalili and Talke, 2016]. Nonetheless, the similarities in spatial results between the $D_{2}$ tide and storm-surge long-waves confirms that trends in tidal constituents [e.g., Jay, 2009; Woodworth, 2010] are a leading indicator that storm surge amplitudes are also changing.

A number of future lines of inquiry remain open in the modeling framework I have developed. The effects of river flow on peak amplitudes during a storm event, 
particularly the changes in river slope caused by channel deepening [e.g., Jay et al., 2011; Ralston et al., 2019] form an important part of the parameter space, particularly upstream of $L_{*}=1$, where river-flow effects likely increase. Further, I have focused here on estuaries marked by strong damping; future work will investigate the dynamics of strongly convergent estuaries where tides can amplify, or conditions in which wave reflection is important. I note also that a number of processes have been neglected: overland flooding, stratification effects, the Coriolis acceleration, and the effect of local wind on the surge wave. Finally, some of the approximations in the model (such as the small-amplitude approximation) may not be valid in extremely shallow systems, especially for large surge. These, and other more complex factors (such as strong variations in depth and width), are likely better modeled numerically.

To conclude, understanding surge-tide interactions in estuaries has important implications for system management and flood prediction. My idealized model suggests that continued deepening of shipping channel worldwide, combined with sea-level rise, can have a significant effect on storm surge amplitudes. Since effects are spatially variable and depend on storm/tide characteristics and geometry, I suggest that studies of environmental impact and sea-level rise effects consider an ensemble of events that well represents natural variability [e.g., Orton et al., 2016] rather than models of the "storm of record", as is often done. 


\section{Chapter 4 Effects of Compound Flooding ${ }^{1,2}$}

Storm surge and river floods often lead to flooding in estuaries. Improving our understanding of how bathymetry affects surge and tidal characteristics, and therefore flood risk, can help in preparation for, and mitigation of, storm impacts. It is also important for planning future coastal development. Here I investigate the spatial and temporal variability of compound flooding (the sum of river flow, tides, and storm surge effects), and the frictional effects of river flow. In particular, I investigate the parameter space of compound flooding analytically and numerically to show what factors are prominent spatially from the coast to upstream of an estuary. I also investigate the effect of changing bathymetry caused by channel deepening and shortening.

\subsection{Introduction}

Flooding along an estuary is typically caused by a combination of tides, surge, and river discharge, with possible additional effects caused by wind waves, and precipitation. The occurrences of surge and river flood in close succession often increase

\footnotetext{
${ }^{1}$ Familkhalili, R., Talke, S., Jay, D., (2019): Compound Flooding in Strongly and Weakly Convergent Estuaries, in preparation

${ }^{2}$ Talke, S., Familkhalili, R., Jay, D., (2019): The influence of channel deepening on extreme water levels: case study of the St Johns River, FL, ready to be submitted
} 
flooding in coastal areas as well as in the upper portion of tidal rivers [e.g., Wong et al., 2014; Wahl et al., 2015]. River floods can highly impact estuarine transport and tidal dynamics [e.g., Jay et al., 2011; Kukulka and Jay, 2003b; Sassi and Hoitink, 2013] by changing the water surface slope, tidal properties, and total flow velocity.

Anthropogenic changes (e.g., channel depth changes, channelization, construction of infrastructures, and filling of wetlands) over time may change the characteristics of tides, surge, and river discharge. Total water levels (TWL) during an extreme event may change due to altered tides, storm surge [e.g., Familkhalili and Talke, 2016], and river discharge [e.g., Pasquier et al., 2018]. Therefore, I investigate in this study the spatial distribution of TWL components (tides, surge, and river discharge) analytically along an idealized estuary and study the contribution of these components in the flooding of Jacksonville and nearby regions during Hurricane Irma 2017. The effects of sea level rise and wind waves are ignored.

Understanding the effects of river discharge on tides and surge characteristics is important in analyzing the spatial patterns of tides and surge along an estuary. Various forms of 1D analytical solutions of tidal wave propagation have long been used for idealized and real estuaries [e.g., Dronkers, 1964; Prandle and Rahman, 1980; Jay, 1991; Friedrichs and Aubrey, 1994; Savenije, 1998; Lanzoni and Seminara, 1998; Godin, 1999], but applying analytical approaches to a real complex estuarine system has limitations. Many analytical studies ignore the effect of river discharge on tidal hydraulics [e.g., Savenije et al., 2008; Toffolon and Savenije, 2011; Savenije, 1998; 
Lanzoni and Seminara, 1998] while other studies have used perturbation and regression analysis [e.g., Godin, 1999; Jay, 1991; Kukulka and Jay, 2003a] to investigate the effects of river discharge on tidal wave propagation in estuaries. Generally, an increased discharge can affect tidal waves propagation by decreasing the tidal range and delaying high and low water [e.g., Godin, 1985; Hoitink and Jay, 2016].

Many estuaries have experienced natural and anthropogenic changes that affect the hydrodynamics of the system [e.g., Sherwood et al., 1990; Familkhalili and Talke, 2016; Ralston et al., 2019; Talke et al., 2019]. Processes such as climate fluctuations and change may modify precipitation patterns and, therefore, alter the spatial distribution of river flow [e.g., Global Climate Change Impacts in the U.S., 2009]. River discharge causes water level to rise in the landward parts of an estuary. In the tidal river during high floods water level is highly influenced by frictional effects of increased river flow. In general, reduced friction (increased hydraulic efficiency), especially during high water, alters the damping and timing of tide waves by changing the wave speed [Godin 1985; Horsburgh and Wilson, 2007; Jay et al., 2011].

Recent studies have statistically investigated the coincidence of storm surge and river discharge [e.g., Klerk et al., 2015; Kew et al., 2013; Wahl et al., 2015], while numerical hydrodynamic modeling has been used to show the importance of river flooding and storm surge on water levels in specific regions [e.g., Ikeuchi et al., 2017; Ralston et al., 2019]. However, a new analytical approach of tidal hydrodynamics equations that includes tides, river flow, surge, and their nonlinear interactions (described 
in Chapter 3) helps us to improve our understanding of river-tide-surge interactions during river floods. Therefore, I use analytical model developed by Familkhalili et al., [2019] (Chapter 3) and numerical models to explore the interaction of river flood and storm surge and to investigate the effects of timing and magnitude of peak river flow on water levels along an estuary. Since analytical modeling of compound flooding has limitations, I develop a Delft-3D numerical model to demonstrate the importance of river discharge during hurricane Irma 2017 in the St Johns River Estuary, FL (SJRE). Then the known physics of long-wave propagation in tidal rivers is used to explain river flood and storm surge characteristics and interactions.

\subsection{Analytical Model}

I use an idealized one-dimensional analytical model developed by Familkhalili et al. [2019] (see Chapter 3) and include river flow to investigate the frictional effect of river flow (and changes in water level due to river flow) in weakly and strongly convergent estuaries. The model has constant depth, while channel width varies exponentially with respect to the longitudinal coordinate $x$ (i.e., $b=B_{0} e^{\left(-\frac{x}{L_{e}}\right)}$, see Figure 4-1). I use a dimensionless coordinate system of $L_{*}=x / L_{e}$, where $L_{*}$ is normalized length. 


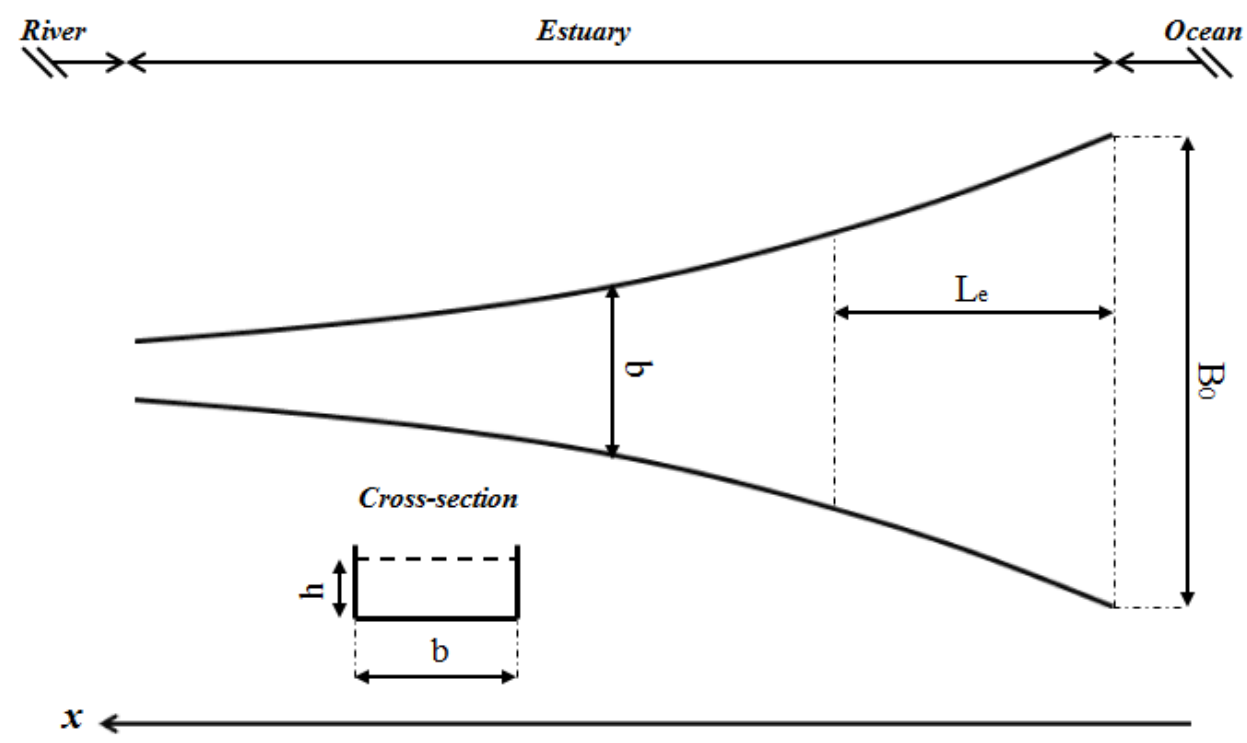

Figure 4-1: Idealized bathymetry and plan view of the conceptual model.

Validation of the analytical model is done by comparing the spatial pattern of tides along an idealized model domain against two analytical models of tides (Toffolon and Savenije, 2011; Jay, 1991) and an idealized Delft-3D numerical model [see Familkhalili et al., 2019; Chapter 3 for more details]. The analytical model results closely resemble the numerical model results, showing that this idealized analytical model can properly estimate spatial variability of surge along an estuary. The validated model is applied to investigate the effects of extreme storm surge combined with a river flood on water level. Although river discharge is not constant on the time scale of weather systems (5-day) and seasonal time scales, I assume for simplicity that the change over a tidal cycle or storm surge wave (generally $<2$ day time scale; see Chapter 3 ) is negligible. Therefore, river discharge is taken as constant. 
The velocity is represented by river flow and three sinusoidal constituents as:

$$
\begin{gathered}
u=u_{0}+u_{1} \cos \left(\omega_{1} t+\phi_{1}\right)+u_{2} \cos \left(\omega_{2} t+\phi_{2}\right) \\
+u_{3} \cos \left(\omega_{3} t+\phi_{3}\right)
\end{gathered}
$$

where $u_{0}, u_{1}, u_{2}$, and $u_{3}$ are velocity amplitudes, $\omega_{1}, \omega_{2}, \omega_{3}$ are frequencies, and $\phi_{1}, \phi_{2}, \phi_{3}$ are phases. I linearize the friction term using Godin [1991a, b, 1999] approach (see Chapter 3 and Appendix B for more details). I decompose surge signal into two sine waves (denoted by the pri and sec subscripts) following Familkhalili et al. [2019] approach:

$$
\text { Surge }=C_{1}+\operatorname{Su} u_{P r i} \operatorname{Cos}\left(\omega_{P r i} t+\phi_{P r i}\right)+S u_{S e c} \operatorname{Cos}\left(\omega_{S e c} t+\phi_{S e c}\right)
$$

where $S u$ is the amplitude, $\omega=2 \pi / T, T$ is the time scale, $\phi$ is the phase, and $C_{l}$ is an arbitrary offset.

Long-wave propagation along an estuary is characterized by a balance of inertial effects, friction, and convergence. Thus, an important factor that affects the damping/amplification of surge is the convergence length scale $\left(L_{e}\right)$. When convergence effects dominate over the frictional effect, tidal amplitudes increase upriver. Conversely, the amplitude of a tidal wave propagating into a divergent estuary (i.e., increasing crosssection) will decrease as the energy is spread over a larger cross-section [Jay, 1991]. In order to study the effects of $L_{e}$, I choose two convergence length scales that represent a weakly $\left(L_{e}=80 \mathrm{~km}\right)$ and strongly convergent $\left(L_{e}=20 \mathrm{~km}\right)$ estuary [see e.g., Jay, 1991; Lanzoni and Seminara, 1998]. 


\subsubsection{River Discharge}

A river flood makes maximum ebb current speeds stronger $\left(u_{r}+u_{t}\right)$ and minimum flood current speeds smaller $\left(u_{r}-u_{t}\right)$, where $u_{t}$ and $u_{r}$ are tide and surge wave velocity, respectively. Hence frictional damping of long waves in estuaries is affected significantly by river floods [e.g., Dronkers, 1964; Cai et al., 2014]. Tidally averaged bed stress is increased, and the difference between flood and ebb stresses is increased over a wide range of flows. In addition, river floods cause low water to occur later while high water occurs earlier, which generates an asymmetric distortion in the tide wave [Parker, 1991].

In this study, river flow velocity is parameterized as the ratio of river velocity to

the major tidal component velocity $\left(\frac{u_{R}}{u_{M_{2}}}\right)$; this ratio is typically rather small in U.S. East Coast coastal plains estuaries, because river inflow is small. For example, St Johns Estuary is significantly tidally influenced, with a non tidal river flow of $\sim 450 \mathrm{~m}^{3} / \mathrm{s}$. Similarly the Delaware River Estuary has a mean river flow of $\sim 340 \mathrm{~m}^{3} / \mathrm{s}$ with median of $285 \mathrm{~m}^{3} / \mathrm{s}$ at Trenton, NJ [USGS, 2018]. To evaluate the effect of river flow during a surge event, I consider a river flow to tide ratio of 0 to 1.

\subsubsection{Water Surface Slope}

The cross-sectionally integrated continuity equation $\left(\frac{\partial Q}{\partial x}+b \frac{\partial H}{\partial t}=0\right.$, see Appendix A for more details) states that the along channel gradient in flow volume is compensated by temporal changes of surface elevation (see Figure 4-2). Figure 4-2 shows 92 
the along channel variation in water surface slope that drives flow. The parameter $h$ is channel depth, $\xi$ is tidal amplitude (small compared to depth), $Z$ is tidally averaged changes in water surface elevation due to river discharge, and $Q$ is discharge. Reduced friction due to increased channel depth can alter the tidally averaged water level gradient $\left(\frac{\partial Z}{\partial x}\right)$. Reduced water surface slope over decadal time scales due to greater depths and less bed roughness may result in lower water levels during river discharge [Jay et al., 2011].

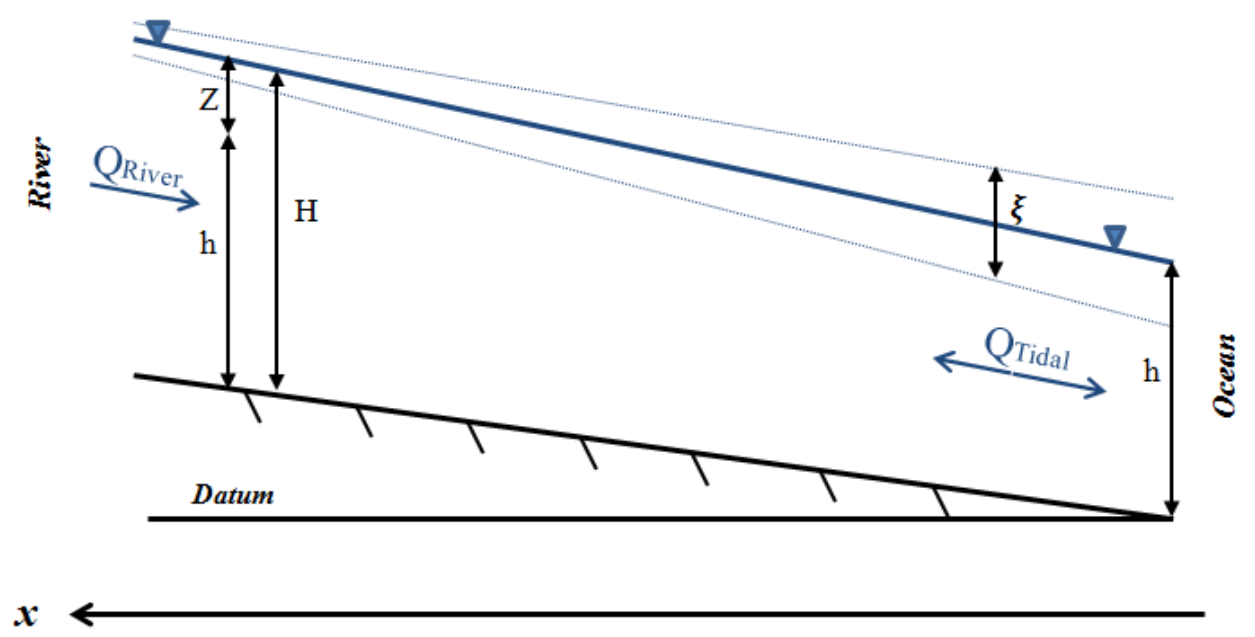

Figure 4-2: Definition of the water surface slope. Along channel direction $x$ is upstream with $x=0$ at the ocean.

The one dimensional equation of motion is [Godin, 1999]:

$$
\underbrace{\frac{1}{g} \frac{\partial u}{\partial t}}_{\begin{array}{c}
\text { Local } \\
\text { acceleration }
\end{array}}+\underbrace{\frac{u}{g} \frac{\partial u}{\partial x}}_{\begin{array}{c}
\text { Convective } \\
\text { acceleration }
\end{array}}=-\underbrace{\frac{\partial H}{\partial x}}_{\begin{array}{c}
\text { Pressure } \\
\text { gradient }
\end{array}}-\underbrace{\frac{u|u|}{C_{h}^{2}(h+\xi)}}_{\text {Friction }}
$$

where $u$ is average value of the current at $x, g$ is acceleration due to gravity, $C_{h}$ is Chézy constant, and $h$ is mean depth of water. Scaling the terms in Equation (4-3) shows that 93 
pressure gradient and friction terms are the main terms that govern the system in most river estuaries. Since my attention and interest lies in the quadratic friction term and in tidal currents dominant the river flow in U.S. East Coast estuaries, I approximate the time averaged equation of motion as a balance between the friction and the pressure gradient terms [Godin and Martinez, 1994; Kukulka and Jay, 2003b]:

$$
\frac{\partial H}{\partial x}=-\frac{u|u|}{C_{h}^{2}(h+\xi)}
$$

The current velocity $u$ is a function of time $t$ as well as of position $x$. The low-frequency momentum equation (4-4) shows that the mean surface slope is defined by bed stress term.

\subsubsection{Dimensional and Non-Dimensional Parameter Space}

Familkhalili et al. [2019; Chapter 3] show that surge problems of this type are governed by ten non-dimensional numbers. I use the most relevant independent nondimensional in this study (i.e., $\Omega=\frac{\text { Period } S u_{P r i}}{\text { Period } D_{2}}$ and $\psi=\frac{C_{d} \xi \omega^{2} L_{e}^{3}}{g h^{3}}$ ) to cover a wide range of possible extreme event and different bathymetric configurations. I also vary another independent parameter that is the ratio of river velocity to the major tidal component velocity $\left(\theta=\frac{u_{R}}{u_{M_{2}}}\right)$. For plotting purposes, I define the following non-dimensional numbers: $S u_{P r i}$ normalized amplitude $\left(A_{*}=\frac{A m p . S u_{P r i}}{\text { Surge Amp. at bounday }}\right)$ and a dimensionless coordinate system of $L_{*}=x / L_{e}$, where $L_{*}$ is normalized length. For all simulations, the 
primary tidal constituent period and amplitude are fixed to $12 \mathrm{hr}$ for simplicity and $0.5 \mathrm{~m}$, respectively, a value that is typical of the primary tide wave on the U.S. East Coast (Table 4-1). Table 4-1 shows the parameter space used in the model. The following parameters are held constant; $B_{0}=5 \mathrm{~km}, S u_{P r i}=0.5 \mathrm{~m}, S u_{S e c}=0.25 \mathrm{~m}$, and Chézy coefficient $=25$.

Table 4-1: Parameter space used in analytical model

\begin{tabular}{|c|c|c|c|c|}
\hline Channel Depth $(\mathrm{m})$ & 5 & 7 & 10 & 15 \\
\hline$S u_{P r i} A m p .(m)$ & \multicolumn{4}{|c|}{0.5} \\
\hline$S u_{S e c} A m p .(m)$ & \multicolumn{4}{|c|}{0.25} \\
\hline Su $u_{\text {Pri }}$ Time Scale $(h r)$ & 12 & 24 & 48 & 72 \\
\hline Su $u_{\text {Sec }}$ Time Scale $(h r)$ & 6 & 12 & 24 & 36 \\
\hline$D_{2} A m p .(m)$ & \multicolumn{4}{|c|}{0.5} \\
\hline$D_{2}$ Time Scale $(h r)$ & \multicolumn{4}{|c|}{12} \\
\hline River flow velocity $\left(\theta=\frac{u_{R}}{u_{M_{2}}}\right)$ & 0 & 0.25 & 0.5 & 1 \\
\hline$L_{e}$ Convergence length scale $(\mathrm{km})$ & \multicolumn{2}{|c|}{80 (weakly convergent) } & \multicolumn{2}{|c|}{20 (strongly convergent } \\
\hline
\end{tabular}

I use an idealized analytical tide-surge model following Familkhalili et al. [2019] and include river flow effects to implement a sensitivity study in which the spatial response of primary surge amplitudes to changes in estuary depth, surge wave time-scale, 
river flow velocity, and convergence length scale are simulated (see Table 4-1). For simplicity, I assume that surge wave is symmetric with a phase lag ( $\phi$ in Equation 4-1) of zero degrees relative to the $D_{2}$ wave, which makes frictional interaction to be largest (see section 3.6, Chapter 3).

\subsection{Results and Discussion}

\subsubsection{Effects of River Discharge on Water Level}

The water level profiles varies with $\theta$ and $\psi$ (flow and channel depth) as shown in Figure 4-3 for a weakly convergent estuary $\left(L_{e}=80 \mathrm{~km}\right)$ (see Table $\left.4-1\right)$. Larger river discharge causes higher mean water level (Z, Figure 4-3). Figure 4-3a shows the effects of depth changes on surface water elevation while Figure 4-3b represents the effects of flow on tidally averaged water level $(Z)$ for three different flows of $0.5-2 \mathrm{k}^{3} / \mathrm{s}$. A

comparison of $h=5 \mathrm{~m}$ (blue line in Figure 4-3a) with $h=10 \mathrm{~m}$ (green line in Figure 4-3a) shows that doubling the channel depth results in $\sim 0.3 \mathrm{~m}$ decrease in mean water level at landward boundary $\left(L_{*}=1.5\right)$. As also suggested by Equation (4-4), each incremental increase in depth produces a smaller change in the slope $\left(d Z / d L_{*}\right)$ (Figure 4-3a). Model results also suggest that the effects of river discharge decreases as the channel depth increases while the slope of water level changes $\left(d Z / d L_{*}\right)$ reduces along the marine portion $\left(L_{*}=0.5-1\right)$ of the estuary. These graphs show at the upstream of the estuary the 
mean water level increases with higher rate due to river discharge than the marine portion where $Z$ goes to zero.

Results suggest that increasing the depth of channel over secular time scales due to channel deepening results in lower surface slope along the estuary [e.g., Jay et al., 2011]. In other words, shallower depth $(h)$ causes a steeper surface slope (Equation 4-4), since larger pressure gradient is required to drive the flow downstream.

a)

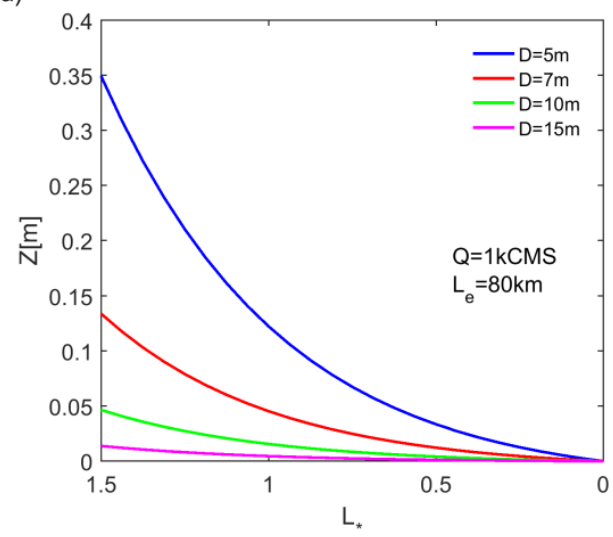

b)

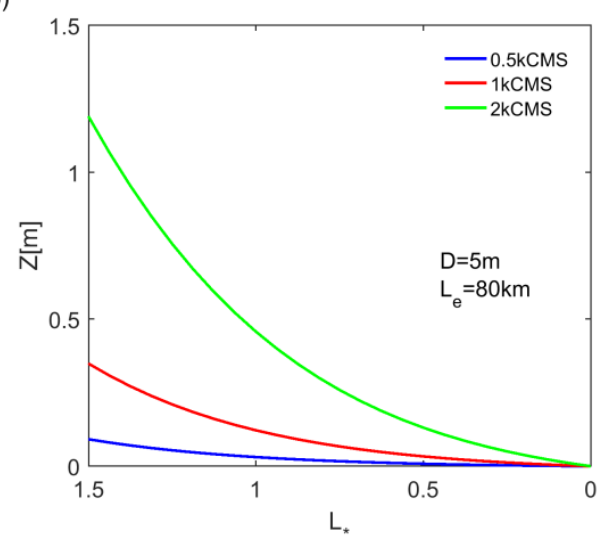

Figure 4-3: (a) The importance of channel depth for $1 \mathrm{k}^{3} / \mathrm{s}$ flow and (b) the importance of river flow for $5 \mathrm{~m}$ depth in an idealized estuary. Vertical axis is $Z$ that is tidally averaged water level and horizontal axis represents dimensionless coordinate system of $L_{*}=x / L_{e}$.

In the case of larger river discharge (Figure 4-3b), the depth averaged velocity increases, and a larger water surface slope $\left(\frac{\partial H}{\partial x}\right)$ is needed to balance the Equation (4-4). Equation 4-4 also states that shallower estuary (smaller $h$ ) has similar impact on water surface slope as increasing averaged river flow velocity (larger $u$ ). 


\subsubsection{Frictional Effects of River Discharge on Surge Amplitude}

River discharge alters surge-tide propagation along an estuary by impacting tidal amplitude and altering energy distribution between tidal frequencies [e.g., Godin, 1999; Jay and Flinchem, 1997; Horrevoets et al., 2004]. Therefore, in order to model the effects

of river flow during a storm surge event, I consider $\theta=\frac{u_{R}}{u_{M_{2}}}=0-1$ (see Section 4-6). Figure 4-4 shows the effects of river discharge on e-folding length-scale of $S u_{\text {Pri }}$ normalized amplitude $\left(A_{*}\right)$. Sensitivity studies show that the largest surge time scale $(\Omega=6)$ increases the e-folding scale of $A_{*}$, which means that the longer the wave period, the slower the amplitude of surge will decrease moving landward (keeping all other variables constant). For example, Figure $4-4 \mathrm{a}$ shows that a $12 \mathrm{hr}(\Omega=1)$ surge amplitude reaches an e-folding reduction in amplitude at $\sim 0.4 L_{*}$ while it takes a distance $\left(\sim 0.9 L_{*}\right)$ for the $72 \mathrm{hr}(\Omega=6)$ surge.

Model results also suggest that including river discharge will increase the damping of surge amplitudes (Figure 4-4). When $\left(\theta=\frac{u_{R}}{u_{M_{2}}}=0\right)$, river flow is zero and only tide-surge interactions can occur. Hence, surge amplitudes decay more slowly than for $\theta>0$ (compare the $\theta=0$ and $\theta=1$ case in Figure 4-4). The slanted contour lines highlight the effects of river flow; as $\theta$ increases the e-folding of normalized amplitude $\left(A_{*}\right)$ decreases for all surge time scales $(\Omega=1-6)$ (Figure 4-4a-d). Therefore, surge amplitude decay is more rapid for higher river flow discharge conditions. 
Generally Figure 4-4 suggests that deepening the channel raises the importance of river flow effects on damping of surge amplitudes and the surge amplitudes decay less quickly (larger e-folding) in a deeper channel for all surge time scales (Figure 4-4). Sensitivity studies show that the largest difference in normalized amplitude between a $12 \mathrm{hr}(\Omega=1)$ and $72 \mathrm{hr}(\Omega=6)$ surge occurs at larger depth $(D=15 \mathrm{~m})$ with changes of $\sim 1 L_{*}$ to $3.5 L_{*}$ in the e-folding length-scale of damping. Increasing the river discharge relative to the $M_{2}$ velocity (larger $\theta$ ) reduces the amplification of the surge wave. For example, e-folding length scale of $A_{*}$ reduces from $\sim 3.4 L_{*}$ to $\sim 2.7 L_{*}$ for $S u_{P r i}$ of $72 \mathrm{hr}$ (Figure 4-4d). 

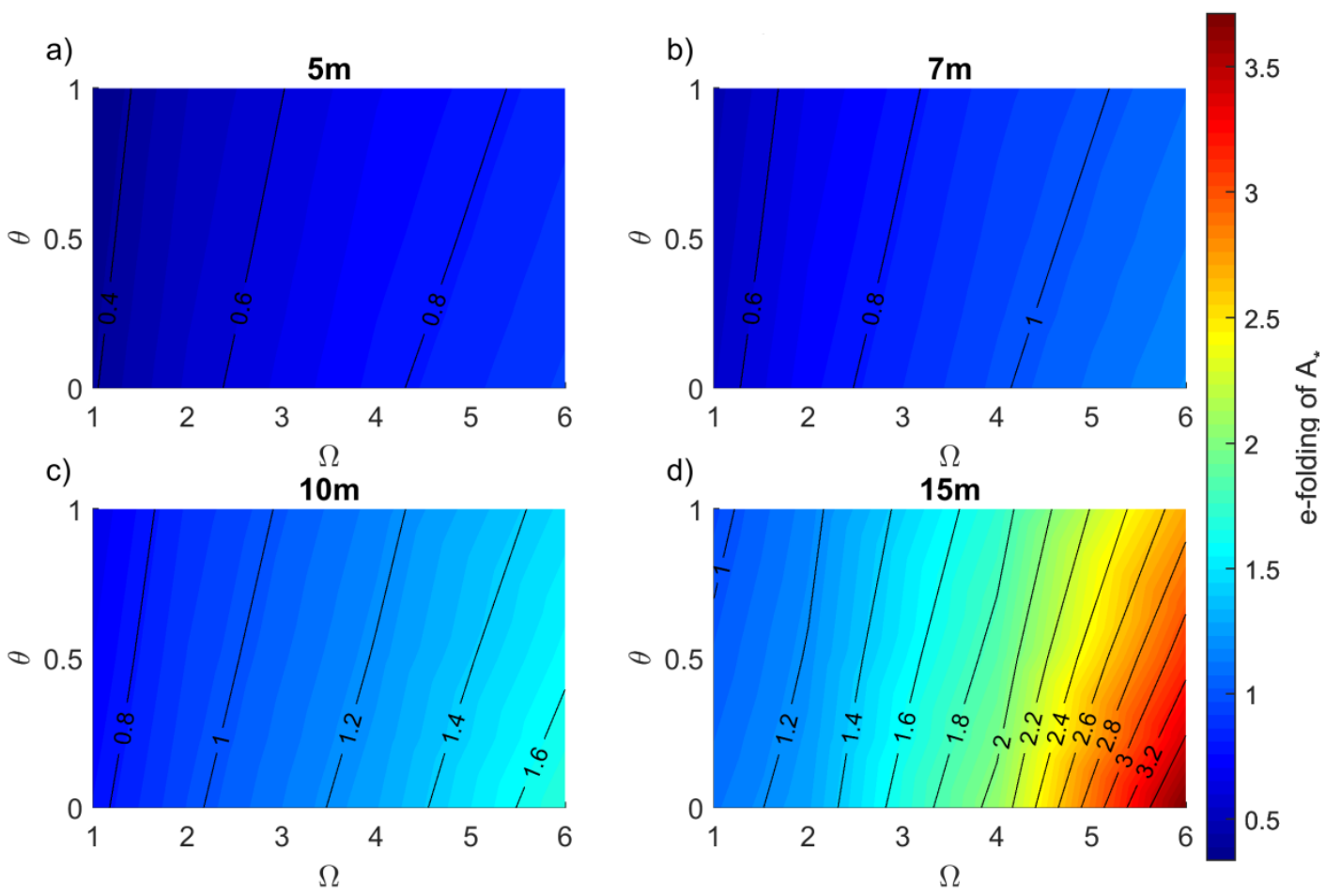

Figure 4-4: The effects of river flow $\left(\theta=\frac{u_{R}}{u_{M_{2}}}\right)$ and surge periods $\left(\Omega=\frac{\text { Period } \text { Su }_{\text {Pri }}}{\text { Period } D_{2}}\right)$ along an idealized weakly convergent estuary for channel depth of (a) $5 \mathrm{~m},(\mathrm{~b}) 7 \mathrm{~m},(\mathrm{c}) 10 \mathrm{~m}$, and (d)15m.

Total water level (TWL) is summation of tide, storm surge, and river discharge effects (TWL $=\mathrm{T}+\mathrm{SS}+\mathrm{R})$. The highest possible total water level (HTWL) occurs when the tide $\left(D_{2}\right)$ and surge has zero relative phase (maximum surge occurs at high water). Because the timing of a meteorological event is usually random compared to tides, and because the hydrology of most systems means that peak run-off is lagged after peak surge, the HTWL rarely if ever occurs. However, it is a useful metric of the potential 
flooding, and provides a means to compare different parameter regimes and evaluate the effect of long-term changes in an individual estuary.

Figure 4-5 represents the contribution of tide, surge, and river flow to TWL when channel depth has increased from $h=5 \mathrm{~m}$ to $h=10 \mathrm{~m}$. TWL, tide, and surge show amplification along the estuary for all river discharge $(\theta=0-1)$, although the amplification is less for higher river discharge. In other words, the contribution of river flow to TWL has decreased due to channel deepening (Figure 4-5d). As previously (see section 4-3-1) mentioned, deepening the channel (larger $h$ ) results in a lower water surface slope $\left(\frac{\partial H}{\partial x}\right)$ to balance the Equation (4-4). As an example, Figure 4-5a shows that TWL has decreased for all river flow scenarios as channel depth increased from $5 \mathrm{~m}$ to $10 \mathrm{~m}$. Due to decreased non-linear interaction, the rate of surge amplitude increase is larger for lower river discharge.

Most of the changes in river flow effects occurs upstream of $0.5 L_{*}$, a location where river flow effects caused by channel deepening outweigh the amplification in tide and surge observed closer to the coast. I define the location in which river flow effects are larger than marine effects to be the "crossover point". The location of crossover point is shown with the zero contour line in Figure 4-5a. This line moves downstream (toward the ocean) as the channel deepens or time scale of $S u_{P r i}$ increases. Therefore, this analytical model suggests that marine and river effects can change over time by changing the controlling depth of an estuary. As an example, Ralston et al. [2019] found that flood risk in Albany (NY) has decreased over time, due in part to a decrease in river slope 
caused by dredging. Closer to the coast, Talke et al. [2014] found that storm surge risk had increased within New York harbor between the $19^{\text {th }}$ and $21^{\text {st }}$ centuries. My results confirm the intuitive result that there must be a crossover point, in which changes to marine and fluvial effects balance and flood risk has remained approximately stationary.

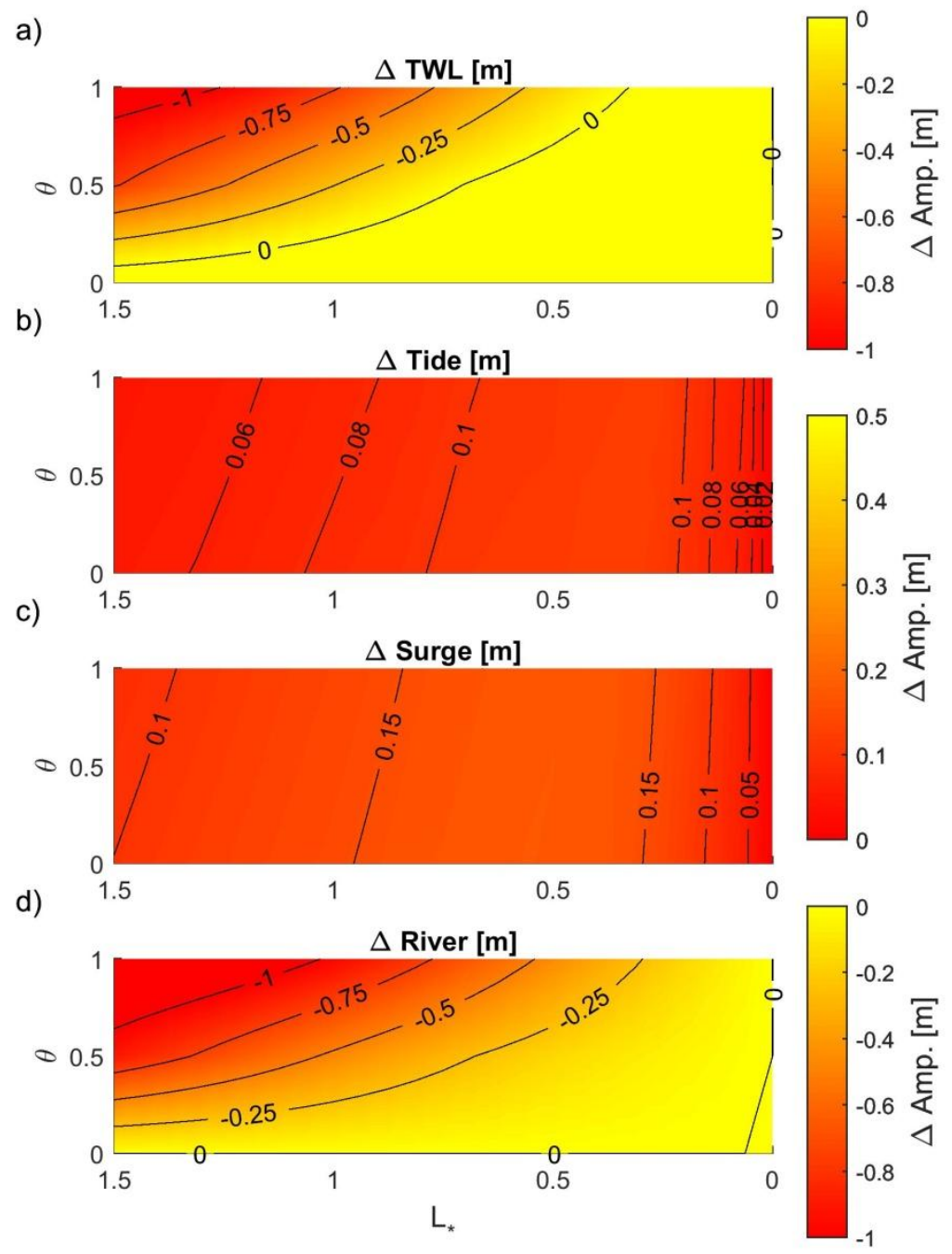

Figure 4-5: Comparison of contribution of tide, surge, and river flow to compound flooding between $5 \mathrm{~m}$ and $10 \mathrm{~m}$ depth channel and $S u_{P r i}=24 \mathrm{hr}$. The convergence length scale is $80 \mathrm{~km}$ and $x$-axis 
represents dimensionless coordinate system of $L_{*}=x / L_{e}$ and $y$-axis shows non-dimensional river flow $\left(\theta=\frac{u_{R}}{u_{M_{2}}}\right)$.

\subsubsection{Convergence Length Scale}

In strongly convergent estuaries, the amplification of the tidal wave due to funneling into a smaller cross-section area is more important than frictional effects. Figure 4-6 shows the normalized amplitude $\left(A_{*}=\frac{A m p .}{\text { Amp.at the Boundary }}\right)$ of primary surge along a strongly convergent estuary. Idealized analytical model runs suggest that the primary surge amplitude decays less quickly or even amplifies, in a deeper channel as it moves upstream (see Figure 4-6). Sensitivity studies show that amplification occurs for surge with large time scales $(\Omega)$ (Figure 4-6). There is a competing effect between the depth change and surge time scale, as larger depth tends to damp the surge less and amplify the surge in some cases (Figure 4-6a). As previously discussed in section 3.6 (Chapter 3), larger surge time scale (less frequency) generates a lower rate of spatial decay, and therefore larger upstream amplitudes. When combined with the shallower channel effects, this tends to amplify the surge amplitudes. 

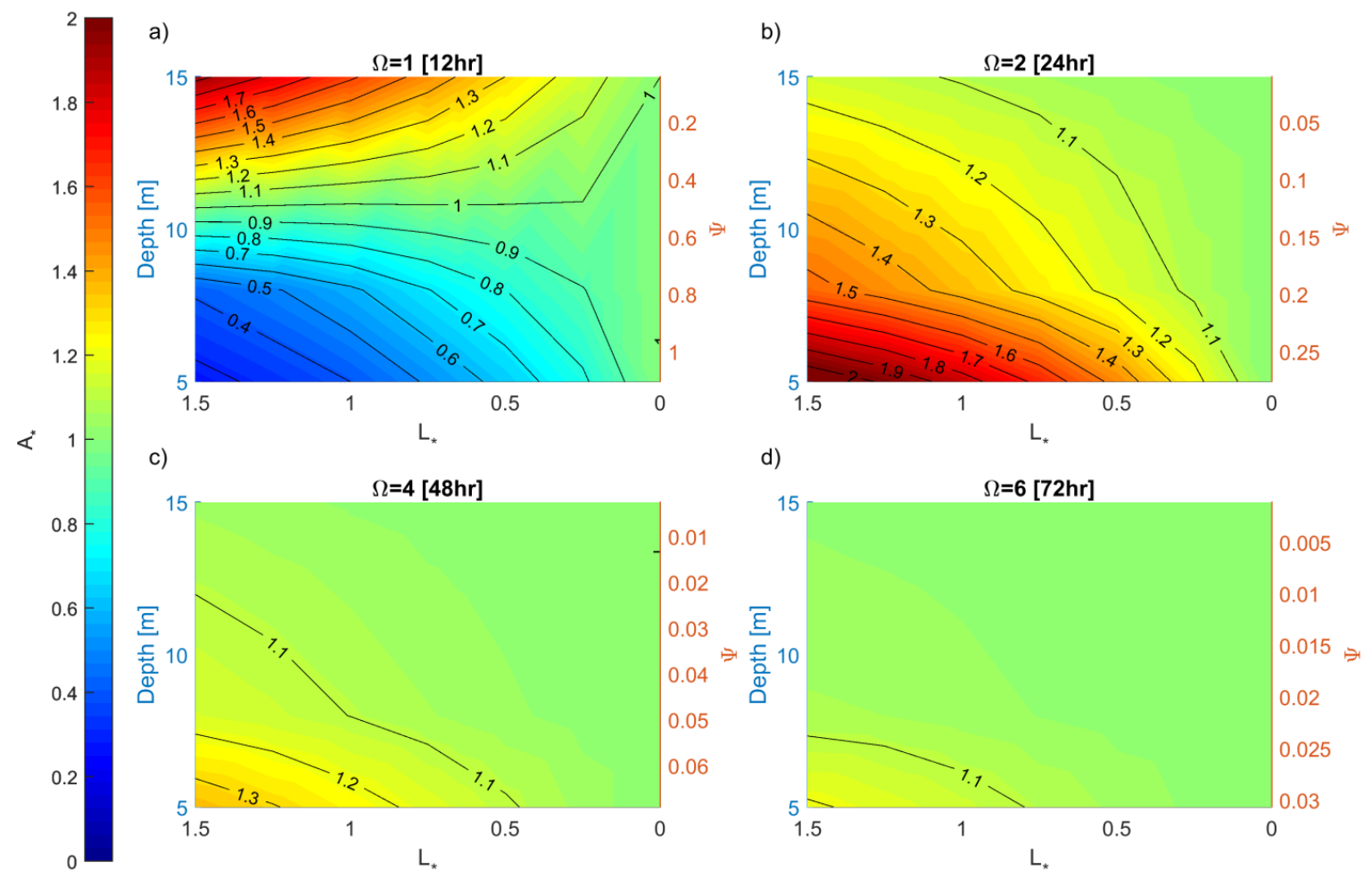

Figure 4-6: The influence of surge period and channel depth on primary surge amplitude ( $A_{*}$ is normalized amplitude to the surge amplitude at ocean boundary $L_{*}=0$ ) along a strongly convergent estuary $\left(L_{e}=20 \mathrm{~km}\right)$.

This analytical analysis gives us more insight into how and why changes to depth, surge time scale, and convergence length-scale affect the damping/amplification of surge in real estuaries. As an example, I next compare the analytical results to the idealized numerical modeling of Familkhalili and Talke [2016] (see Chapter 2). As shown in Familkhalili and Talke [2016], the Cape Fear River Estuary (CFRE) is an example of a strongly convergent estuary upstream of Rkm 12 (e-folding length scale of $\sim 20 \mathrm{~km}$ ). 
Since Wilmington, $\mathrm{NC}$ is located at $\mathrm{Rkm} 47\left(\sim L_{*}=1.5\right)$, I use Figure 4-6a to verify the numerical modeling results of the CFRE [Familkhalili and Talke, 2016], where the channel depth has been almost doubled to $\sim 15 \mathrm{~m}$. As analytical model results show, the surge amplitude reduces $\sim 60 \%$ at $L_{*}=1.5$ (from $0.5 \mathrm{~m}$ to $0.2 \mathrm{~m}$ ) along the estuary for $7 \mathrm{~m}$ depth (Figure 4-6a), while it amplifies by $80 \%$ for channel depth of $15 \mathrm{~m}$. These results are qualitatively consistent with modeling results, which show doubling of surge heights at Wilmington (see Chapter 2). Therefore, in a shallow estuary the effects of friction are dominant over the convergence and cause the wave amplitudes (tides and surge) to decrease, while deepening the estuary may cause amplification of long waves upriver of an estuary.

The patterns in Figures 4-5 to 4-6 can also be explained by considering the nondimensional friction number $\left(\psi=\frac{c_{d} \xi \omega^{2} L_{e}^{3}}{g h^{3}}\right.$, see Chapter 3). This number suggests that increases in channel depth and wave time scale have similar effects on wave amplitudes (i.e., increasing depth $h$ and increasing time scale which is reducing $\omega=\frac{1}{T}$ ). Therefore, increasing the depth from $5 \mathrm{~m}$ to $15 \mathrm{~m}$ causes the $A_{*}$ (i.e., normalized amplitude by boundary depth) to increase from 0.3 to 1.9 (Figure 4-6a). Similarly, changing time scale from $12 \mathrm{hr}(\Omega=1)$ to $72 \mathrm{hr}(\Omega=6)$ causes the normalized amplitude to decrease from 1.9 to 1 for $15 \mathrm{~m}$ depth case at $L_{*}=1.5$.

Model results also confirm the hypothesis that an estuary with a constant depth and convergence length-scale could behave differently to different time scales surge. 
Therefore, in some cases the larger time scale results in damping ( $h=15 \mathrm{~m}$ in Figures 4-6) while in some other cases $(h=10 \mathrm{~m})$ the larger time scale results in amplification. For example one can compare Figures $4-6 \mathrm{a}, \mathrm{b}$ and show that $A_{*}$ increases from $\sim 0.9$ to 1.4 at $L_{*}=1.5$ when time scale is doubled from $12 \mathrm{hr}$ to $24 \mathrm{hr}$.

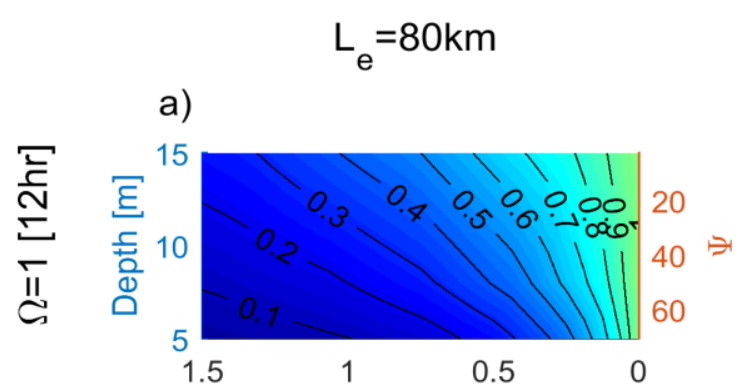

b)

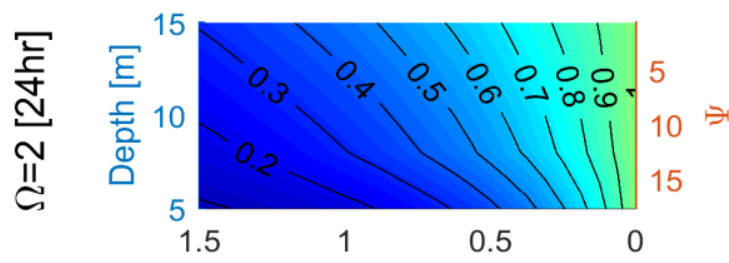

c)

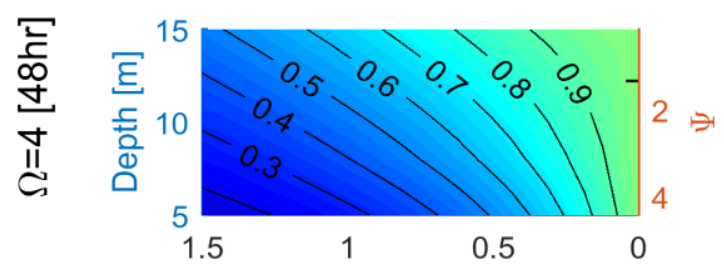

d)

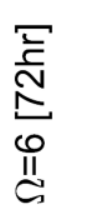

b)

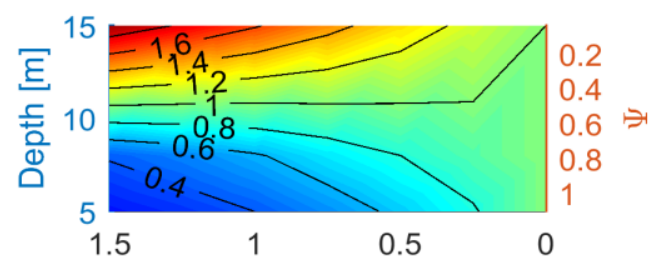

d)

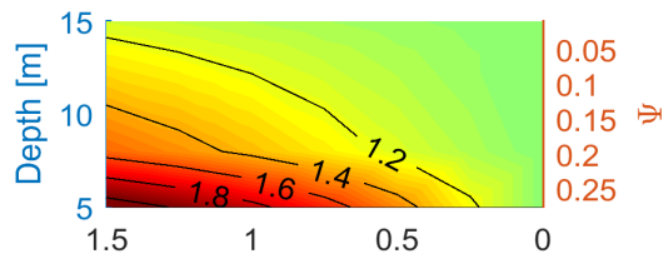

f)

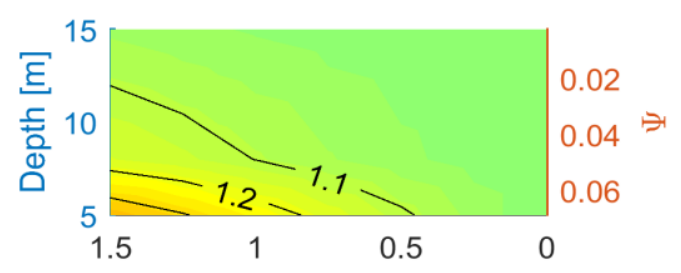

h)

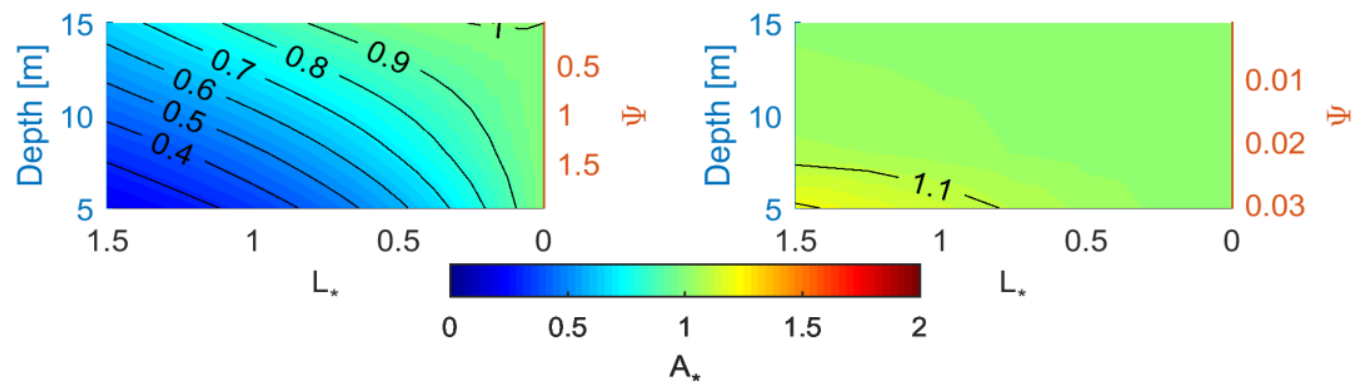


Figure 4-7: The effects of convergence length scale on primary surge amplitude $\left(A_{*}\right.$ is normalized amplitude) along an estuary $\left(L_{e}=20-80 \mathrm{~km}\right)$.

To help interpret the normalized surge amplitudes $\left(A_{*}\right)$ in Figure 4-7, I note that four subplots on left panel represent $A_{*}$ along a weakly convergent estuary for four different $S u_{P r i}$ time scales $\left(\Omega=\frac{\text { Period } S u_{P r i}}{\text { Period } D_{2}}=1-6\right)$, while right panel show the same values for a strongly convergent estuary. All surge amplitudes with time scales $(\Omega=1$ to 6) damp in a weakly convergent $\left(L_{e}=80 \mathrm{~km}\right)$ estuary. The factor $4 \mathrm{x}$ change in convergence length scale in Figure 4-7 alters the friction scale $(\psi)$ by a factor $64 x$ change. In a strongly convergent estuary, relative magnitudes of the depth and time-scale determine whether a surge wave decays or amplifies (Figure 4-7). Generally, increasing surge time scale has a similar effect as increasing the depth; however, the model is more sensitive to depth, due to the cubic relationship in the friction term, as opposed to the squared effect of time scale. The non-dimensional friction number $(\psi)$ suggest that the effects of surge amplitude at boundary $(\xi)$ and drag coefficient $\left(C_{d}\right)$ have a lesser, but still important, influence on the spatial damping of surge as the depth increases.

\subsection{Numerical Model}

I next develop a depth-averaged Delft-3D numerical model [Booij et al., 1999] of the St. Johns River Estuary (SJRE), FL to investigate how river flow, surge, and tides interact during a real event, hurricane Irma (2017). The model is divided into two 
domains, A and B (Figure 4-8). Domain decomposition allows running each sub domain in parallel, which reduces the time of model run. I digitize a nautical chart for historic (1898) configuration and use a digital elevation map for modern configuration to construct Delft-3D hydrodynamic grid and depth. Since I am interested in tide and surge characteristics in lower SJRE, I approximate domain B as a long and shallow river to allow damping of the tidal wave. Thus, the river is modeled with a constant width of $3500 \mathrm{~m}$ and a constant depth of $3 \mathrm{~m}$ (for 1898) and $5 \mathrm{~m}$ (for 2017) for $100 \mathrm{~km}$ upstream of Jacksonville. For data analysis purposes, I use observation points located every $1 \mathrm{~km}$ along the SJRE channel. The water level at each observation point is extracted from the model every 5 minutes. 


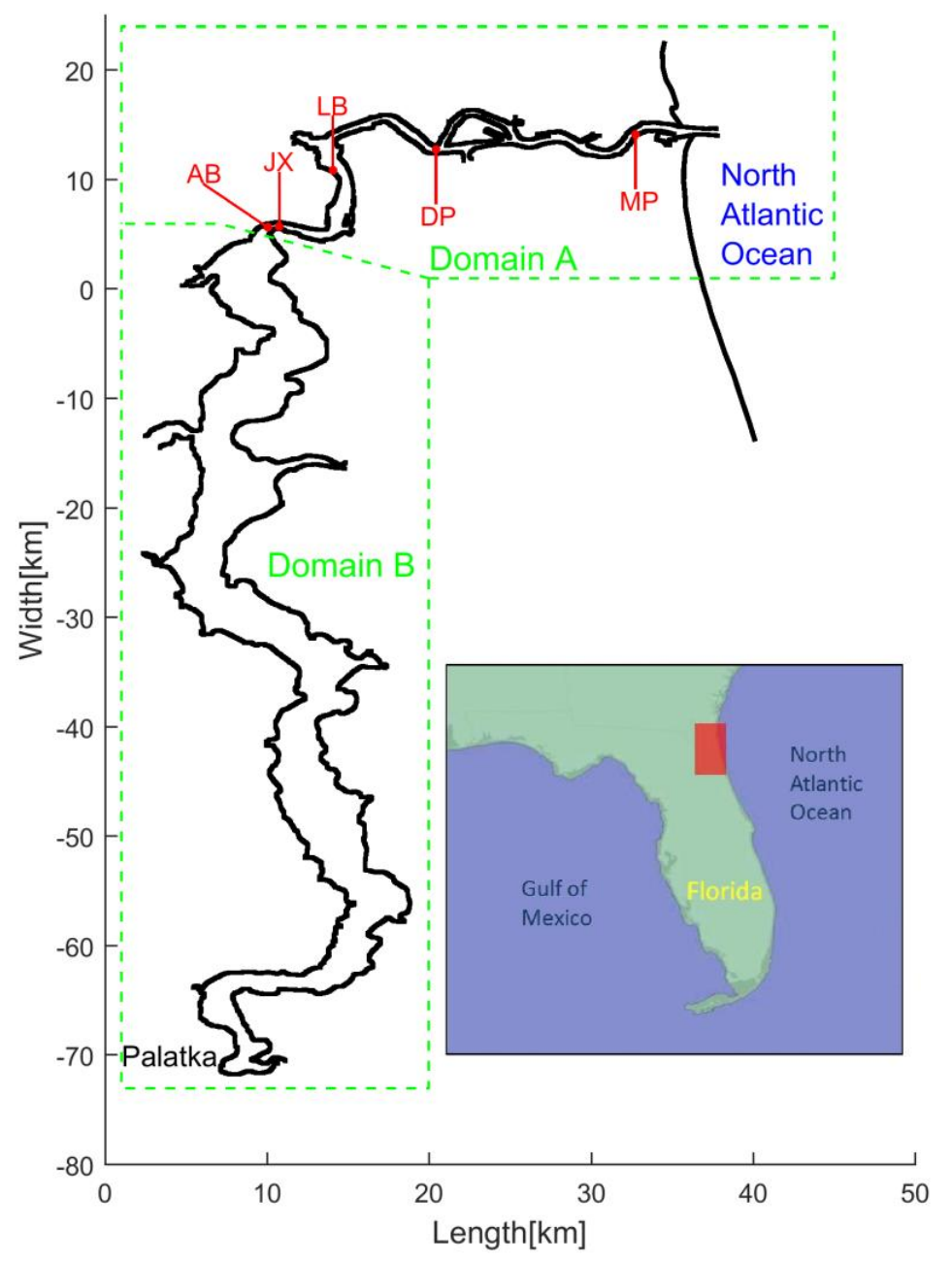

Figure 4-8: Map of St Johns River Estuary, FL with locations of gauges, MP =NOAA gauge at Mayport (Station ID: 8720218), DP =NOAA gauge at Dames Point (Station ID: 8720219), LB= NOAA gauge at Longbranch (Station ID: 8720242), JX = NOAA gauge at Jacksonville (Station ID: 8720226), and $\mathrm{AB}=$ USGS gauge at Acosta Bridge. 


\subsubsection{Bathymetric Change}

To investigate changes over the past century, I use historic nautical charts of late $19^{\text {th }}$ century to create a historic hydrodynamic model of the St Johns River Estuary, FL (SJRE), a tidal estuary that has been greatly modified over the past 120 years. I have digitized the 1898 bathymetry of the SJRE and obtained 2014 bathymetry from NOAA/NOS (National Oceanic and Atmospheric Administration/National Ocean Survey, Figure 4-9). The overall mean depth of the SJRE has increased through channel deepening. Large scale changes have occurred over the past century in the SJRE; with the channel depth has increased from $5.5 \mathrm{~m}$ in $1890 \mathrm{~s}$ to $12.5 \mathrm{~m}$ in 2014 . Extensive navigational channel streamlining and shortening projects also altered the length of river that several U.S. Army Corps projects resulted in $\sim 4 \mathrm{~km}$ shortening of the shipping channel from the estuary mouth to Jacksonville (Rkm 40.4) (Figure 4-10). Dredging the channel deepens the river which alters amplitude of a tidal wave that is proportional to the channel depth, and channel width (see Chapter 2). 
a)

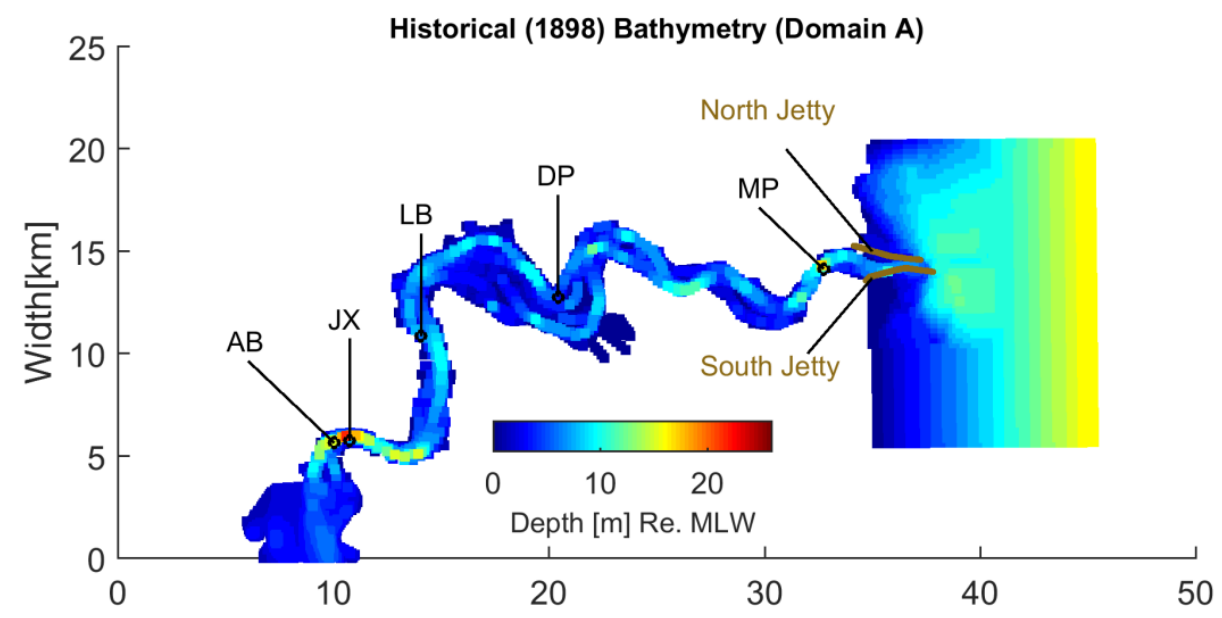

b)

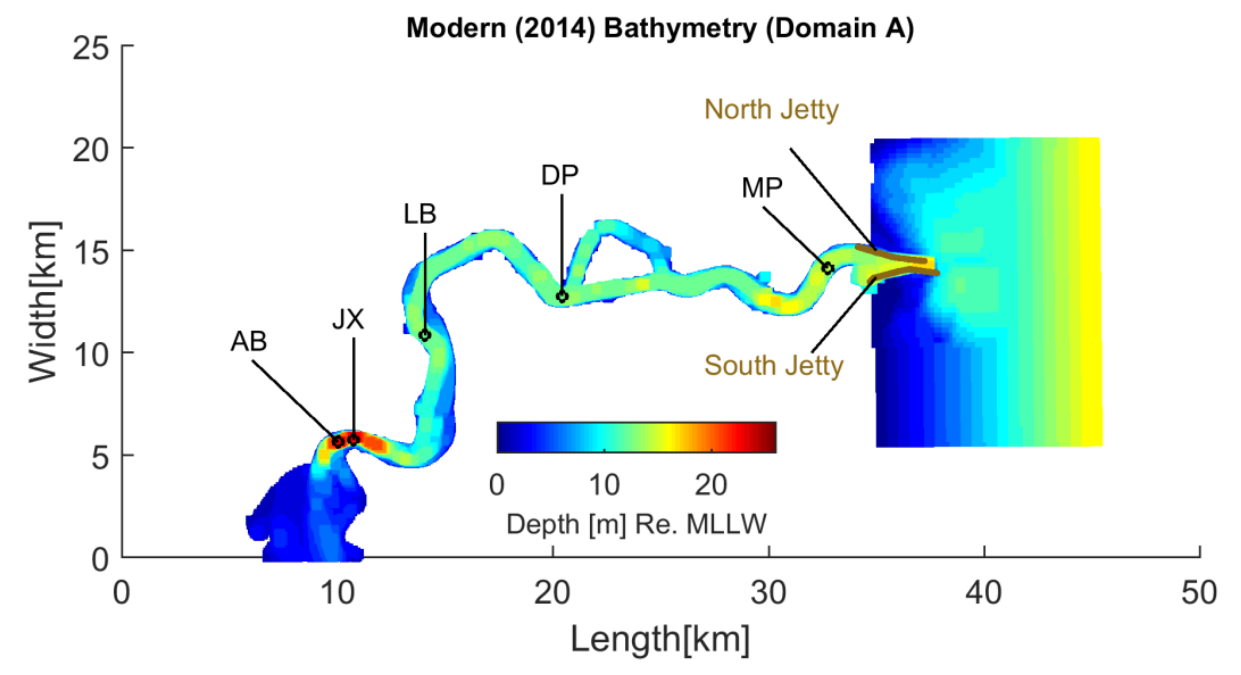

Figure 4-9: (a) historic (1898), and (b) modern (2014) bathymetry of St Johns River Estuary, FL with locations of gauges at Mayport (MP), Dames Point (DP), Longbranch (LB), Jacksonville (JX), and USGS gauge $(\mathrm{AB})$. 


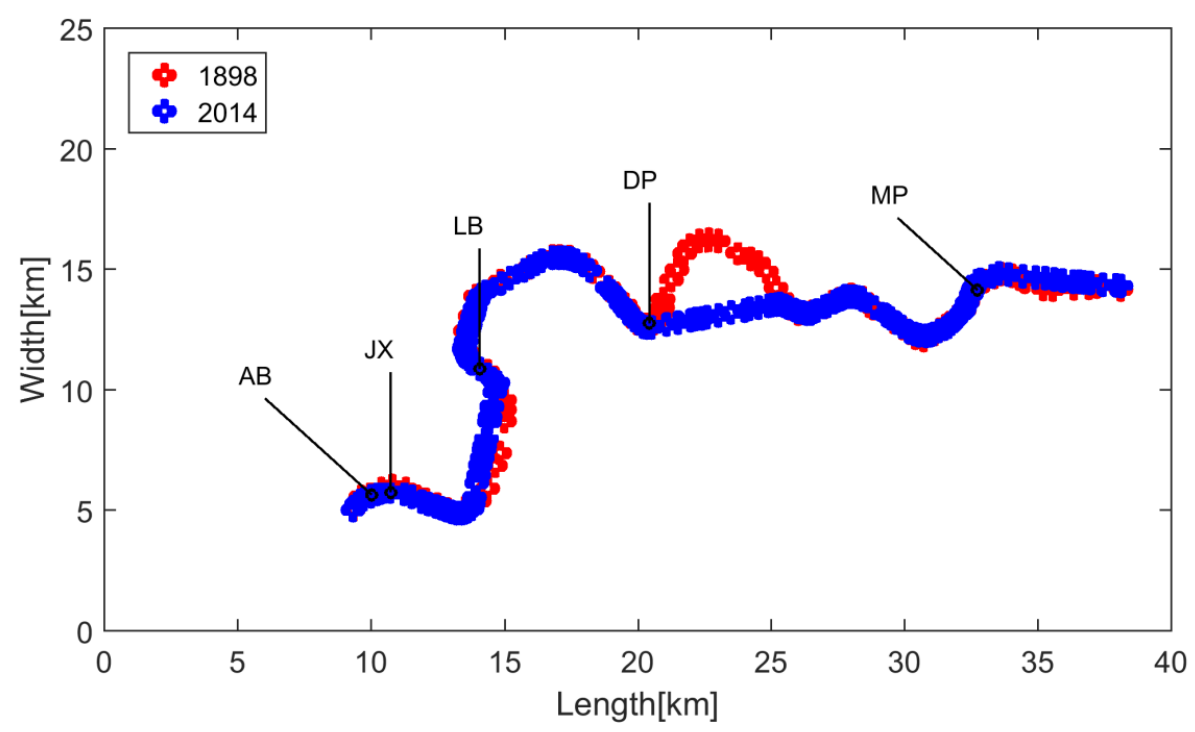

Figure 4-10: Changes in shipping channel between 1898 and 2014.

\subsubsection{Tide Data}

Hourly tide data used to drive and validate the Delft-3D numerical model were obtained from the National Oceanographic and Atmospheric Administration (NOAA) for Mayport, FL (2000-2018, Station ID: 8720218) and, Dames Point, FL (2001-2002, 20132018, Station ID: 8720219), Longbranch, FL (Station ID: 8720242), and Jacksonville, FL (2001-2007, 2014-2018, Station ID: 8720226).

\subsubsection{Boundary Conditions}

Two different types of boundary conditions are applied to the model; a seaward boundary is forced by estuary entrance tides and an upstream river boundary condition. 
To calibrate the model, the Delft-3D model is forced by eight tidal constituents; semidiurnal $\left(M_{2}, S_{2}, N_{2}, K_{2}\right)$, diurnal $\left(P_{1}, K_{1}, O_{1}\right)$, and quarter-diurnal $\left(M_{4}\right)$. Mayport tides were used. The amplitude and phase of the tidal constituents are defined by applying harmonic analysis [e.g., Leffler and Jay, 2009]. The model contains an average discharge of $450 \mathrm{~m}^{3} / \mathrm{s}$ for the St. Johns River.

\subsection{Calibration and Validation}

The model is calibrated by adjusting the Chézy coefficient until the modeled progression of the dominant $M_{2}$ tide produce an optimal agreement with observations from different stations along the river (Figure 4-9). Figure 4-11 shows the spatial calibration of $M_{2}$ amplitude along the river against measurements. Chézy coefficients of 25 and 75 were applied for the historic and modern configurations, respectively. The larger friction (smaller Chézy coefficient) in historic configuration represents the effects of wetlands and small-scale roughness features. The solid lines denote historic and modern model results. Location of observation gauges are shown by vertical dashed lines. Due to the shortening of the channel the Rkm of stations has changed over time (Figure 4-10). The results indicate a good fit between model results and data with RMSE of $0.02 \mathrm{~m}$ and $0.03 \mathrm{~m}$ for historic and modern configurations, respectively. 


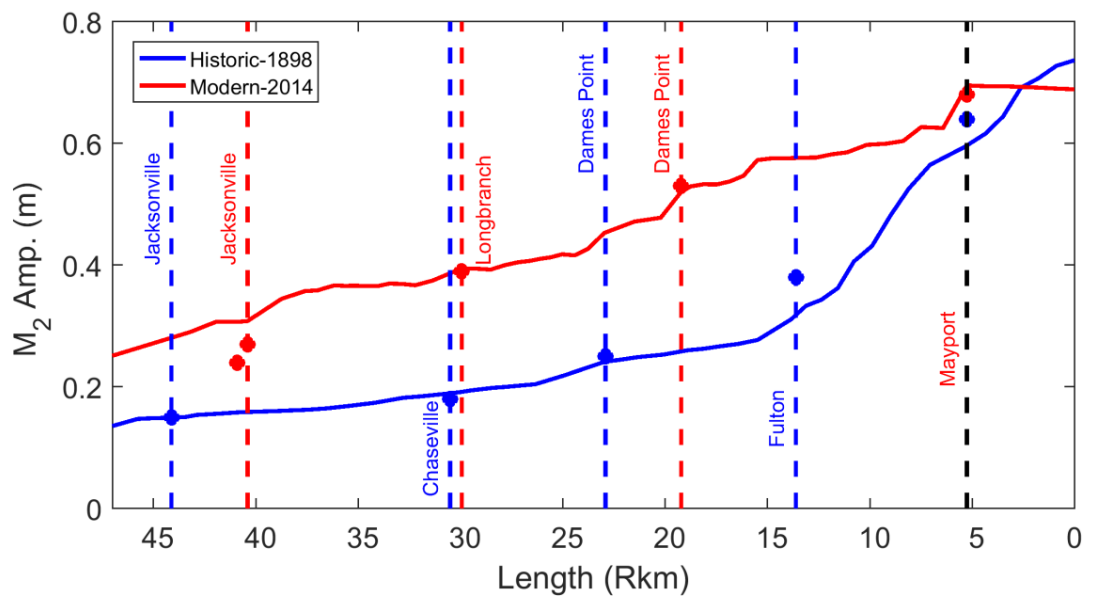

Figure 4-11: Spatial changes of measured and modeled $M_{2}$ tidal amplitude for historic and modern model.

After calibration of the models, 40d of observed water levels (i.e., storm tides) and predictions used to simulate hurricane Irma 2017 in Jacksonville, FL. The effect of river discharge on historical and modern water levels is modeled by applying river discharge at Jacksonville. I run the model with 40d observed water level from Mayport and measured flow as boundary condition.

\subsection{Compound Flooding}

\subsubsection{Analysis of 2017 Flood Event}

To investigate how changes to bathymetry have altered surge and flood propagation, I simulate the 2017 Irma hurricane with both the historic and modern grids. These models help us understand how the hydrodynamics of compound flooding have 
changed over time. There are three sets of runs for each grid; I) observed coastal water level and measured river flow; II) observed coastal water level and no river flow; and III) predicted water level and no river flow as boundary conditions. By subtracting III from I and II, I obtain two sets of output for each grid; one has surge effects (IV) and the other one has surge and river flow effects (V). Therefore, I am able to calculate the river flow effects as the difference between IV and V (see Figure 4-12d). 
a)

b)

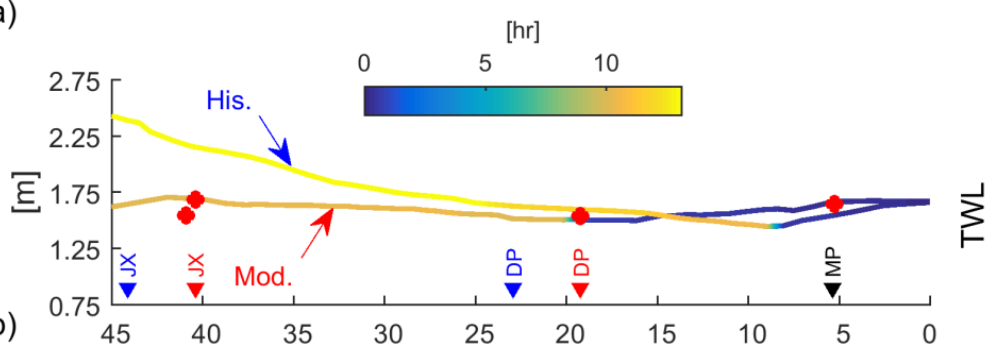

c)

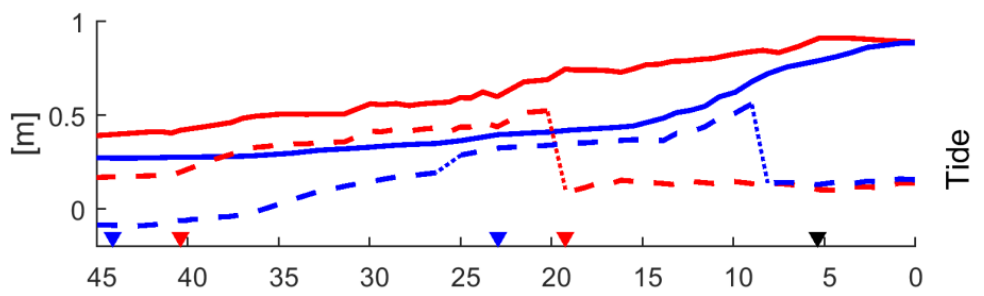

d)
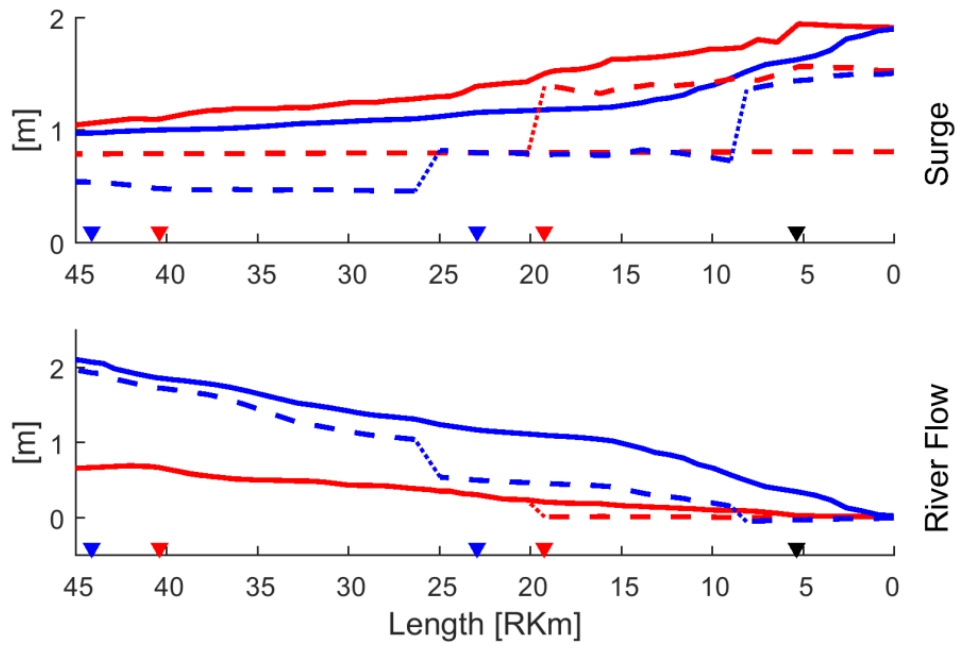

- Mod. - His.

Figure 4-12: Comparison of spatial pattern of (a) TWL, (b) tide, (c) surge, and (d) river flow during hurricane Irma 2017 under modern (red) and historic (blue) configurations.

In Figure 4-12, the amplitude of total water level (TWL) along the SJRE during Irma 2017 is shown. Color coding represents the timing of maximum TWL relative to maximum TWL at ocean boundary $(\mathrm{Rkm} 0)$ and shows that there are step function 
changes in the timing of peak TWL. A comparison of the modern and historical TWL demonstrates the magnitude of change over the past century. Maximum TWL at Jacksonville is $1.6 \mathrm{~m}$ for modern and $2.45 \mathrm{~m}$ for historic configuration. There is an approximately $3 \mathrm{hr}$ delay in timing of peak TWL for the historic event relative to modern configuration.

The solid lines is Figure $4-12 b, c, d$ show the theoretical max of tide, surge, and river flow, respectively which result in HTWL while the dashed lines are the actual modeled contribution to peak TWL. The effect of river discharge on historical and modern water levels along the SJRE is shown in Figure 4-12d. Maximum river flow effect shows a $60 \%$ decrease from $\sim 2 \mathrm{~m}$ in historic to $\sim 0.8 \mathrm{~m}$ in modern configuration at Jacksonville while the effects of peak tide and surge have amplified from $0.28 \mathrm{~m}$ historic to $0.4 \mathrm{~m}$ modern and from $1 \mathrm{~m}$ historic to $1.1 \mathrm{~m}$ modern, respectively.

Evaluating the significance of each factor into peak TWL shows that river flow effect increases along the channel from $\sim 0 \mathrm{~m}$ in Mayport (Rkm 5.2) to $\sim 0.67 \mathrm{~m}$ in Jacksonville ( $\mathrm{Rkm}$ 40.4) in the modern configuration while there is a much bigger change in historic configuration with $\sim 1.94 \mathrm{~m}$ increase from Mayport to Jacksonville (Figure 4$13)$.

Model runs also suggest that a deeper system will produce a greater surge for the same meteorological forcing which is applied as boundary condition (Figure 4-13). For the modern model, storm surge at Jacksonville is modeled to be $0.83 \mathrm{~m}$, or about $50 \%$ of peak flood $(1.7 \mathrm{~m})$ observed (Figure 4-13c). By contrast, the modeled storm surge at 
Jacksonville with historic bathymetry is $0.54 \mathrm{~m}$, or about $23 \%$ of peak flood $(2.39 \mathrm{~m})$ (Figure 4-13d). Overall, tide and surge heights at Jacksonville increased between the 1889 and 2017 models, while river flow heights decreased. This creates a complicated situation in which flood risk changes over time due to different parameters.

a)

$$
\text { Modern - MP - TWL=1.67 m }
$$

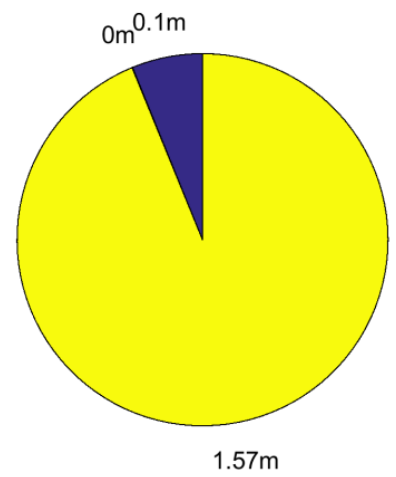

$$
\text { Historic }- \text { MP }- \text { TWL }=1.55 \mathrm{~m}
$$

b)

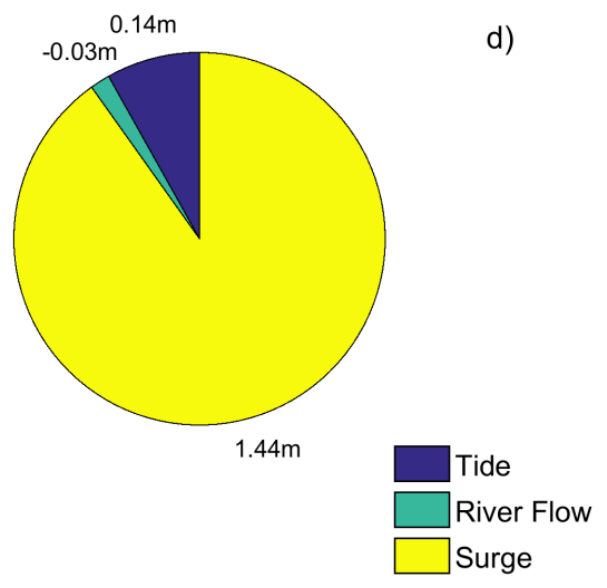

Modern - JX - TWL=1.7 m

c)

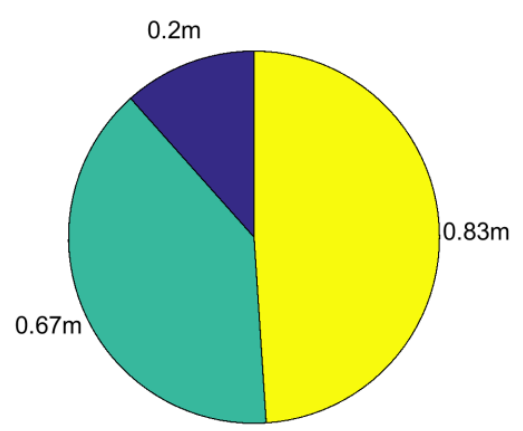

Historic $-\mathrm{JX}-\mathrm{TWL}=2.39 \mathrm{~m}$

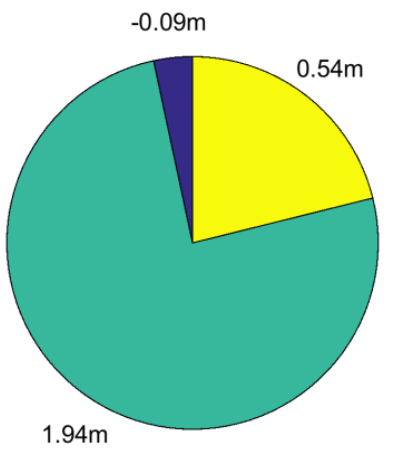

Figure 4-13: Modeled contribution of tide, surge, and river flow into peak TWL at Mayport (MP) and Jacksonville (JX) for historic and modern configuration. 


\subsection{Sensitivity to Timing and Amplitude of Peak Flow}

I obtained river hydrograph (Figure 4-14) from USGS station (Gauge No= 02246500) in Jacksonville (labeled as AB, see Figure 4-8) that is a combination of wind, circulation, and river flow effects. Figure 4-14 shows the measured river discharge at AB; it confirms that the river is tidally dominant. There is a change in the direction (i.e., from negative to positive) of the flow which results when storm surge flow reaches the gauge. The measured discharge includes tides, storm surge, local wind effect, and precipitation, therefore I use harmonic analysis to remove tidal flow signal from the total measured flow and estimate river flow. The effects of wind and precipitation remain in the flow estimate.

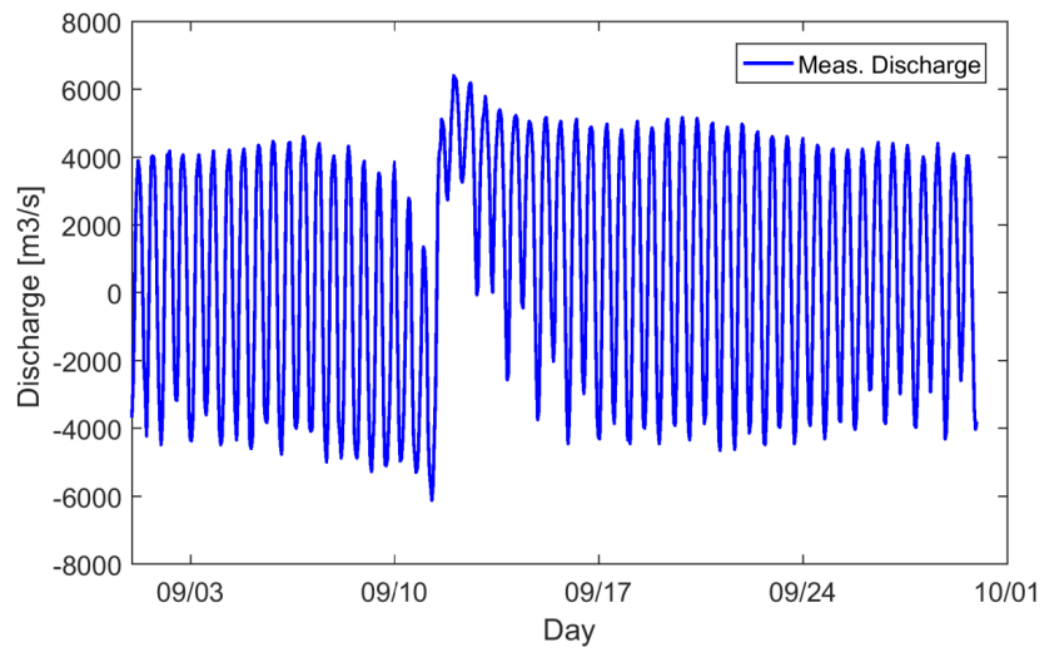

Figure 4-14: St. Johns hourly river discharge at Acosta Bridge (AB), negative value is toward upstream and positive is toward the ocean. 
Figure 4-15 shows hourly river flow at Jacksonville in red circles and a Gaussian fit. I assess the effects of magnitude of river flow and timing of its peak on amplitude of TWL and river flow by running the model with the Gaussian fit with peak flow ranging from $2 \mathrm{~km}^{3} / \mathrm{s}-10 \mathrm{~km}^{3} / \mathrm{s}$ and $+/-12$ hourly shifted increments.

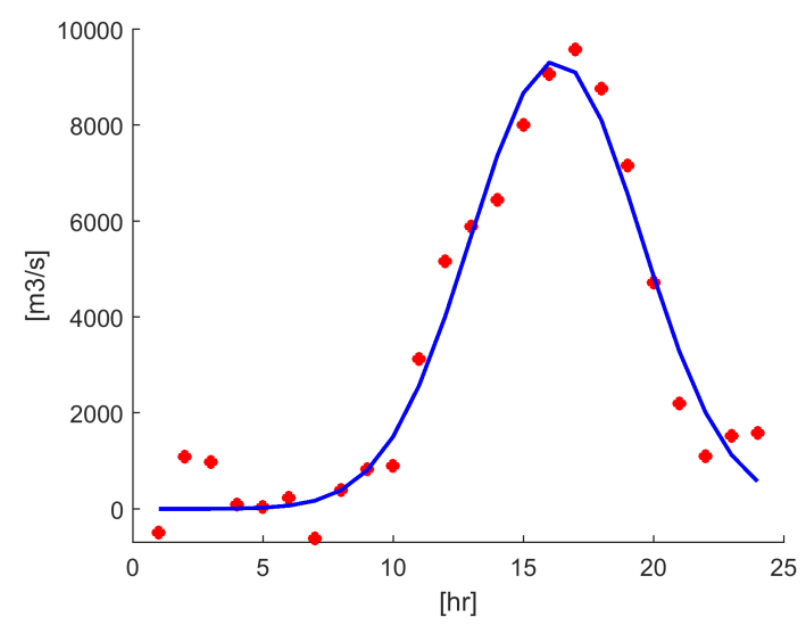

Figure 4-15: Flow at Jacksonville (red dots) and Gaussian estimate (blue line) after removing tidal flow from total measured flow, day hour of 2017/9/11.

The effects of river flow discharge on historical and modern water levels along the channel are shown graphically in Figure 4-16 and 4-17 as a function of river $\mathrm{km}$. The fill area in Figure 4-16 corresponds to the effects of time of backwater reaches Jacksonville with respect to the time of maximum surge amplitude at Jacksonville (2017/9/11-12:00 GMT). It highlights the importance of river discharge and its contribution to TWL. Sensitivity studies show that moving the timing of peak river flow $+/-12 \mathrm{hr}$ relative to the time of maximum surge at Jacksonville causes very large changes in the amplitude of TWL, and in river flow effects at Jacksonville for modern 120 
configuration than for the historic model (Figure 4-16a, d). Historically, when the peak of river flow happens within $+/-12 \mathrm{hr}$ of the time of maximum surge, this causes a $\sim 0.7 \mathrm{~m}$ rise of TWL at Jacksonville (2.75m to $3.45 \mathrm{~m})$. The historic configuration is less sensitive to the timing of river flood peak (Figure 4-16a), while it is more sensitive than the modern model to the amplitude of the flow (Figure 4-17a). Overall, modeled TWL at Jacksonville increased for historic and modern configuration for all timing scenarios. 
a)

b)

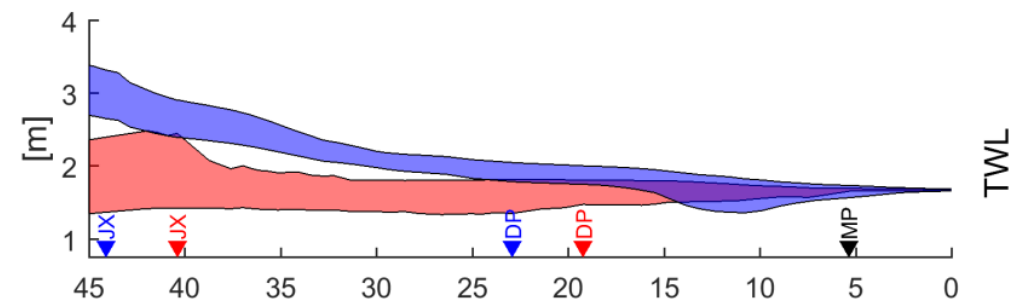

c)

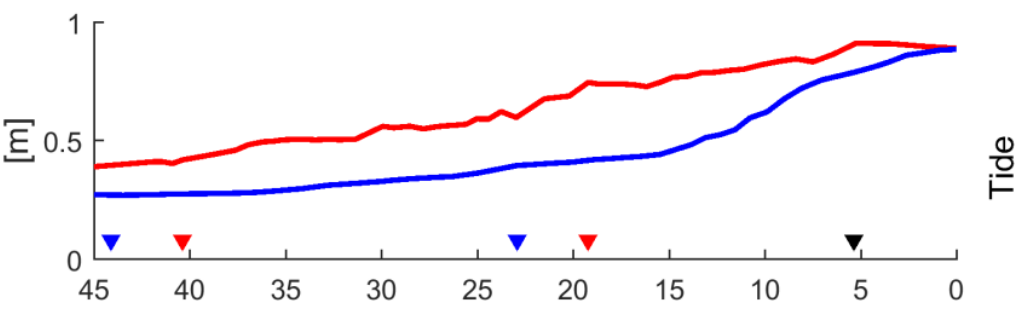

d)
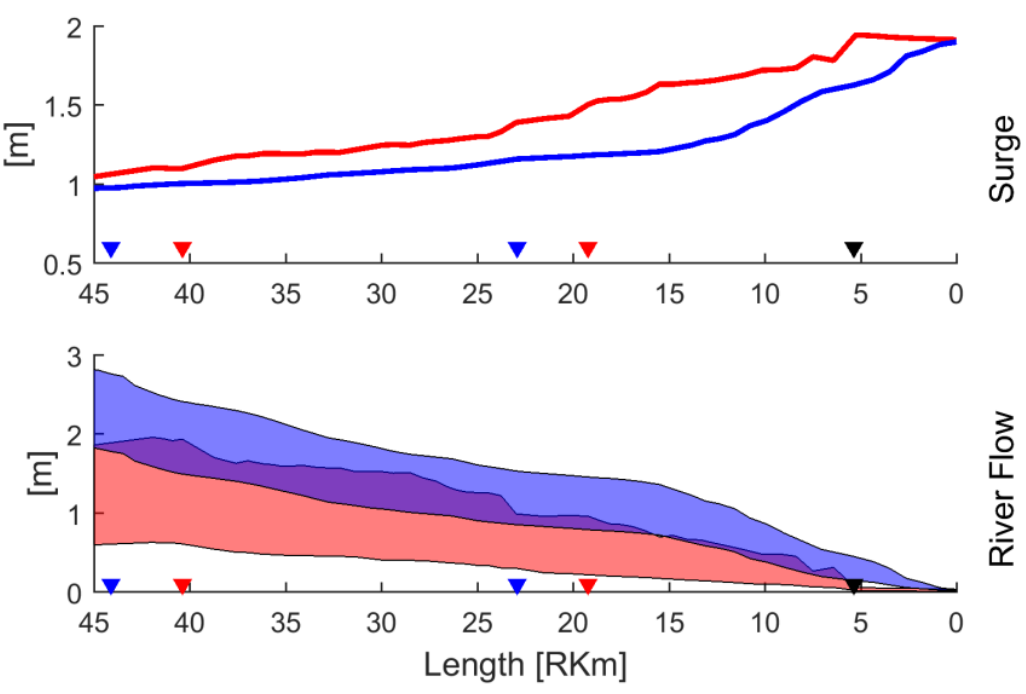

$\square$ Mod. $\square$ His.

Figure 4-16: The effects of timing of river flow max peak $\left(10 \mathrm{~km}^{3} / \mathrm{s}\right)$ on TWL components along the channel for modern (red) and historic (blue) configuration. The fill areas represent the range of results obtained from changing the timing of peak river flow $+/-12 \mathrm{hr}$ relative to the time of maximum surge. 
a)

b)

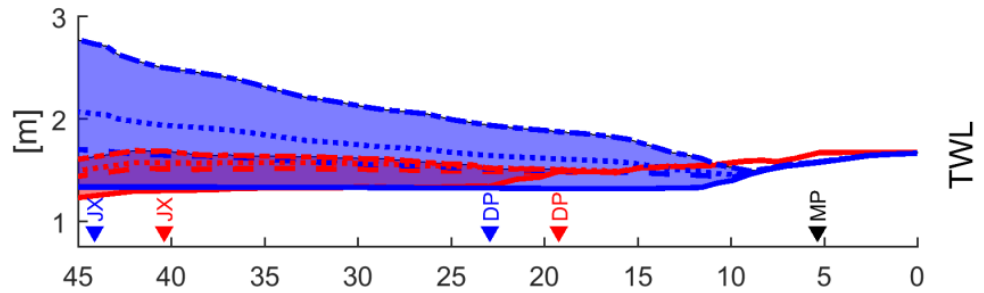

c)

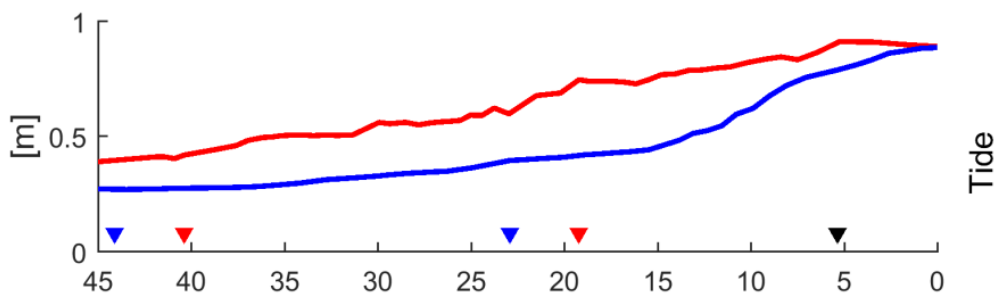

d)
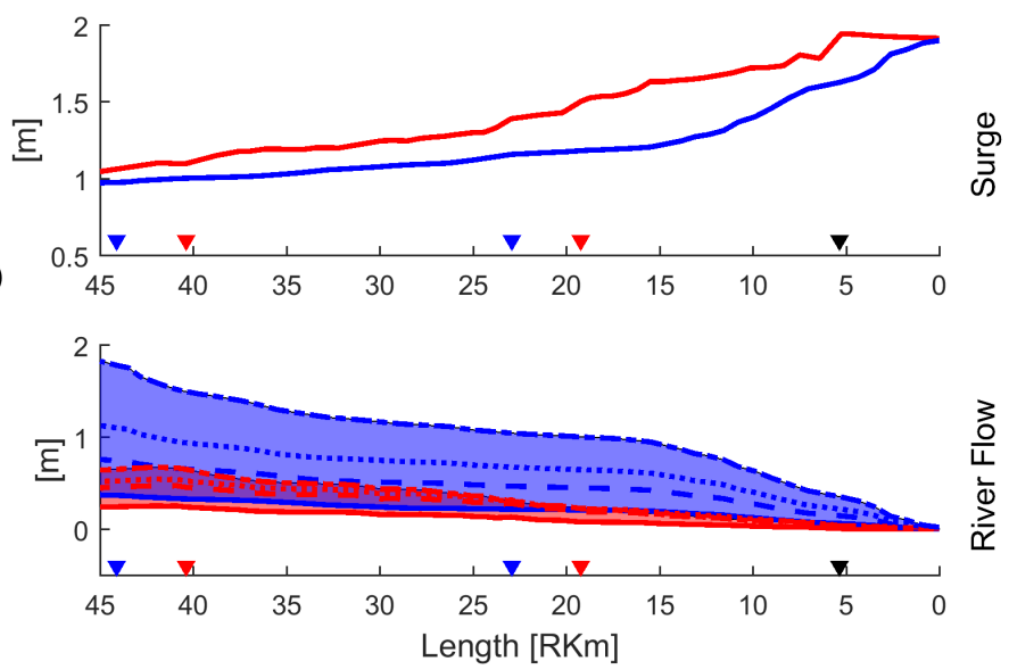

$\square$ Mod. $\square$ His.

Figure 4-17: The effects of river flow magnitude $\left(2 \mathrm{~km}^{3} / \mathrm{s}-10 \mathrm{~km}^{3} / \mathrm{s}\right)$ on TWL components along the channel for modern (red) and historic (blue) configuration.

The historic model shows more sensitivity to changes in the magnitude of river flow than the modern model. The historic TWL increases from $\sim 1.35 \mathrm{~m}$ to $2.8 \mathrm{~m}$ at Jacksonville for increase of river flow from $2 \mathrm{~km}^{3} / \mathrm{s}$ to $10 \mathrm{~km}^{3} / \mathrm{s}$, while the modern TWL 
only increases $\sim 0.4 \mathrm{~m}(1.2 \mathrm{~m}$ to $1.6 \mathrm{~m})$. Furthermore, my analytical model (see section 4.3 ) suggest that for higher flows, the slope of peak water level has decreased over time, which is a sign of reduced friction and therefore reduce in the rate of water level increase. In other words, less surface slope is needed to drive the water down the river and balance the Equation 4-4. Sensitivity studies show that river flow has an important effect on historic TWL amplitudes along the channel (Figure 4-17). For example, river flow effects contribute about $30-67 \%$ of TWL at Jacksonville for increasing river flow $\left(2-10 \mathrm{~km}^{3} / \mathrm{s}\right)$. Therefore, increase in river flow effects due to larger floods result in a larger possible TWL.

The numerical modeling results support the hypothesis that significant change has occurred in tides, surge, and river flow amplitudes due to channel deepening. Furthermore, historic bathymetry (shallow channel) is more sensitive to river flow effects while in the modern model tide and surge amplitudes have amplified over time.

\subsection{Conclusion}

Human activities, such as deepening of navigation channels can significantly alter the tidal and surge dynamics in estuaries (e.g., by increasing tide and surge amplitudes in landward areas). Alternatively, channel deepening can help to reduce the effects of flooding by reducing the average river slope in an estuary. Therefore, the spatial contribution of compound flooding in estuaries is important to investigate. In this study I have applied a new river-tide-surge analytical model to investigate the propagation of 
water waves along idealized estuaries. I investigate the effects of channel depth, convergence length scale, surge time scale, and river discharge on surge tide amplitudes along an estuary. I show that the rate of damping in storm tide is sensitive to fluctuations of river discharge, alterations in the surge time scale, and channel geometry changes (depth and width). Analytical model results are verified by numerically analyzing a case study of SJRE and hurricane Irma 2017. Model results suggest that storm tide effects have fewer effects on TWL during hurricane Irma that river flow which has amplified more by deepening the channel. I show that storm tide and surge has increased over time by mainly deepening the channel while more efficient (deeper) channel causes less river flood for the same river discharge. Therefore, the flood risk at a location along an estuary is a combination of reduced river flood risk and increased storm tide risk. 


\section{Chapter 5 Concluding Remarks and Future Directions}

In this study I have developed novel analytical and numerical modeling approaches to investigate the effects of altered bathymetric conditions, surge characteristics, and river discharge on storm surge and tidal properties in estuaries. Specifically, I develop idealized analytical and numerical models to investigate secular trends of tides and storm surge and investigate the mechanism of river-surge-tide dynamics in estuaries with altered bathymetric conditions, such as the Cape Fear River Estuary, NC (CFRE) and the St Johns River Estuary, FL (SJRE). I use the results of this study to establish that insights into storm surge waves can be found using the tools and methods of tidal analysis and tidal theory. Therefore, local changes of estuaries can alter both tides and storm surges magnitudes, in a spatially variable way.

Each of the previous chapters contributes to understanding the interaction of tide, surge, and river discharge in estuaries and provides guidance for development of coastal protection policies and natural hazards management. Chapter 2 demonstrates a numerical modeling of coastal storm surge and focuses on storm tide and surge changes in Wilmington, NC over the past 130 years. Results of sensitivity studies using idealized, parametric tropical cyclones suggest that the storm surge in the worst-case (CAT-5) event may have increased from $3.8 \pm 0.25 \mathrm{~m}$ to $5.6 \pm 0.6 \mathrm{~m}$ since the nineteenth century. 
Findings of this study also suggest that increased channel depths are the primary cause of altered tidal and surge wave dynamics. Model results demonstrate that channel deepening from $7 \mathrm{~m}$ (1888 condition) to $15.5 \mathrm{~m}$ (modern condition) has increased the conveyance of tides and surge into the system, which increases the risk of flood upstream of the estuary. This chapter also highlights the possibility of using tidal analysis tools to investigate changes in dynamical properties of storm surge to better understand of major causes of increased extreme water levels risk. Therefore, I develop an idealized river-tide-surge analytical model following widely used tidal propagation equations to investigate the importance of surge characteristics and channel depth in surge and tidal wave propagation (Chapter 3).

In Chapter 3, I develop an idealized analytical model and compare results against a conceptual numerical model (Delft-3D). Three sinusoidal waves are used in the analytical model; two represent surge wave while the third sine wave is the dominant semi-diurnal tide. This model is applied to understand how surge amplitude, surge time scale, surge wave asymmetry, and surge-tide relative phase affect the spatial pattern of surge amplitude growth and decay, and how depth changes influence the magnitude of storm surge. I also use non-dimensional numbers that represent the effect of change in bed friction, geometry (e.g., channel depth and convergence length scales), wave characteristics (e.g., amplitude and time scale) to interpret the results and show the important parameters that alter the storm surges. 
The along channel rate of damping is sensitive to fluctuations in the variables discussed in Table 3-1. Sensitivity studies show that surges with larger primary amplitudes (or shorter time scales) damp faster than those with smaller amplitudes (or larger timescales) (Figure 3-7, 3-8). Model results show that increased depth (equivalent to reduced bottom friction) can amplify the surge in estuaries. Moreover, results show that the time scale and amplitude of surge strongly affect the tidal propagation in an idealized estuary (Figure 3-9). Further, the relative phase of surge to tide and surge asymmetry can change the spatial location of maximum change in surge (see Figure 310); the maximum change occurs further upstream for a deeper channel than a shallow channel. Therefore, strongly dissipative and weakly convergent estuaries are vulnerable to increased flooding, with a spatial variability that is a function of system geometry and surge characteristics. Finally, the location of maximum change in surge amplitudes moves landward as the channel deepens due to nonlinear friction, which shows that flood risk has changed over time for specific locations. Thus, spatial scale alteration in local storm surge dynamics over the past century is plausible and should be considered in system management.

Chapter 4 builds on the research from Chapter 3. It uses the analytical model to investigate the importance of river discharge, convergence length, and surge time scale on peak water level and to determine the contribution of tide, surge, and river flow to TWL. Idealized model sensitivity studies imply that increasing the river discharge relative to the $M_{2}$ velocity reduces the amplification of surge wave (Figure 4-4). Model 
results also suggest that there is a location landward of which river flow effects outweigh tide and surge amplifying due to channel deepening. Moreover, this location moves toward the ocean as the channel deepens or surge time scale increases (Figure 4-5). I use numerical analysis of hurricane Irma in the SJRE to show the spatial pattern of TWL, tide, river flow, and surge along the estuary (Figure 4-12). Numerical model results show that maximum river flow effect has decreased by $60 \%$ at Jacksonville while the effects of peak tide and surge have amplified by $40 \%$ (from $0.28 \mathrm{~m}$ to $0.4 \mathrm{~m}$ ) and $10 \%$ (from $1 \mathrm{~m}$ to $1.1 \mathrm{~m})$ from historic to modern configuration, respectively.

Moreover, numerical model results confirm the analytical model results that show depth changes produce amplifying effect on tides and surge while reduce the amplitudes of river flood effects. The non-dimensional friction number $\left(\psi=\frac{C_{d} \xi \omega^{2} L_{e}^{3}}{g D^{3}}\right.$, see Chapter 3) helps to explain the analytical model results (see Figure 4-6). This number suggests that increases in surge wave time scale $\left(T=\frac{1}{\omega}\right)$ have a similar influence on the spatial damping of surge as the depth. Combining analytical and numerical results can help to better understand the interactions of contributed factors in peak water level and their changes over time under anthropogenic changes of systems.

The analytical model developed here includes river discharge and three sinusoidal waves. It performs well in a wide range of estuary types (strongly and weakly convergent estuaries with different channel depth). Therefore, it provides direct insight into nonlinear interactions of tides, surge, and river discharge and is an important tool to give insight into the inner functioning of an idealized hydrodynamic system. In conclusion, this study 
increases understanding of long-term bathymetric changes and surge characteristics on river-surge-tide interactions analyzing historical data and idealized analytical and numerical models to elucidate system sensitivities.

There are several questions that remain to be answered. For example, what is the effect of partial reflection in highly convergent estuaries? What is the impact of losing wetlands and intertidal areas on storm tide and surge? Future studies are necessary to explore the possibility of analytical models to answer these questions as well as numerical models. Due to simplifying assumptions of analytical models (e.g., small amplitude relative to depth, no variations in depth), numerical models should be used for further study of complex factors such as strong variations in depth and width. Future analytical studies can include varying depth geometry and interactions of different diurnal/semidiurnal tidal constituents to better reflect the non-linear interactions of tides and surge wave. I neglect overland flood, stratification effects, and the Coriolis acceleration in the analytical model, all of which could be included in future studies. 


\section{References}

Arns, A., S. Dangendorf, J. Jensen, S. Talke, J. Bender, and C. Pattiaratchi (2017), Sealevel rise induced amplification of coastal protection design heights, Sci. Rep., 7, art. no. 40171. https://doi.org/10.1038/srep40171.

Becker, M. L., Luettich, R. a., \& Mallin, M. a. (2010). Hydrodynamic behavior of the Cape Fear River and estuarine system: A synthesis and observational investigation of discharge-salinity intrusion relationships. Estuarine, Coastal and Shelf Science, 88(3), 407-418. http://doi.org/10.1016/j.ecss.2010.04.022

Bertin, X., N. Bruneau, J.-F. Breilh, A. B. Fortunato, and M. Karpytchev (2012), Importance of wave age and resonance in storm surges: The case Xynthia, Bay of Biscay, Ocean Modell.,42,16-30, doi:10.1016/j. ocemod.2011.11.001

Booij, N., R. C. Ris, and L. H. Holthuijsen (1999), A third-generation wave model for coastal regions: 1. Model description and validation, J. Geophys. Res., 104(C4), 7649-7666, doi:10.1029/98JC02622.

Brandon, C.M.; Woodruff, J.D.; Donnelly, J.P., and Sullivan, R.M., 2014. How unique was Hurricane Sandy? Sedimentary reconstructions of extreme flooding from New York Harbor. Scientific Reports, http://dx.doi.org/10.1038/srep07366 
Buschman, F. A., A. J. F. Hoitink, M. Van Der Vegt, and P. Hoekstra (2009), Subtidal water level variation controlled by river flow and tides, Water Resour. Res., 45, W10420, doi:10.1029/2009WR008167.

Cai, H., H. H. G. Savenije, and M. Toffolon (2012), A new analytical framework for assessing the effect of sea-level rise and dredging on tidal damping in estuaries, J. Geophys. Res., 117, C09023, doi:10.1029/2012JC008000.

Cai, H., H. H. G. Savenije, and M. Toffolon (2014), Linking the river to the estuary: influence of river discharge on tidal damping, Hydrol. Earth Syst. Sci., 18(1), 287304, doi:10.5194/hess-18-287-2014.

Cameron, W. M. and D. W. Pritchard (1963) Estuaries. In M. N. Hill (editor), The Sea, Vol. 2. John Wiley \& Sons, New York, 306-324.

Chant, R. J., Sommerfield, C. K., \& Talke, S. A. (2018). Impact of Channel Deepening on Tidal and 608 Gravitational Circulation in a Highly Engineered Estuarine Basin. Estuaries and Coasts, 1-14. 609 https://doi.org/10.1007/s12237-018-0379-6

Chernetsky, A. S., Schuttelaars, H. M., \& Talke, S. A. (2010). The effect of tidal asymmetry and temporal settling lag on sediment trapping in tidal estuaries. Ocean Dynamics, 60(5), 1219-1241. http://doi.org/10.1007/s10236-010-0329-8

Church J.A., White N.J. (2011) Sea-level rise from the late 19th to the early 21 st century. Surveys in Geophysics 32 (4-5), 585-602 doi:10.1007/s10712-011-9119-1 
Climate Change Science Program Synthesis and Assessment Product 4-7 (2008), Impacts of climate change and variability on transportation systems and infrastructure: Gulf coast study.

Colle, B. a. (2003). Numerical Simulations of the Extratropical Transition of Floyd (1999): Structural Evolution and Responsible Mechanisms for the Heavy Rainfall over the Northeast United States. Monthly Weather Review, 131(12), 29052926.http://doi.org/10.1175/1520-0493(2003)131<2905:NSOTET> 2.0.CO;2

Dangendorf, S., Calafat, F. M., Arns, A., Wahl, T., Haigh, I. D., \& Jensen, J. (2014). Mean sea level variability in the North Sea: Processes and implications. Journal of Geophysical Research: Oceans, 119, 6820-6841. https://doi.org/10.1002/2014JC009901

de Jonge, V.N., Schuttelaars, H.M., van Beusekom, J.E.E., Talke, S.A. \& de Swart, H.E., 2014. The influence of channel deepening on estuarine turbidity levels and dynamics, as exemplified by the Eems estuary. Estuarine, Coastal and Shelf Science 139: 46-59.

DiLorenzo, J. L., Huang, P., Thatcher, M. L., and Najarian, T. O. (1993). "Dredging impacts of Delaware estuary tides." Proc. 3rd Int. Conf. Sponsored by the Waterway, Port, Coastal and Ocean Division, ASCE Estuarine and Coastal Modeling III, Oak Brook, IL, 86-104. 
Divoky, D., R. Battalo, R. Dean, I. Collins, D. Hatheway, and N. Scheffner (2005), Storm meteorology: FEMA coastal flood hazard analysis and mapping guidelines focused study report, 31 pp., Fed. Emerg. Manage. Agency, Washington, D. C.

Donelan, M. a., Haus, B. K., Reul, N., Plant, W. J., Stiassnie, M., Graber, H. C., Saltzman, E. S. (2004). On the limiting aerodynamic roughness of the ocean in very strong winds. Geophysical Research Letters, 31(18), 1-5. http://doi.org/10.1029/2004GL019460

Doocy S, Daniels A, Murray S, Kirsch TD (2013). The Human Impact of Floods: a Historical Review of Events 1980-2009 and Systematic Literature Review. PLOS Currents Disasters.

Doodson A. T. (1956), Tides and storm surge in a long uniform gulf. Proceedings of the RoyalSociety of London, A237, 325-343.

Dronkers, J. J. (1964), Tidal Computations in Rivers and Coastal Waters, North-Holland, New York, 296-304.

Familkhalili, R. and Talke, S., (2016): The Effect of Channel Deepening on Storm Surge: Case Study of Wilmington, NC, Geophysical Research Letters. 43, 9138-9147.

Familkhalili, R. and Talke, S., Jay, D. (2019): Tide-Storm Surge Interactions in Highly Altered Estuaries: How Channel Deepening Increases Surge Vulnerability, Submitted. 
Friedrichs, C. T., and Aubrey, D. G. (1994), Tidal propagation in strongly convergent channels. Journal of Geophysical Research, 99(C2), 3321-3336. http://doi.org/10.1029/93JC03219

Friedrichs, C. T., and D. G. Aubrey, Nonlinear tidal distortion in shallow well-mixed estuaries: A synthesis, Estuarine Coastal Shelf Sci., 26, 521-545, 1988

Garel, E. and Cai, H.: Effects of Tidal-Forcing Variations on Tidal Properties Along a Narrow Convergent Estuary, Estuar. Coast, https://doi.org/10.1007/s12237-0180410-y,2018.

Geyer, W. R., and P. MacCready, 2014: The estuarine circulation. Annu. Rev. Fluid Mech., 46, 175-197, doi:10.1146/annurev-fluid-010313-141302.

Giese, B. S., and D. A. Jay (1989), Modeling tidal energetics of the Columbia River estuary, Estuarine Coastal Shelf Sci., 29(6), 549-571, doi:10.1016/02727714(89)90010-3.

Giese, G. L., H. B. Wilder, and G. G. Parker (1985), Hydrology of major estuaries and sounds of North Carolina, United States Geological Survey Water-Supply, (8.1).

Global Climate Change Impacts in the United States, Thomas R. Karl, Jerry M. Melillo, and Thomas C. Peterson, (eds.). Cambridge University Press, 2009

Godin, G. (1985), Modification of rivertides by the discharge, J. Waterway, Port, Coastal, Ocean Eng., 1985, 111(2): 257-274

Godin, G. (1999), The propagation of tides up rivers with special considerations on the upper Saint Lawrence River, Estuarine, Coastal and Shelf Science, 48, 307 - 324. 
Godin, G. (1991a), Compact approximations to the bottom friction term for the study of tides propagating in channels. Continental Shelf Research 11 (7), 579-589.

Godin, G. (1991b), Frictional Effects in River Tides. In Tidal Hydrodynamics (Parker, B. B., eds). John Wiley \& Sons, New York, pp. 379-402.

Godin, G., Martinez, A., (1994): Numerical experiments to investigate the effects of quadratic friction on the propagation of tides in a channel, Continental Shelf Research, Vol. 14, No. 7•8, pp. 723-748, 1994

Godin and Gutierrez (1986), Non-linear effects in the tide of the Bay of Fundy, Continental Shelf Research, 5 (1986), pp. 379-402

Graumann et al. (2006). Hurricane Katrina: A Climatological Perspective, 1-28. Retrieved from papers2://publication/uuid/1C0C5002-0416-4F9C-B41D$215836514 \mathrm{~F} 75$.

Grinsted, A., J. C. Moore, and S. Jevrejeva (2012), Homogeneous record of Atlantic hurricane surge, Proc. Natl. Acad. Sci. U.S.A., 109(48), 19,513-19,514, doi:10.1073/pnas.1216735109.

Hansen, D. V., and M. Rattray (1966), New dimensions in estuary classification, Limnol. Oceanogr. 11, $319-326$.

Hoitink, A. J. F., and D. A. Jay (2016), Tidal river dynamics: Implications for deltas, Rev. Geophys., 54, 240-272, doi:10.1002/2015RG000507.

Holland, G. J. (1980), An analytic model of the wind and pressure profiles in hurricanes, Mon. Weather Rev., doi:10.1175/1520-0493, 108<1212:AAMOTW>2.0.CO;2. 
Holleman, R.C., and M.T. Stacey (2014), Coupling of Sea Level Rise, Tidal Amplification and Inundation. Journal of Physical Oceanography, 44: 1439-1455.

Horsburgh, K. J., and C. Wilson (2007), Tide-surge interaction and its role in the distribution of surge residuals in the North Sea, J. Geophys. Res., 112, C08003, doi:10.1029/2006JC004033.

Holland, G. J., and P. J. Webster (2007), Heightened tropical cyclone activity in the North Atlantic: Natural variability or climate trend?, Philos. Trans. R Soc. A., 365(1860), 2695-2716.

Horrevoets, A., H. Savenije, J. Schuurman, and S. Graas (2004), The influence of river discharge on tidal damping in alluvial estuaries, J. Hydrol., 294(4), 213-228.

Hurricane Research Division, Atlantic Oceanographic and Meteorological Laboratory (AOML), 2014.

Hulme, P. E. (2009). Trade, transport and trouble: Managing invasive species pathways in an era of globalization. Journal of Applied Ecology, 46, 10-18. https://doi.org/10.1111/j.1365-2664.2008.01600.

Hsu, S. a, \& Yan, Z. (1998). A Note on the Radius of Maximum Wind for Hurricanes. Journal of Coastal Research, 14(2), 667-668. Retrieved from http://www.jstor.org/stable/4298820.

Ianniello, J. P., Tidally induced residual currents in estuaries of constant breadth and depth, J.Mar.Res.,35,755-785,1977 
Ikeuchi, H., Y. Hirabayashi, D. Yamazaki, S. Muis, P. J. Ward, H. C. Winsemius, M. Verlaan, and S. Kanae (2017), Compound simulation of fluvial floods and storm surges in a global coupled river-coast flood model: Model development and its application to 2007 Cyclone Sidr in Bangladesh, J. Adv. Model. Earth Syst., 9, 1847-1862, doi:10.1002/2017MS000943.

IPCC Climate change 2007: The Physical Science Basis. Contribution of Working Group I to the Fourth Assessment Report of the IPCC, (eds. Solomon, S., Qin, D., Manning, M., Chen, Z., Marquis, M., Averyt, K.B., Tignor, M. and Miller, H.L.). Cambridge University Press, Cambridge.

Ippen, A. T. and Harleman, D. R. F. 1961. One dimensional analysis of salinity intrusion in estuaries. Tech. Bull. 5, Comm. Tidal Hydraul., U.S. Army Corps of Engineers.

Jarosz, E., Mitchell, D. A., Wang, D. W., \& Teague, W. J. (2007). Bottom-Up Determination of Air-Sea Momentum Exchange Under a Major Tropical Cyclone, 557(March), 2005-2007.

Jay, D. A., and J. D. Smith (1990), Residual circulation in shallow estuaries. Highly stratified, narrow estuaries, J. Geophys. Res.,95(C1), 711-731, doi:10.1029/JC095iC01p00711.

Jay, D. (1991). Green's law revisited: Tidal long-wave propagation in channels with strong topography. Journal of Geophysical Research, 96(C11), 20585. http://doi.org/10.1029/91JC01633. 
Jay, D. A. (2009), Evolution of tidal amplitudes in the eastern Pacific Ocean, Geophys. Res. Lett., 36, L04603, DOI: 101029/2008GL036185.

Jay, D. A. and E. P. Flinchem (1997), Interaction of fluctuating river flow with a barotropic tide: A test of wavelet tidal analysis methods, J. Geophys. Res. 102: $5705-5720$.

Jay, D.A., K. Leffler, H.L. Diefenderfer, and A.B. Borde (2015), Tidal-Fluvial and Estuarine Processes in the Lower Columbia River: I. Along-Channel Water Level Variations, Pacific Ocean to Bonneville Dam, Estuaries and Coasts 38:415-433 DOI 10.1007/s12237-014-9819-0

Jay, D. A., K. Leffler and S. Degens (2011), Long-term evolution of Columbia River tides, ASCE Journal of Waterway, Port, Coastal, and Ocean Engineering, 137:182191; doi: 10.1061/(ASCE)WW.1943- 5460.0000082.

Kemp, A. C., and B. P. Horton (2013), Contribution of relative sea-level rise to historical hurricane flooding in New York City, J. Quat. Sci., 28(6), 537-541.

Kew, S. F., F. M. Selten, G. Lenderink, and W. Hazeleger (2013), The simultaneous occurrence of surge and discharge extremes for the Rhine delta, Nat. Hazards Earth Syst. Sci., 13(8), 2017-2029, doi:10.5194/nhess-13-2017-2013.

Klerk, W. J., H. C. Winsemius, W. J. van Verseveld, A. M. R. Bakker, and F. L. M. Diermanse (2015), The co-incidence of storm surges and extreme discharges within the Rhine-Meuse Delta, Environ. Res. Lett., 10(3), 035005, doi:10.1088/17489326/10/3/035005. 
Kulkulka, T. \& D.A. Jay, 2003a. Impacts of Columbia River discharge on salmonid habitat: 1. A nonstationary fluvial tidal model. Journal of Geophysical Research v108 No. C9, doi:10.1029/2002JC001382

Kulkulka, T. \& D.A. Jay, 2003b. Impacts of Columbia River discharge on salmonid habitat: 2. Changes in shallow-water habitat. Journal of Geophysical Research v108 No. C9, doi:10.1029/2002JC001829

Landsea, C. W., G. A. Vecchi, L. Bengtsson, and T. R. Knutson, 2010: Impact of duration thresholds on Atlantic tropical cyclone counts. J. Climate, 23,2508-2519, doi:10.1175/2009JCLI3034.1.

Lanzoni, S., and G. Seminara (1998), On tide propagation in convergent estuaries, J. Geophys. Res., 103, 30,793-30,812.

LeBlond, P. H. (1978), On tidal propagation in shallow rivers, Journal of Geophysical Research, 83, 4717-4721.

Lee, S. B., M. Li, and F. Zhang (2017), Impact of sea level rise on tidal range in Chesapeake and Delaware Bays, J. Geophys. Res. Oceans, 122, 3917-3938, doi:10.1002/2016JC012597.

Leffler, K.E., Jay, D.A., Enhancing tidal harmonic analysis: Robust (hybrid L1/L2) solutions. Continental Shelf Research (2009), doi: 10.1016/j.csr.2008.04.011.

Lin, N., K. Emanuel, M. Oppenheimer, and E. Vanmarcke (2012), Physically based assessment of hurricane surge threat under climate change, Nat. Clim. Change, 2, 462-467, doi:10.1038/nclimate1389. 
Lowery, T. A. 1992. Apalachicola Bay’s proclivity for sediment export during hurricanes and its impact on oyster production from 1960 to 1985. Journal of Shellfish Research 11:461-466.

Ludlam, D. M. (1963), Early American Hurricanes, 1492-1870, 198 pp., Am. Meteorol. Soc., Boston, Mass.

Mallin, M. a, Posey, M. H., Shank, G. C., Mciver, M. R., Ensign, S. H., \& Alphin, T. D. (1999). Hurricane Effects on Water Quality and Benthos in the Cape Fear Watershed : Natural and Anthropogenic Impacts Published by : Ecological Society of America Stable URL : http://www.jstor.org/stable/2641190, 9(1), 350-362.

Maskell, J., Horsburgh, K., Lewis, M., Bates, P., (2013), Investigating River-Surge Interaction in Idealised Estuaries. J. Coast. Res. 30, 248-259.

Mawdsley, R. J., I. D. Haigh, and N. C. Wells (2015), Global secular changes in different tidal high water, low water and range levels, Earth's Future, 1-16, doi:10.1002/2014EF000282.

Mei, W., C. Pasquero, and F. Primeau (2012), The effect of translation speed upon the intensity of tropical cyclones over the tropical ocean, Geophys. Res. Lett., 39, L07801, doi:10.1029/2011GL050765.

Merkens, J. L., Reimann, L., Hinkel, J. and Vafeidis, A. T., (2016), Gridded population projections for the coastal zone under the Shared Socioeconomic Pathways. Global Planet. Change 145, 57-66. 
McRobie, A., Spencer, T. and Gerritsen, H. 2005. The Big Flood: North Sea storm surge. Philosophical Transactions of the Royal Society, A, 363, 1263-1270, doi:10.1098/ rsta.2005.1567.

Moldwin, M. (2016), Tidal river dynamics, Eos, 97, https://doi.org/10.1029/ 2018EO049541. Published on 06 April 2016.

National Hurricane Center (NHC), 2018, The deadliest, Costliest, and Most Intense US Tropical Cyclones Report.

Neumann, J. E., Emanuel, K., Ravela, S., Ludwig, L., Kirshen, P., Bosma, K., \& Martinich, J. (2015). Joint effects of storm surge and sea-level rise on US Coasts: new economic estimates of impacts, adaptation, and benefits of mitigation policy. Climatic Change, 129(1-2), 337-349. http://doi.org/10.1007/s10584-014-1304-z

Nicholls, R. J., P. P. Wong, V. R. Burkett, J. O. Codignotto, J. E. Hay, R. F. McLean, S. Ragoonaden, and C. D. Woodroffe (2007), IPCC, Coastal systems and low-lying areas, in Climate Change 2007: Impacts, Adaptation and Vulnerability. Contribution of Working Group II to theFourth Assessment Report of the Intergovernmental Panel on Climate Change, edited by M. L. Parry, O. F. Canziani, J. P. Palutikof, P. J. van der Linden, and C. E. Hanson, pp. 315-356, Cambridge Univ. Press, Cambridge, U. K.

Olsen Associates Inc. (2012), Calibration of a Delft3D model for Bald Head Island and the Cape Fear River entrance phase 1, 6114(April). 
Orton, P., Georgas, N., Blumberg, A., \& Pullen, J. (2012), Detailed modeling of recent severe storm tides in estuaries of the New York City region. Journal of Geophysical Research: Oceans, 117(9), 1-17. http://doi.org/10.1029/2012JC008220

Orton, P. M., T. M. Hall, S. Talke, A. F. Blumberg, N. Georgas, and S. Vinogradov, 2016: A validated tropical-extratropical flood hazard assessment for New York Harbor. J. Geophys. Res. Oceans, 121, 8904-8929, doi:https://doi.org/10.1002/2016JC011679.

Orton, P., Talke, S., Jay, D., Yin, L., Blumberg, A., Georgas, N., Zhao, H., Roberts, H., MacManus, K. (2015). Channel Shallowing as Mitigation of Coastal Flooding. Journal of Marine Science and Engineering, 3(3), 654-673. http://doi.org/10.3390/jmse3030654

Parker, B. B., (1991).Tidal hydrodynamics. John Wiley and Sons, New York, pp. 237268.

Pasquier, U., He, Y., Hooton, S. et al. Nat Hazards (2018). https://doi.org/10.1007/ s11069-018-3462-1

Pawlowicz, R., Beardsley, B., and Lentz, S., "Classical tidal harmonic analysis including error estimates in MATLAB using T_TIDE", Computers and Geosciences 28 (2002), 929-937.

Peng, M., Xie, L., \& Pietrafesa, L. J. (2004). A numerical study of storm surge and inundation in the Croatan-Albemarle-Pamlico Estuary System. Estuarine, Coastal and Shelf Science, 59(1), 121-137. http://doi.org/10.1016/j.ecss.2003.07.010 
Powell, M. D., P. J. Vickery, and T. A. Reinhold (2003), Reduced drag coefficient for high wind speeds in tropical cyclones, Nature, 422(6929), 279-283, doi:10.1038/nature01481.

Pritchard, D. W. (1952), Estuarine hydrography, Adv. Geophys. 1, 243 - 280.

Pritchard, D. W. (1955), Estuarine circulation patterns, Proc. Am. Soc. Civil Eng. 81 (717), 1-11.

Prandle, D. (2003). Relationships between Tidal Dynamics and Bathymetry in Strongly Convergent Estuaries. Journal of Physical Oceanography, 33(12), 2738-2750. http://doi.org/10.1175/1520-0485(2003)033<2738:RBTDAB>2.0.CO;2

Prandle, D. (2009). Estuaries: Dynamics, Mixing, Sedimentation and Morphology. Cambridge University Press.

Prandle, D., and Rahman, M. (1980). Tidal response in estuaries. Journal of Physical Oceanography, 10(10), 1552-1573.

Prandle D, Wolf J (1978). The interaction of surge and tide in the North Sea and river Thames. Geophysical Journal of the Royal Astronomical Society 55: 203-216.

Proudman J (1955). The propagation of tide and surge in an estuary. Proc R Soc Lond A231: 8-24.

Pugh, D., and P. L. Woodworth (2014), Sea-level Science: Understanding Tides, Surges, Tsunamis and Mean Sea-level Changes, Cambridge Univ. Press, Cambridge, U.K. 
Ralston, D. K., Warner, J. C., Geyer, W. R., \& Wall, G. R., 2013. Sediment transport due to extreme events: The Hudson River estuary after tropical storms Irene and Lee. Geophysical Research Letters, doi:10.1002/2013GL057906

Ralston, D. K., Talke, S., Geyer, W. R., Al-Zubaidi, H. A. M., \& Sommerfield, C. K. (2019). Bigger tides, less flooding: Effects of dredging on barotropic dynamics in a highly modified estuary. Journal of Geophysical Research: Oceans, 124, 196-211. https://doi.org/10.1029/2018JC014313

Rego, J. L., \& Li, C. (2010). Nonlinear terms in storm surge predictions: Effect of tide and shelf geometry with case study from Hurricane Rita. Journal of Geophysical Research: Oceans, 115(6), 1-19. http://doi.org/10.1029/2009JC005285

Ross, A. C., Najjar, R. G., Li, M., Lee, S. B., Zhang, F., \& Liu, W. (2017). Fingerprints of sea level rise on changing tides in the Chesapeake and Delaware Bays. Journal of Geophysical Research: Oceans, 122. https://doi.org/10.1002/2017JC012887

Robinson, I.S., 1981. Tidal vorticity and residual circulation. Deep-Sea research, 28A(3):195-212.

Rumpf, J., Weindl, H., Höppe, P., Rauch, E., \& Schmidt, V. (2009). Tropical cyclone hazard assessment using model-based track simulation. Natural Hazards, 48(3), 383-398. http://doi.org/10.1007/s11069-008-9268-9

Sassi, M. G., and A. J. F. Hoitink (2013), River flow controls on tides and tide-mean water level profiles in a tidal freshwater river, J. Geophys. Res. Oceans, 118, 41394151, doi:10.1002/jgrc.20297. 
Savenije, H. H. G. (1998), Analytical expression for tidal damping in alluvial estuaries, J Hydraul Eng-Asce, 124(6), 615-618.

Savenije, H. H. G., M. Toffolon, J. Haas, and E. J. M. Veling (2008), Analytical description of tidal dynamics in convergentestuaries,J. Geophys. Res.,113, C10025, doi:10.1029/2007JC004408.

Schureman, P. (1934). Tides and currents in Hudson River (Vol. 180). Washington, DC: United States 688 Government Printing Office.

Shibayama, T.(2015), Field Surveys of Recent Storm Surge Disasters, Procedia Engineering, 116, 179-186. (Proceeding of the 8th International Conference on Asian and Pacific Coasts (APAC), IIT Madras, Chennai, India) doi:10.1016/j.proeng.2015.08.280

Shen, J., \& Gong, W. (2009). Influence of model domain size, wind directions and Ekman transport on storm surge development inside the Chesapeake Bay: A case study of extratropical cyclone Ernesto, 2006. Journal of Marine Systems, 75(1-2), 198-215. http://doi.org/10.1016/j.jmarsys.2008.09.001

Shen, J., Wang, H., Sisson, M., \& Gong, W. (2006). Storm tide simulation in the Chesapeake Bay using an unstructured grid model. Estuarine, Coastal and Shelf Science, 68(1), 1-16. http://doi.org/10.1016/j.ecss.2005.12.018

Sherwood, C.R., Jay, D A., Harvey, R.B., Hamilton, P., Simenstad, C.A. (1990), Historical changes in the Columbia River estuary, Progress in Oceanography 25, 299-352. 
Smith, S. D. (1980), Wind stress and heat flux over the ocean in gale force winds, J. Phys. Oceanogr., $\quad 10, \quad 709-726, \quad$ doi:10.1175/15200485(1980)010<0709>WSAHFO.2.0.CO;2.

Talke, S. a., \& Jay, D. a. (2013). Nineteenth Century North American and Pacific Tidal Data: Lost or Just Forgotten? Journal of Coastal Research, 29(6A), 118-127. http://doi.org/10.2112/JCOASTRES-D-12-00181.1

Talke, S. A., P. Orton, and D. A. Jay (2014), Increasing storm tides in New York Harbor, 1844-2013, Geophys. Res. Lett., 41, 3149-3155, doi:10.1002/2014GL059574.

Talke, S.A. \& D.A. Jay (2017). Archival Water-Level Measurements: Recovering Historical Data to Help Design for the Future. US Army Corps of Engineers: Civil Works Technical Series, Report CWTS-02, 49pp.

Talke, S.A., R. Familkhalili, D.A. Jay (2019). The influence of channel deepening on extreme water levels: case study of the St Johns River, FL, Submitted

Toffolon, M., and H. H. Savenije (2011), Revisiting linearized one-dimensional tidal propagation, J. Geophys. Res.,116, C07007,doi:10.1029/2010JC006616.

Tebaldi, C., Strauss, B. H., \& Zervas, C. E. (2012). Modelling sea level rise impacts on storm surges along US coasts. Environmental Research Letters, 7(1), 014032. http://doi.org/10.1088/1748-9326/7/1/014032

USACE COE, (1873), Report of the Secretary of War, Annual Report of the Chief of Engineers to the Secretary of War for the fiscal year ending June 30, 1873, Appendix T20-T21, U.S. Govt. Print. Off., Washington, D. C. 
USACE COE, (1915), Report of the Secretary of War, Annual Report of the Chief of Engineers for historical summary giving the scope of previous projects for the improvement of certain rivers and harbors, U.S. Govt. Print. Off., Washington, D.C.

United States Army Corps of Engineers, Jacksonville District, 2014. Final Integrated General Reevaluation Report II and supplemental Environmental Impact Statement. Jacksonville Harbor, Duval County, Florida.

Valle-Levinson, A. (2010), Definition and classification of estuaries, in Contemporary Issues in Estuarine Physics, edited by A. Valle-Levinson, pp. 1-10, Cambridge University Press, Cambridge, UK.

Van Dolah, R. F., and G. S. Anderson. 1991. Effects of Hurricane Hugo on salinity and dissolved oxygen conditions in the Charleston Harbor Estuary. Journal of Coastal Research 8:83-94.

Van Rijn, L., Grasmeijer, B. \& Perk, L. Ocean Dynamics (2018) 68: 1457. https://doi.org/10.1007/s10236-018-1204-2

Wahl, T., S. Jain, J. Bender, S. D. Meyers, and M. E. Luther (2015), Increasing risk of compound flooding from storm surge and rainfall for major US cities, Nat. Clim. Change,5(12), 1093-1097, doi:10.1038/NCLIMATE2736.

Wamsley, T. V., Cialone, M. a., Smith, J. M., Atkinson, J. H., \& Rosati, J. D. (2010). The potential of wetlands in reducing storm surge. Ocean Engineering, 37(1), 59-68. http://doi.org/10.1016/j.oceaneng.2009.07.018 
Welch, J. M., \& Parker, B. (1979). NOAA Technical Report - Circulation and Hydrodynamics of the Lower Cape Fear River, North Carolina, 1-18.

Wolf, J. and Flather, R. A. 2005. Modelling waves and surges during the 1953 storm. Philosophical Transactions of the Royal Society, A, 363, 1359-1375, doi:10.1098/rsta.2005.1572.

Wong, P. P., I. J. Losada, J.-P. Gattuso, J. Hinkel, A. Khattabi, K. L. McInnes, Y. Saito, and A. Sallenger (2014), Coastal systems and low-lying areas, in Climate Change 2014: Impacts, Adaptation, and Vulnerability, Part A: Global and Sectoral Aspects, Contribution of Working Group II to the Fifth Assessment Report of the Intergovernmental Panel on Climate Change, edited by C. B. Field et al., pp. 361409, Cambridge Univ. Press, Cambridge, U. K.

Woodworth, P. L., and D. L. Blackman, 2002: Changes in extreme high waters at Liverpool since 1768. Int. J. Climatol., 22, 697-714

Woodworth, P. L. (2010), A survey of recent changes in the main components of the ocean tide, Cont. Shelf Res., 30(15), 1680-1691, doi:10.1016/j.csr.2010.07.002.

WRI; UNEP; UNDP; World Bank; 1996. World resources 1996-97: a guide to the global environment - the urban environment. Washington, D.C.

Xia, M., Xie, L., Pietrafesa, L. J., \& Peng, M. (2008). A Numerical Study of Storm Surge in the Cape Fear River Estuary and Adjacent Coast. Journal of Coastal Research, 24(September 2006), 159-167. http://doi.org/10.2112/06-0795.1 
Yelland, M., \& Taylor, P. K. (1996). Wind Stress Measurements from the Open Ocean. Journal of Physical Oceanography. http://doi.org/10.1175/15200485(1996)026<0541:WSMFTO>2.0.CO;2

Zimmerman, J. T. F., 1978, Topographic generation of residual circulation by oscillatory tidal currents, Geophys. Astrophys. Fluid Dynamics, 11:35-47 


\section{Appendix A Riverine Tides Equation}

Here the integration of equations of motions is presented that will simplify the equations by vertically and sectionally integration to eliminate lateral and vertical terms. Since the channel flows are mainly along the channel axis the lateral and vertical terms could be neglected.

\section{A.1 Integral Mass Conservation}

Tide waves are described by the St. Venant equations in open channel flow systems from depth-integrating the Navier-Stokes equations. I start with the continuity equation (Equation A-1) for an incompressible flow and integrate laterally (Equation A2):

$$
\begin{gathered}
\frac{\partial u}{\partial x}+\frac{\partial v}{\partial y}+\frac{\partial w}{\partial z}=0 \\
\int_{b_{1}}^{b_{2}} \frac{\partial u}{\partial x} d y+\int_{b_{1}}^{b_{2}} \frac{\partial v}{\partial y} d y+\int_{b_{1}}^{b_{2}} \frac{\partial w}{\partial z} d y=0
\end{gathered}
$$

And then apply the Leibniz integral rule for each term of Equation (A-2): 
First term: $\quad \int_{b_{1}}^{b_{2}} \frac{\partial u}{\partial x} d y=\frac{\partial}{\partial x} \int_{b_{1}}^{b_{2}} u d y-u\left(b_{2}\right) \frac{\partial b_{2}}{\partial x}+u\left(b_{1}\right) \frac{\partial b_{1}}{\partial x}$

Second term:

$$
\int_{b_{1}}^{b_{2}} \frac{\partial v}{\partial y} d y=v\left(b_{2}\right)-v\left(b_{1}\right)
$$

Third term:

$$
\int_{b_{1}}^{b_{2}} \frac{\partial w}{\partial z} d y=\frac{\partial}{\partial z} \int_{b_{1}}^{b_{2}} w d y-w\left(b_{2}\right) \frac{\partial b_{2}}{\partial z}+w\left(b_{1}\right) \frac{\partial b_{1}}{\partial z}
$$

Substitute Equations (A-3to5) into equation (A-2) results in:

$$
\begin{aligned}
& \frac{\partial}{\partial x} \int_{b_{1}}^{b_{2}} u d y-u\left(b_{2}\right) \frac{\partial b_{2}}{\partial x}+u\left(b_{1}\right) \frac{\partial b_{1}}{\partial x}+v\left(b_{2}\right)-v\left(b_{1}\right)+\frac{\partial}{\partial z} \int_{b_{1}}^{b_{2}} w d y \\
& -w\left(b_{2}\right) \frac{\partial b_{2}}{\partial z}+w\left(b_{1}\right) \frac{\partial b_{1}}{\partial z}=0
\end{aligned}
$$

Then I apply the kinematic boundary conditions considering the lateral boundary condition that the flow cannot leave the side and is parallel to the wall.

$$
\begin{gathered}
\frac{D b_{2}}{D t}=v\left(b_{2}\right)=u\left(b_{2}\right) \frac{\partial b_{2}}{\partial x}+w\left(b_{2}\right) \frac{\partial b_{1}}{\partial z} \\
\frac{D b_{1}}{D t}=v\left(b_{1}\right)=u\left(b_{1}\right) \frac{\partial b_{1}}{\partial x}+w\left(b_{1}\right) \frac{\partial b_{1}}{\partial z} \\
\frac{\partial b_{1}}{\partial t}=\frac{\partial b_{2}}{\partial t}=0
\end{gathered}
$$

The laterally averaged results are as follow: 


$$
\begin{aligned}
& \frac{\partial}{\partial x} \int_{b_{1}}^{b_{2}} u d y+\frac{\partial}{\partial z} \int_{b_{1}}^{b_{2}} w d y=0 \\
& \frac{\partial(b\langle u\rangle)}{\partial x}+\frac{\partial(b\langle w\rangle)}{\partial z}=0
\end{aligned}
$$

Where the $<>$ represents the width averaged value. Now I integrate vertically (from depth $-h$ to the surface $\xi)$ and apply the Leibniz integral rule and boundary conditions:

$$
\int_{-h}^{\zeta} \frac{\partial(b\langle u\rangle)}{\partial x} d z+\int_{-h}^{\zeta} \frac{\partial(b\langle w\rangle)}{\partial z} d z=0
$$

First term: $\quad \int_{-h}^{\zeta} \frac{\partial(b\langle u\rangle)}{\partial x} d z=\frac{\partial}{\partial x} \int_{-h}^{\zeta} b\langle u\rangle d z-b\left(\left.u\right|_{\zeta}\right) \frac{\partial \zeta}{\partial x}+b\left(\left.u\right|_{-h}\right) \frac{\partial(-h)}{\partial x}$

Second term:

$$
\int_{-h}^{\zeta} \frac{\partial(b\langle w\rangle)}{\partial z} d z=b\left(\left.\langle w\rangle\right|_{\zeta}\right)-b\left(\left.\langle w\rangle\right|_{-h}\right)
$$

The kinematic boundary conditions:

$$
\begin{gathered}
b w(\zeta)=b \frac{D \zeta}{D t}=b \frac{\partial \zeta}{\partial t}+b u(\zeta) \frac{\partial \zeta}{\partial x} \\
\frac{\partial \zeta}{\partial y}=\frac{\partial\langle\zeta\rangle}{\partial y}=0
\end{gathered}
$$

No slip conditions:

$$
\left.w\right|_{-h}=\left.u\right|_{-h}=0
$$

Therefore, I can rewrite the Equation (A-11) as: 


$$
\begin{aligned}
& \frac{\partial}{\partial x} \int_{-h}^{\zeta} b\langle u\rangle d z+\left.b\right|_{\zeta} \frac{\partial \zeta}{\partial t}= \\
& \frac{\partial Q}{\partial x}+\left.b\right|_{\zeta} \frac{\partial \zeta}{\partial t}=0
\end{aligned}
$$

which means that along channel changes in water transport $\frac{\partial Q}{\partial x}$ will fill or empty the channel $\left.b\right|_{\zeta} \frac{\partial \zeta}{\partial t}$

\section{A.2 Integral Momentum Conservation}

In order to integrate the momentum equation along channel over the cross-section area for the purpose of analytical solution, I assume that the estuary is narrow which means; the external Kelvin number is $<<1$, various flow mechanisms are laterally uniform, and Coriolis force is neglected that means Rossby number is small. Consider the Navier-Stokes in $x$ direction:

$$
\frac{\partial u}{\partial t}+u \frac{\partial u}{\partial x}+v \frac{\partial u}{\partial y}+w \frac{\partial u}{\partial z}=-\frac{1}{\rho} \frac{\partial p}{\partial x}+v \nabla^{2} u
$$

where

$$
\nabla^{2} u=\frac{\partial^{2} u}{\partial x^{2}}+\frac{\partial^{2} u}{\partial y^{2}}+\frac{\partial^{2} u}{\partial z^{2}}
$$

Rewriting the Equation (A-15) for incompressible flow:

$$
\frac{\partial u}{\partial t}+\frac{\partial u^{2}}{\partial x}+\frac{\partial u v}{\partial y}+\frac{\partial u w}{\partial z}=-\frac{1}{\rho} \frac{\partial p}{\partial x}+v\left(\frac{\partial^{2} u}{\partial x^{2}}+\frac{\partial^{2} u}{\partial y^{2}}+\frac{\partial^{2} u}{\partial z^{2}}\right)
$$


Then I assume that the lateral variations in stress and slope are small and apply the Reynolds averaging where the velocity components are separated into mean and fluctuating terms $\left(U=\bar{U}+U^{\prime}\right)$ :

$$
\begin{aligned}
& \frac{\partial \bar{u}}{\partial t}+\bar{u} \frac{\partial \bar{u}}{\partial x}+\bar{v} \frac{\partial \bar{u}}{\partial y}+\bar{w} \frac{\partial \bar{u}}{\partial z}=-\frac{1}{\rho} \frac{\partial \bar{p}}{\partial x}+ \\
& \frac{\left.\partial \overline{\left(-u^{\prime} u^{\prime}\right.}\right)}{\partial x}+\frac{\partial\left(\overline{-u^{\prime} v^{\prime}}\right)}{\partial x}+\frac{\partial\left(\overline{-u^{\prime} w^{\prime}}\right)}{\partial x}+v \nabla^{2}(\bar{u})
\end{aligned}
$$

Neglecting the small terms $\frac{\partial\left(\overline{-u^{\prime} u^{\prime}}\right)}{\partial x}, \frac{\partial\left(\overline{-u^{\prime} v^{\prime}}\right)}{\partial x}, v \nabla^{2}(\bar{u})$ by scaling results in a new term called Reynolds stress which is the stress in the $x$ direction on the $z$ face $\tau_{z x}=-\overline{u^{\prime} w^{\prime}}$.

\section{A.2.1 Turbulence Closures}

The Reynolds stresses do not vanish, even though $u^{\prime}, v^{\prime}$, and $w^{\prime}$ all average separately to zero since these pairs of variables are correlated and vary together. They transfer momentum as a slow parcel of water from near the bed is being pushed up in the water column that will exchange momentum in the ambient water which is moving faster, therefore, the ambient water is slowed down. This process continues by moving a faster parcel of water down to take the place of the first parcel (i.e., mass conservation). This parcel transfers the momentum toward the bed, where it is dissipated.

In order to deal with the Reynolds stress component came from the averaging over the Navier-Stokes equations to account for turbulent fluctuations, I use a simple 
closure that uses an eddy diffusivity to specify the magnitude of turbulent momentum transfer:

$$
-\overline{u^{\prime} w^{\prime}}=\left(K_{V} \frac{\partial \bar{u}}{\partial z}+K_{H} \frac{\partial \bar{w}}{\partial x}\right) \cong K_{V} \frac{\partial \bar{u}}{\partial z}
$$

where $K_{V}$ and $K_{H}$ are vertical and horizontal eddy diffusivity, respectively. I neglect the horizontal term compared to vertical term and rewrite the Equation (A-18) without overbars, knowing that they have been averaged to remove turbulence as:

$$
\frac{\partial u}{\partial t}+\frac{\partial u^{2}}{\partial x}+\frac{\partial u v}{\partial y}+\frac{\partial u w}{\partial z}=-g \frac{\partial \zeta}{\partial x}+\frac{\partial \tau_{z x}}{\partial z}
$$

Then similar to mass conservation integral, repeat the lateral integration from side $\left(b_{1}\right)$ to side $\left(b_{2}\right)$ and using the Leibniz integral rule:

Second term: $\quad \int_{b_{1}}^{b_{2}} \frac{\partial u^{2}}{\partial x} d y=\frac{\partial}{\partial x} \int_{b_{1}}^{b_{2}} u^{2} d y-u^{2}\left(b_{2}\right) \frac{\partial b_{2}}{\partial x}+u^{2}\left(b_{1}\right) \frac{\partial b_{1}}{\partial x}$

Third term:

$$
\int_{b_{1}}^{b_{2}} \frac{\partial u v}{\partial y} d y=u v\left(b_{2}\right)-u v\left(b_{1}\right)
$$

Fourth term: $\quad \int_{b_{1}}^{b_{2}} \frac{\partial u w}{\partial z} d y=\frac{\partial}{\partial z} \int_{b_{1}}^{b_{2}} u w d y-u w\left(b_{2}\right) \frac{\partial b_{2}}{\partial x}+u w\left(b_{1}\right) \frac{\partial b_{1}}{\partial x}$

Knowing that:

$$
u\left(b_{2}\right) \frac{D v b_{2}}{D t}=u v\left(b_{2}\right)=u\left(b_{2}\right)\left(u\left(b_{2}\right) \frac{\partial b_{2}}{\partial x}+w\left(b_{2}\right) \frac{\partial b_{2}}{\partial z}\right)
$$




$$
\begin{gathered}
-u\left(b_{1}\right) \frac{D v b_{1}}{D t}=u v\left(b_{1}\right)=u\left(b_{1}\right)\left(u\left(b_{1}\right) \frac{\partial b_{1}}{\partial x}+w\left(b_{1}\right) \frac{\partial b_{1}}{\partial z}\right) \\
\frac{\partial b_{1}}{\partial t}=\frac{\partial b_{2}}{\partial t}=0
\end{gathered}
$$

Finally I get Equation (A-23):

$$
\frac{\partial\langle u\rangle b}{\partial t}+\frac{\partial\left\langle u^{2}\right\rangle b}{\partial x}+\frac{\partial\langle u w\rangle b}{\partial z}=-g b\left\langle\frac{\partial \zeta}{\partial x}\right\rangle+b\left\langle\frac{\partial \tau_{z x}}{\partial z}\right\rangle
$$

Now I integrate vertically (from depth $-h$ to the surface $\xi$ ) and apply the boundary conditions and neglect surface wind stress:

$$
\frac{\partial\langle u\rangle A}{\partial t}+\frac{\partial\left\langle u^{2}\right\rangle A}{\partial x}=-g A\left\langle\frac{\partial \zeta}{\partial x}\right\rangle+b \tau_{b}
$$

Rewrite the equation in terms of flow $(Q)$ :

$$
\frac{\partial Q}{\partial t}+\frac{\partial}{\partial x}\left(\frac{Q^{2}}{A}\right)+g A \frac{\partial \zeta}{\partial x}+b \tau_{b}=0
$$

Now I have the equations that are the basis of estuarine tidal theory (Equation A-14 and A-25). 


\section{Appendix B Approximating the Friction Term}

Following the Godin [1991, 1999] approach, the $u|u|$ term is approximated as:

$$
\frac{u|u|}{U_{(x)}{ }^{2}} \approx A_{g} u^{\prime}+B_{g} u^{\prime 3}
$$

where $A_{g}$ and $B_{g}$ are constants. The algebraic development of the time dependent portion of $u|u|$ is:

$$
\begin{gathered}
u_{(x, t)}=-u_{0(\mathrm{x})}+\sum_{i=1}^{n} u_{i_{(\mathrm{x})}} \cos \left(\omega_{i} t-b_{i(\mathrm{x})}\right)= \\
U_{(x)}\left[-\mathrm{u}_{0(\mathrm{x})}^{\prime}+\sum_{i=1}^{n} \mathrm{u}_{\mathrm{i}(\mathrm{x})}^{\prime} \cos \left(\omega_{i} t-b_{i_{(\mathrm{x})}}\right)\right] \\
U_{(x)}=\sum_{i=1}^{n} u_{i(\mathrm{x})} \\
u^{\prime}=\frac{u_{i(x)}}{\left|U_{(x)}\right|}
\end{gathered}
$$

where $U_{(x)}$ is maximum possible value of the current at point $x, u_{i}$ is amplitude of the current component of frequency $\omega_{i}$ at $x$, and $u^{\prime}$ is dimensionless variable. The outward current $u_{0}$ created by the fresh water discharge $Q$ behaves as a harmonic of frequency zero and eventually becomes dominant as the wave progresses upstream. Chebyshev polynomials that are used here to expand and simplify solutions are defined as:

$$
\cos 3 x=4 \cos ^{3} x-3 \cos x
$$


The linearization process starts with applying a two term expansion which results in one linear and one cubic term (Equation B-1). I use trigonometric identities based on the Chebyshev expansion to form the cubic term $\left({u^{\prime}}^{3}\right)$ and get linear combinations of higher harmonics terms. As an example, consider a case where river flow $\left(u_{0}\right)$ is negligible and one single harmonic is considered, i.e.,

$$
u_{(x, t)}=u_{1} \cos \left(\omega_{1} t-\phi_{1}\right)
$$

I neglect the phase lag here and follow to form the $u|u|$ two term approximation:

$$
u|u|=u_{1}^{2} \cos \omega_{1} t\left|\cos \omega_{1} t\right| \approx u_{1}^{2}\left[A_{g} \cos \omega_{1} t+B_{g} \cos ^{3} \omega_{1} t\right]
$$

where $A_{g}$ and $B_{g}$ are constants [Doodson, 1956; Godin, 1991a, b]. I linearize by using $\left(\cos ^{3} x=\frac{1}{4}(3 \cos x+\cos 3 x)\right)$ to obtain: $u|u|=u_{1}^{2}\left[\left(A_{g}+\frac{3 B_{g}}{4}\right) \cos \omega_{1} t+\frac{B_{g}}{4} \cos 3 \omega_{1} t\right]$

I consider a more complicated case where the velocity is defined by river flow and three sinusoidal frequencies which are multiples of each other:

$$
\begin{gathered}
u^{\prime}=u_{0}^{\prime}+u_{1}^{\prime} \cos \left(\omega_{1} t+\phi_{1}\right)+u_{2}^{\prime} \cos \left(\omega_{2} t+\phi_{2}\right) \\
+u_{3}^{\prime} \cos \left(\omega_{3} t+\phi_{3}\right)
\end{gathered}
$$

where $u_{0}^{\prime}$ is non-dimensional subtidal velocity, $u_{1}^{\prime}, u_{2}^{\prime}$ and $u_{3}^{\prime}$ are dimensionless velocity amplitudes, $\omega_{1}, \omega_{2}, \omega_{3}$ are angular frequency and $\phi_{1}, \phi_{2}$, and $\phi_{3}$ are phases. In order to form the friction term (Equation B-1), I calculate the cubed term as: 


$$
\begin{aligned}
& \left(u_{0}^{\prime}+u_{1}^{\prime} \cos \left(\omega_{1} t+\phi_{1}\right)+u_{2}^{\prime} \cos \left(\omega_{2} t+\phi_{2}\right)+u_{3}^{\prime} \cos \left(\omega_{3} t+\phi_{3}\right)\right)^{3}= \\
& \underbrace{u_{0}^{3}}_{\text {Term } B-4-1}+\underbrace{u_{1}^{\prime 3} \cos ^{3}\left(\omega_{1} t+\phi_{1}\right)}_{\text {Term } B-4-2}+\underbrace{u_{2}^{\prime 3} \cos ^{3}\left(\omega_{2} t+\phi_{2}\right)}_{\text {Term } B-4-3}+ \\
& \underbrace{u_{3}^{\prime 3} \cos ^{3}\left(\omega_{3} t+\phi_{3}\right)}_{\text {Term } B-4-4}+\underbrace{3 u_{0}^{\prime 2} u_{1}^{\prime} \cos \left(\omega_{1} t+\phi_{1}\right)}_{\text {Term } B-4-5}+ \\
& \underbrace{3 u_{0}^{\prime 2} u_{2}^{\prime} \cos \left(\omega_{2} t+\phi_{2}\right)}_{\text {Term } B-4-6}+\underbrace{3 u_{0}^{\prime 2} u_{3}^{\prime} \cos \left(\omega_{3} t+\phi_{3}\right)}_{\text {Term } B-4-7}+ \\
& \underbrace{3 u_{1}^{\prime 2} \cos ^{2}\left(\omega_{1} t+\phi_{1}\right) u_{0}^{\prime}}_{\text {Term } B-4-8}+\underbrace{3 u_{1}^{\prime 2} \cos ^{2}\left(\omega_{1} t+\phi_{1}\right) u_{2}^{\prime} \cos \left(\omega_{2} t+\phi_{2}\right)}_{\text {Term } B-4-9}+ \\
& \underbrace{3 u_{1}^{\prime 2} \cos ^{2}\left(\omega_{1} t+\phi_{1}\right) u_{3}^{\prime} \cos \left(\omega_{3} t+\phi_{3}\right)}_{\text {Term } B-4-10}+ \\
& \underbrace{3 u_{2}^{\prime 2} \cos ^{2}\left(\omega_{2} t+\phi_{2}\right) u_{0}^{\prime}}_{\text {Term } B-4-11}+\underbrace{3 u_{2}^{\prime 2} \cos ^{2}\left(\omega_{2} t+\phi_{2}\right) u_{1}^{\prime} \cos \left(\omega_{1} t+\phi_{1}\right)}_{\text {Term } B-4-12} \\
& +\underbrace{3 u_{2}^{\prime 2} \cos ^{2}\left(\omega_{2} t+\phi_{2}\right) u_{3}^{\prime} \cos \left(\omega_{3} t+\phi_{3}\right)}_{\text {Term } B-4-13}+ \\
& \underbrace{3 u_{3}^{\prime 2} \cos ^{2}\left(\omega_{3} t+\phi_{3}\right) u_{0}^{\prime}}_{\text {Term } B-4-14}+\underbrace{3 u_{3}^{\prime 2} \cos ^{2}\left(\omega_{3} t+\phi_{3}\right) u_{1}^{\prime} \cos \left(\omega_{1} t+\phi_{1}\right)}_{\text {Term } B-4-15} \\
& +\underbrace{3 u_{3}^{\prime 2} \cos ^{2}\left(\omega_{3} t+\phi_{3}\right) u_{2}^{\prime} \cos \left(\omega_{2} t+\phi_{2}\right)}_{\text {Term } B-4-16}+ \\
& \underbrace{6 u_{0}^{\prime} u_{1}^{\prime} \cos \left(\omega_{1} t+\phi_{1}\right) u_{2}^{\prime} \cos \left(\omega_{2} t+\phi_{2}\right)}_{\text {Term B-4-17 }}+ \\
& \underbrace{6 u_{0}^{\prime} u_{1}^{\prime} \cos \left(\omega_{1} t+\phi_{1}\right) u_{3}^{\prime} \cos \left(\omega_{3} t+\phi_{3}\right)}_{\text {Term } B-4-18}+ \\
& \underbrace{6 u_{0}^{\prime} u_{2}^{\prime} \cos \left(\omega_{2} t+\phi_{2}\right) u_{3}^{\prime} \cos \left(\omega_{3} t+\phi_{3}\right)}_{\text {Term } B-4-19}+ \\
& \underbrace{6 u_{1}^{\prime} \cos \left(\omega_{1} t+\phi_{1}\right) u_{2}^{\prime} \cos \left(\omega_{2} t+\phi_{2}\right) u_{3}^{\prime} \cos \left(\omega_{3} t+\phi_{3}\right)}_{\text {Term } B-4-20}
\end{aligned}
$$

In order to simplify the equations and compare my results with the Buschman et al. [2009], I assume that $\omega=\omega_{1}, \omega_{2}=2 \omega_{1}, \omega_{3}=4 \omega_{1}$ which represent diurnal, 
semidiurnal, and quarterdiurnal tides. I then look at each term individually and apply further expansion and simplification. There are several terms that produce overtides which are two, three, four, and..... times the frequency of the leading wave frequency. I will take a closer look at these terms (written in blue) and will explain how overtides (e.g., $M_{4}, M_{6 . .}$ ) are created. The terms written in red are leading order terms that will be used to compare my results with the Buschman et al. [2009].

\begin{tabular}{|c|c|}
\hline Term (B-4-1) & $U_{0}^{3}$ \\
\hline \multirow[b]{2}{*}{ Term (B-4-2) } & $u_{1}^{\prime 3} \cos ^{3}\left(\omega t+\phi_{1}\right)=$ \\
\hline & $\frac{1}{4} u_{1}^{\prime 3}\left(3 \cos \left(\omega t+\phi_{1}\right)+\cos 3\left(\omega t+\phi_{1}\right)\right) \cong \frac{3}{4} u_{1}^{\prime 3} \cos \left(\omega t+\phi_{1}\right)$ \\
\hline \multirow[b]{2}{*}{ Term (B-4-3) } & $u_{2}^{\prime 3} \cos ^{3}\left(2 \omega t+\phi_{2}\right)=$ \\
\hline & $\frac{1}{4} u_{2}^{\prime 3}\left(3 \cos \left(2 \omega t+\phi_{2}\right)+\cos 3\left(2 \omega t+\phi_{2}\right)\right) \cong \frac{3}{4} u_{2}^{\prime 3} \cos \left(2 \omega t+\phi_{2}\right)$ \\
\hline \multirow{3}{*}{ Term (B-4-4) } & $u_{4}^{\prime 3} \cos ^{3}\left(4 \omega t+\phi_{4}\right)=$ \\
\hline & $\frac{1}{4} u_{4}^{\prime 3}\left(3 \cos \left(4 \omega t+\phi_{4}\right)+\cos 3\left(4 \omega t+\phi_{4}\right)\right)$ \\
\hline & $\cong \frac{3}{4} u_{4}^{\prime 3} \cos \left(4 \omega t+\phi_{4}\right)$ \\
\hline Term (B-4-5) & $3 u_{0}^{\prime 2} u_{1}^{\prime} \cos \left(\omega t+\phi_{1}\right)$ \\
\hline Term (B-4-6) & $3 u_{0}^{\prime 2} u_{2}^{\prime} \cos \left(2 \omega t+\phi_{2}\right)$ \\
\hline Term (B-4-7) & $3 u_{0}^{\prime 2} u_{4}^{\prime} \cos \left(4 \omega t+\phi_{4}\right)$ \\
\hline \multirow[b]{2}{*}{ Term (B-4-8) } & $3 u_{1}^{\prime 2} \cos ^{2}\left(\omega t+\phi_{1}\right) u_{0}^{\prime}=3 u_{1}^{\prime 2}\left(\frac{\cos \left(2\left(\omega t+\phi_{1}\right)\right)+1}{2}\right) u_{0}^{\prime}=$ \\
\hline & $\frac{3}{2} u_{1}^{\prime 2} u_{0}^{\prime}+\frac{3}{2} u_{1}^{\prime 2} u_{0}^{\prime} \cos \left(2\left(\omega t+\phi_{1}\right)\right)$ \\
\hline
\end{tabular}




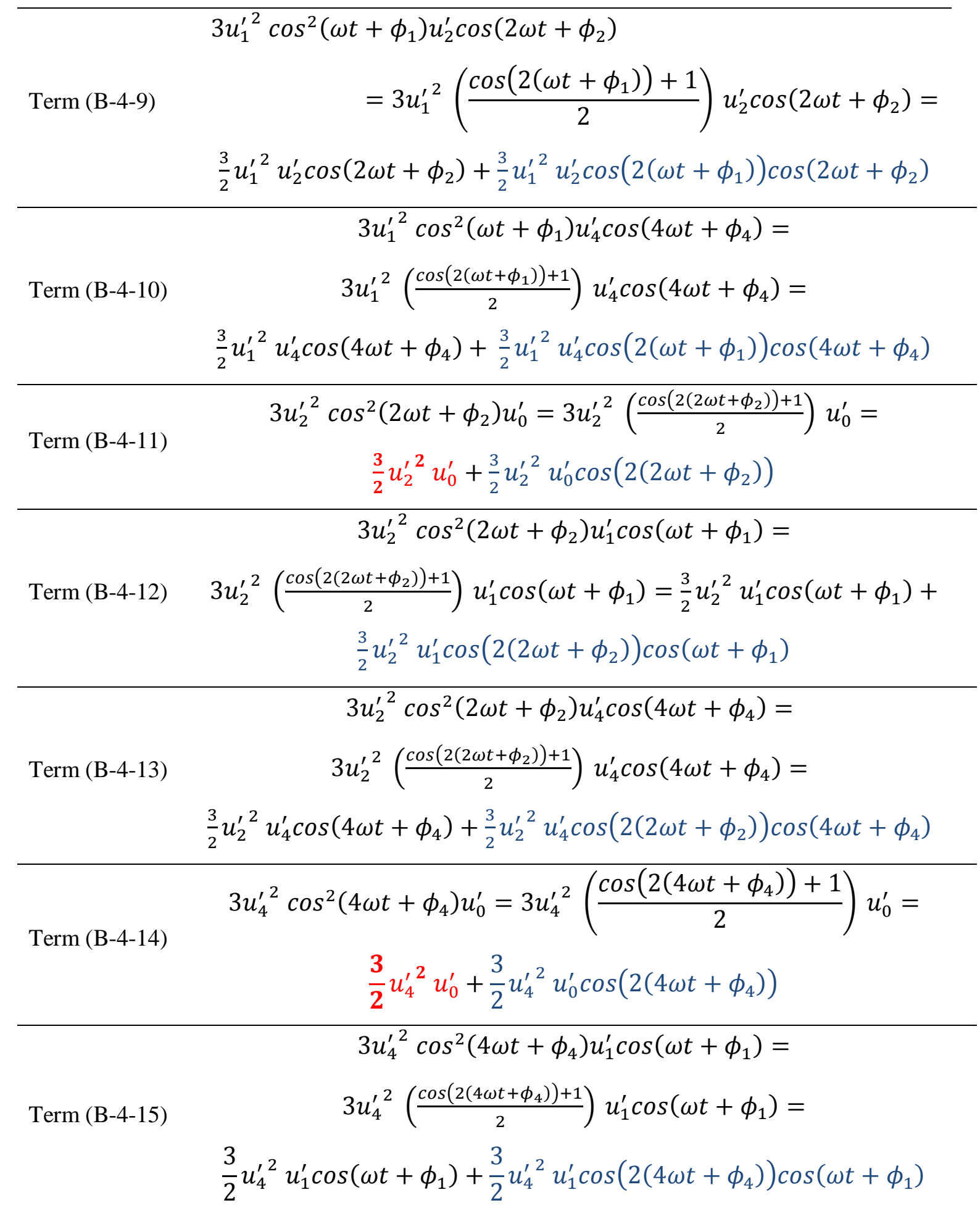




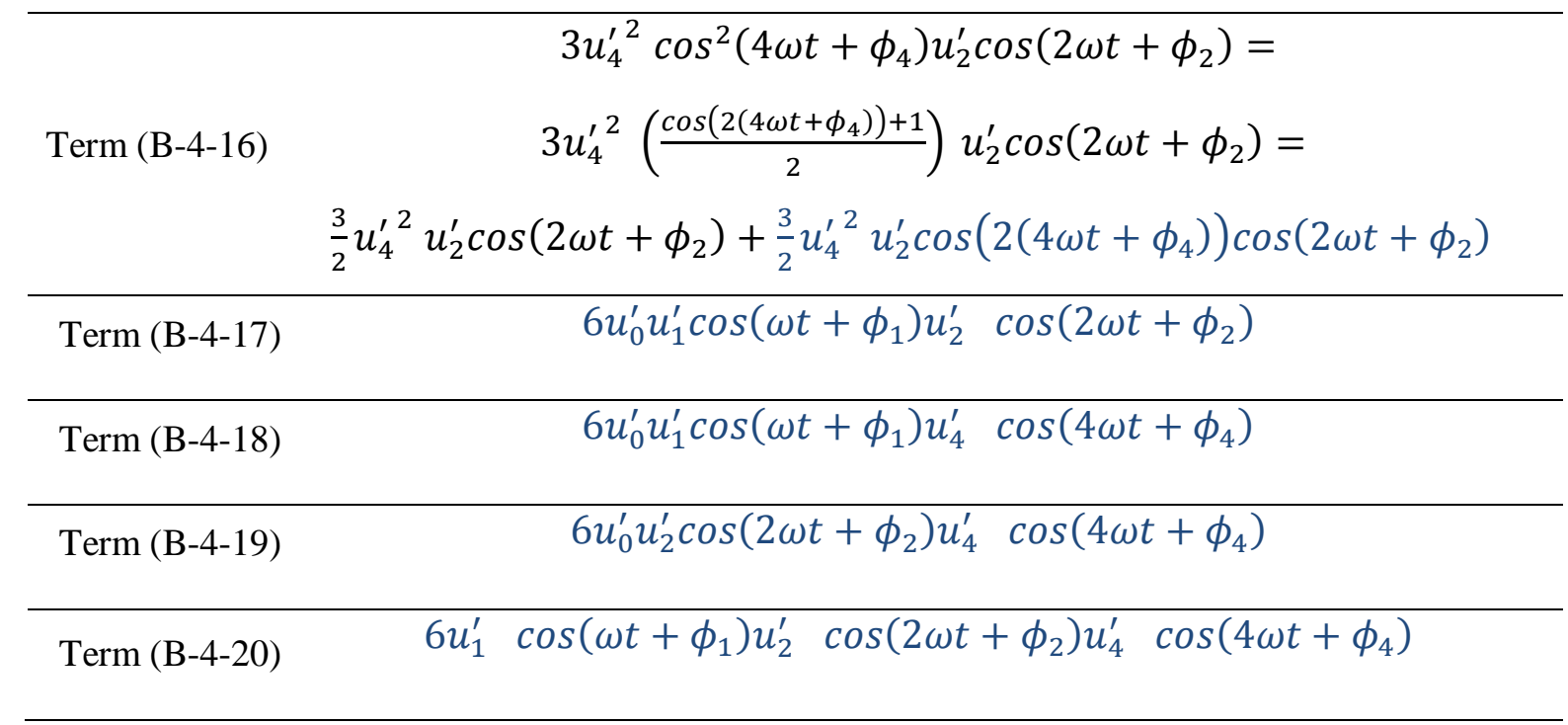

\section{B.1 The Origin of Overtides}

A useful trigonometric function that will be used to expand terms written in blue is $\left(\cos (x) \cdot \cos (y)=\frac{1}{2}[\cos (x+y)+\cos (x-y)]\right)$, which leads to additional overtides (harmonics) with frequencies that are sums and differences of the parent (driving) frequencies. Hence:

$$
\frac{3}{2} u_{1}^{\prime 2} u_{2}^{\prime} \cos \left(2\left(\omega t+\phi_{1}\right)\right) \cos \left(2 \omega t+\phi_{2}\right)=
$$

Term (B-4-9)

$$
\begin{gathered}
\frac{3}{4} u_{1}^{\prime 2} u_{2}^{\prime}\left[\left(\cos \left(4 \omega t+2 \phi_{1}+\phi_{2}\right)+\cos \left(2 \phi_{1}-\phi_{2}\right)\right)\right]= \\
\frac{3}{4} u_{1}^{\prime 2} u_{2}^{\prime} \cos \left(4 \omega t+2 \phi_{1}+\phi_{2}\right)+\frac{3}{4} u_{1}^{\prime 2} u_{2}^{\prime} \cos \left(2 \phi_{1}-\phi_{2}\right)
\end{gathered}
$$




\begin{tabular}{|c|c|}
\hline Term (B-4-10) & $\begin{array}{c}\frac{3}{2} u_{1}^{\prime 2} u_{4}^{\prime} \cos \left(2\left(\omega t+\phi_{1}\right)\right) \cos \left(4 \omega t+\phi_{4}\right)= \\
\frac{3}{4} u_{1}^{\prime 2} u_{4}^{\prime}\left[\cos \left(6 \omega t+2 \phi_{1}+\phi_{4}\right)+\cos \left(2 \phi_{1}-\phi_{4}\right)\right]= \\
\frac{3}{4} u_{1}^{\prime 2} u_{4}^{\prime} \cos \left(6 \omega t+2 \phi_{1}+\phi_{4}\right)+\frac{3}{4} u_{1}^{\prime 2} u_{4}^{\prime} \cos \left(2 \phi_{1}-\phi_{4}\right)\end{array}$ \\
\hline Term (B-4-11) & $\frac{3}{2} u_{2}^{\prime 2} u_{0}^{\prime} \cos \left(4 \omega t+2 \phi_{2}\right)$ \\
\hline Term (B-4-12) & $\begin{array}{c}\frac{3}{2} u_{2}^{\prime 2} u_{1}^{\prime} \cos \left(2\left(2 \omega t+\phi_{2}\right)\right) \cos \left(\omega t+\phi_{1}\right)= \\
\frac{3}{4} u_{2}^{\prime 2} u_{1}^{\prime}\left[\cos \left(5 \omega t+2 \phi_{2}+\phi_{1}\right)+\cos \left(3 \omega t+2 \phi_{2}-\phi_{1}\right)\right]\end{array}$ \\
\hline Term (B-4-13) & $\begin{array}{c}\frac{3}{2} u_{2}^{\prime 2} u_{4}^{\prime} \cos \left(2\left(2 \omega t+\phi_{2}\right)\right) \cos \left(4 \omega t+\phi_{4}\right) \\
\frac{3}{4} u_{2}^{\prime 2} u_{4}^{\prime}\left[\cos \left(8 \omega t+2 \phi_{2}+\phi_{4}\right)+\cos \left(2 \phi_{2}-\phi_{4}\right)\right]= \\
\frac{3}{4} u_{2}^{\prime 2} u_{4}^{\prime} \cos \left(8 \omega t+2 \phi_{2}+\phi_{4}\right)+\frac{3}{4} u_{2}^{\prime 2} u_{4}^{\prime} \cos \left(2 \phi_{2}-\phi_{4}\right)\end{array}$ \\
\hline Term (B-4-14) & $\frac{3}{2} u_{4}^{\prime 2} u_{0}^{\prime} \cos \left(8 \omega t+2 \phi_{4}\right)$ \\
\hline Term (B-4-15) & $\begin{array}{c}\frac{3}{2} u_{4}^{\prime 2} u_{1}^{\prime} \cos \left(2\left(4 \omega t+\phi_{4}\right)\right) \cos \left(\omega t+\phi_{1}\right)= \\
\frac{3}{4} u_{4}^{\prime 2} u_{1}^{\prime}\left[\cos \left(8 \omega t+2 \phi_{4}+\phi_{1}\right)+\cos \left(7 \omega t+2 \phi_{4}-\phi_{1}\right)\right]\end{array}$ \\
\hline Term (B-4-16) & $\begin{array}{c}\frac{3}{2} u_{4}^{\prime 2} u_{2}^{\prime} \cos \left(2\left(4 \omega t+\phi_{4}\right)\right) \cos \left(2 \omega t+\phi_{2}\right)= \\
\frac{3}{4} u_{4}^{\prime 2} u_{2}^{\prime}\left[\cos \left(10 \omega t+2 \phi_{4}+\phi_{2}\right)-\cos \left(6 \omega t+2 \phi_{4}-\phi_{2}\right)\right]\end{array}$ \\
\hline Term (B-4-17) & $\begin{array}{c}6 u_{0}^{\prime} u_{1}^{\prime} \cos \left(\omega t+\phi_{1}\right) u_{2}^{\prime} \cos \left(2 \omega t+\phi_{2}\right)= \\
3 u_{0}^{\prime} u_{1}^{\prime} u_{2}^{\prime}\left[\cos \left(3 \omega t+\phi_{1}+\phi_{2}\right)+\cos \left(\omega t+2 \phi_{2}-\phi_{1}\right)\right]\end{array}$ \\
\hline Term (B-4-18) & $\begin{array}{c}6 u_{0}^{\prime} u_{1}^{\prime} \cos \left(\omega t+\phi_{1}\right) u_{4}^{\prime} \cos \left(4 \omega t+\phi_{4}\right)= \\
3 u_{0}^{\prime} u_{1}^{\prime} u_{4}^{\prime}\left[\cos \left(5 \omega t+\phi_{1}+\phi_{4}\right)+\cos \left(3 \omega t+\phi_{4}-\phi_{1}\right)\right]\end{array}$ \\
\hline
\end{tabular}


Term (B-4-19)

$$
6 u_{0}^{\prime} u_{2}^{\prime} \cos \left(2 \omega t+\phi_{2}\right) u_{4}^{\prime} \cos \left(4 \omega t+\phi_{4}\right)=
$$

$$
3 u_{0}^{\prime} u_{2}^{\prime} u_{4}^{\prime}\left[\cos \left(6 \omega t+\phi_{2}+\phi_{4}\right)+\cos \left(2 \omega t+\phi_{4}-\phi_{2}\right)\right]
$$

$$
6 u_{1}^{\prime} \cos \left(\omega t+\phi_{1}\right) u_{2}^{\prime} \cos \left(2 \omega t+\phi_{2}\right) u_{4}^{\prime} \cos \left(4 \omega t+\phi_{4}\right)=
$$

$$
3 u_{1}^{\prime} u_{2}^{\prime} u_{4}^{\prime}\left[\cos \left(3 \omega t+\phi_{1}+\phi_{2}\right)+\cos \left(\omega t+\phi_{2}-\phi_{1}\right)\right] \cos \left(4 \omega t+\phi_{4}\right)=
$$

Term (B-4-20) 3

$$
\begin{aligned}
& \frac{3}{2} u_{1}^{\prime} u_{2}^{\prime} u_{4}^{\prime}\left[\cos \left(7 \omega t+\phi_{1}+\phi_{2}+\phi_{4}\right)+\cos \left(\omega t+\phi_{4}-\phi_{2}-\phi_{1}\right)\right. \\
& \left.+\cos \left(5 \omega t+\phi_{4}+\phi_{2}-\phi_{1}\right)+\cos \left(3 \omega t+\phi_{4}-\phi_{2}+\phi_{1}\right)\right]
\end{aligned}
$$

\section{B.2 Verification and Comparison of Results}

To verify my model, I compare results with Buschman et al. [2009]. Buschman et al. [2009] approximated $u|u|$ term with the Chebyshev polynomial approach using the first and third order terms of the non-dimensionalized velocity and averaged the friction term over a tidal cycle:

$$
\frac{g W}{2 \pi C^{2}} \int_{0}^{2 \pi} \mathrm{u}|\mathrm{u}| d t \approx \frac{g W}{2 \pi C^{2}} \int_{0}^{2 \pi}\left(a U+b U^{3}\right) d t
$$

where $U$ is the velocity non-dimensionalized by the maximum velocity. The total velocity consists of non-dimensional river flow and diurnal, semidiurnal, and quarterdiurnal terms:

$$
U=U_{0}+U_{1} \cos \left(\omega t+\phi_{1}\right)+U_{2} \cos \left(2 \omega t+\phi_{2}\right)+U_{4} \cos \left(4 \omega t+\phi_{4}\right)
$$

Substitute Equation (B-6) in Equation (B-5) results in: 


$$
\begin{gathered}
\frac{U_{m}^{2} W g}{C^{2}}(\underbrace{a U_{0}+b U_{0}^{3}}_{S_{r}}+\underbrace{\frac{3 b}{2}\left(U_{0} U_{1}^{2}+U_{0} U_{2}^{2}+U_{0} U_{4}^{2}\right)}_{S_{r t}} \\
+\underbrace{\frac{3 b}{4}\left(U_{1}^{2} U_{2} \cos \left(2 \phi_{1}-\phi_{2}\right)+U_{2}^{2} U_{4} \cos \left(2 \phi_{2}-\phi_{4}\right)\right)}_{S_{t}})
\end{gathered}
$$

where $S_{r}, S_{r t}$ and $S_{t}$ quantify the contributions by river flow alone, river-tide interactions and tidal asymmetry to the generation of subtidal friction. Considering the integral over a tidal cycle I can do the same for all terms Equation (B-4-1) to (B-4-20). There is a cosine in each term; hence, after integrating from 0 and $2 \pi$, each term that has a cosine will be zero (e.g., $\left.\int_{0}^{2 \pi} A \cos (\omega t+\phi) d t=0\right)$. Therefore the remaining terms are the ones written in red which yield:

$$
\begin{aligned}
\frac{g W}{2 \pi C^{2}} \int_{0}^{2 \pi} u|u| & d t \\
& \approx \frac{g W}{2 \pi C^{2}} \int_{0}^{2 \pi}\left(a\left(U_{0}\right)\right. \\
& +b\left(U_{0}^{3}+\frac{3}{2} U_{1}^{2} U_{0}+\frac{3}{2} U_{2}^{2} U_{0}+\frac{3}{2} U_{4}^{2} U_{0}+\frac{3}{4} U_{1}^{2} U_{2} \cos \left(2 \phi_{1}-\phi_{2}\right)\right. \\
& \left.\left.+\frac{3}{4} U_{1}^{2} U_{4} \cos \left(2 \phi_{1}-\phi_{4}\right)+\frac{3}{4} U_{2}^{2} U_{4} \cos \left(2 \phi_{2}-\phi_{4}\right)\right)\right) d t= \\
\frac{g W}{C^{2}}\left[\left(a U_{0}\right)+\right. & b\left(U_{0}^{3}+\frac{3}{2} U_{1}^{2} U_{0}+\frac{3}{2} U_{2}^{2} U_{0}+\frac{3}{2} U_{4}^{2} U_{0}+\frac{3}{4} U_{1}^{2} U_{2} \cos \left(2 \phi_{1}-\phi_{2}\right)\right. \\
& \left.\left.+\frac{3}{4} U_{1}^{2} U_{4} \cos \left(2 \phi_{1}-\phi_{4}\right)+\frac{3}{4} U_{2}^{2} U_{4} \cos \left(2 \phi_{2}-\phi_{4}\right)\right)\right]
\end{aligned}
$$

This agrees well with Buschman et al. [2009]. Note that the term $\left(\frac{3}{4} U_{1}^{2} U_{4} \cos \left(2 \phi_{1}-\right.\right.$ $\left.\left.\phi_{4}\right)\right)$ is ignored by Buschman et al. [2009]. 


\section{Appendix C Analytical Solution to the Tidal Propagation Equations}

In this study I develop an analytical solution to the tidal propagation equations along a channel with variable width (exponentially convergence) and steady river flow. I assume depth is constant and do not consider subtidal flats. The cross-sectionally integrated along-channel momentum and continuity equations are:

$$
\begin{gathered}
\frac{\partial Q}{\partial t}+\frac{\partial}{\partial x}\left(\frac{Q^{2}}{A}\right)+g A \frac{\partial \zeta}{\partial x}+b T=0 \\
\frac{\partial Q}{\partial x}+b \frac{\partial \zeta}{\partial t}=0
\end{gathered}
$$

where $Q$ is steady river flow, $b$ is width, $g$ is acceleration due to gravity, $\xi$ is wave amplitude, and $T$ is bed stress divided by water density. Cross-sectionally integrated flow $(Q)$ can be rewritten as summation of river flow $Q_{R}$, invariant with time, and tidal transport $Q_{T}(x, t)$ :

$$
Q_{(x, t)}=Q_{R}+Q_{T(x, t)}
$$

In order to solve Equations (C-1) and (C-2), I subtract the partial derivative with respect $x$ of momentum equation from the partial derivative with respect to $t$ of the continuity equation and then use the continuity equation to get the following Equation: 


$$
\begin{aligned}
& \underbrace{\frac{\partial^{2} Q}{\partial x^{2}}}_{\text {Pressuregradient }}-\underbrace{\frac{1}{b} \frac{\partial b}{\partial x} \frac{\partial Q}{\partial x}}_{\text {Pressure gradientand convergene }}-\underbrace{2 \frac{1}{g h} U_{R} \frac{\partial^{2} Q}{\partial x \partial t}+2 \frac{1}{g h} U_{R} \frac{1}{A} \frac{d A}{d x} \frac{\partial Q}{\partial t}}_{\text {Convectivacceleration }} \\
& -\underbrace{\frac{1}{g h} \frac{\partial^{2} Q}{\partial t^{2}}}_{\text {Local acceleration }}-\underbrace{\frac{b}{g h} \frac{\partial T}{\partial t}}_{\text {Friction }}=0
\end{aligned}
$$

where $U_{R}$ is the river flow velocity. After linearizing the friction term (see Appendix B), and following the solution procedure described in Jay [1991], a solution for an exponentially convergent channel $\left(b_{(x)}=B e^{-x x}=B e^{-\frac{x}{L_{e}}}\right)$ of the following form can be derived:

$$
\begin{aligned}
& Q(x, t)=\operatorname{Re}\left[\left(C_{1} e^{i s x}+C_{2} e^{-i s x}\right) e^{\left(\frac{x}{L_{e}}-\frac{2 i \omega x U_{R}}{g h}\right)} e^{i \omega t}\right] \\
& \zeta(x, t)=-\int \frac{1}{b} \frac{\partial Q}{\partial x} d t= \\
& \operatorname{Re}\left[-\frac{e^{\frac{2 x}{L_{e}}+i \omega\left(t-\frac{2 x U_{R}}{g h}\right)}}{B}\left(\frac{s}{\omega}\left(C_{1} e^{i s x}-C_{2} s e^{-i s x}\right)+\frac{1}{i \omega}\left(C_{1} e^{i s x}+C_{2} e^{-i s x}\right)\left(\frac{1}{L_{e}}-\frac{2 i \omega U_{R}}{g h}\right)\right)\right] \\
& s=\left(-\frac{1}{4 L_{e}^{2}}+\left(\frac{U_{R} \omega}{g h}\right)^{2}-\frac{i U_{R} \omega}{g h L_{e}}+\frac{\omega^{2}-b i \omega c_{d}\left(\frac{\overline{Q_{m(x)}}}{A_{(x)}^{2}}\left(A_{g} q^{\prime}+B_{g} q^{\prime 3}\right)\right)}{g h}\right)^{\frac{1}{2}}=k+i r
\end{aligned}
$$

where $B$ is the width at the entrance, $L_{e}$ is the convergence length scale, $C_{d}$ is the drag coefficient, $A_{g}$ and $B_{g}$ are constants (see Appendix B), and $C_{1}$ and $C_{2}$ are constant coefficients determined from boundary conditions. $k$ is the real part-inviscid wave 
number, $r$ is the imaginary part-the damping modulus [Dronkers, 1964; Jay 1991], and the frequency $\omega=\frac{2 \pi}{T}$ is related to the tide period. $Q_{m(x)}$ is maximum possible value of the current discharge at point $x$, and $q^{\prime}$ is the non-dimensionalized discharge [Godin, 1991] (see Appendix B) and is solved iteratively.

\section{C.1 Scaling}

Scaling shows the relative importance of the terms in the momentum equation for any specific hydrodynamics system. I define non-dimensional variables in terms of the dimensional variables, using the scaling parameters described in Jay [1991] as:

$$
\begin{gathered}
\hat{Q}=U_{0} b_{0} D_{0} Q=\frac{u_{*}}{\sqrt{C_{d}}} b_{0} D_{0} Q \quad \widehat{U}_{R}=U_{R 0} U_{R} \\
\hat{T}=C_{d} U_{o}^{2} T \quad \hat{b}=b_{0} b \\
\hat{h}=h_{0} h \quad \hat{t}=\frac{t}{\omega} \\
\hat{x}=x_{0} x=\frac{\sqrt{g h_{0}}}{\omega} x
\end{gathered}
$$

where $b_{0}, h_{0}, x_{0}, \omega, U_{0}$ and $U_{R 0}$ denote scales for width, depth, length, frequency, velocity and river flow velocity, respectively. To study the effect of damping processes, I can use frictional velocity scale of velocity as $U_{0}=\frac{u_{*}}{\sqrt{C_{d}}}$ and the frictional velocity is $\sqrt{\tau / \rho}$. Now I substitute all of the above into Equation (C-4) to obtain:

$$
\begin{gathered}
\frac{U_{0} b_{0} h_{0}}{x_{0}{ }^{2}}\left(\frac{\partial^{2} Q_{T}}{\partial x^{2}}\right)-\frac{U_{0} b_{0} h_{0}}{x_{0}{ }^{2}}\left(\frac{1}{b} \frac{\partial b}{\partial x} \frac{\partial Q_{T}}{\partial x}\right)- \\
\frac{U_{R 0} U_{0} b_{0} \omega}{g x_{0}}\left(\frac{2 U_{R}}{h} \frac{\partial^{2} Q_{T}}{\partial x \partial t}\right)+\frac{U_{R 0} U_{0} b_{0} \omega}{g x_{0}}\left(\frac{2 U_{R}}{h} \frac{1}{A} \frac{d A}{d x} \frac{\partial Q_{T}}{\partial t}\right)-
\end{gathered}
$$




$$
\frac{U_{0} b_{0} \omega^{2}}{g}\left(\frac{1}{h} \frac{\partial^{2} Q_{T}}{\partial t^{2}}\right)-\frac{b_{0} C_{d} U_{O}^{2} \omega}{g h_{0}}\left(\frac{b}{h} \frac{\partial T}{\partial t}\right)=0
$$

Every additive term in the above equation has primary dimensions $\left\{\frac{M}{T}\right\}$. To nondimensionalize the equation, I multiply every term by $\frac{x_{0}^{2}}{U_{0} b_{0} h_{0}}$, which has primary dimension $\left\{\frac{T}{M}\right\}$, so that the dimensions cancel. After some rearrangement I obtain:

$$
\begin{gathered}
\frac{\partial^{2} Q_{T}}{\partial x^{2}}-\frac{1}{b} \frac{\partial b}{\partial x} \frac{\partial Q_{T}}{\partial x}-\frac{U_{R 0} x_{0} \omega}{g h_{0}}\left(\frac{2 U_{R}}{h} \frac{\partial^{2} Q_{T}}{\partial x \partial t}\right)+ \\
\frac{U_{R 0} x_{0} \omega}{g h_{0}}\left(\frac{2 U_{R}}{h} \frac{1}{A} \frac{d A}{d x} \frac{\partial Q_{T}}{\partial t}\right)-\frac{x_{0}^{2} \omega^{2}}{g \mathrm{~h}_{0}}\left(\frac{1}{h} \frac{\partial^{2} Q_{T}}{\partial t^{2}}\right)- \\
\frac{C_{d} U_{0} \omega x_{0}^{2}}{g h_{0}^{2}}\left(\frac{b}{h} \frac{\partial T}{\partial t}\right)=0
\end{gathered}
$$

Now I use the last term in Equation (C-9) and assume that $x_{0}=L_{e}$ and $U_{0}=\frac{\xi \omega L_{e}}{h_{0}}$ [Friedrichs and Aubrey, 1994], therefore, I can obtain an important non-dimentional number as $\frac{C_{d} \xi \omega^{2} L_{e}^{3}}{g h_{0}^{3}}$. With this scaling the importance of wave frequency (time scale) and amplitude, estuary length scale, channel depth, and frictional drag is shown. It also shows that reducing frictional drag can have similar effect as increasing depth with higher sensitivity. 